\title{
A Review of Hydrogen Sulfide Synthesis, Metabolism, and Measurement: Is Modulation of Hydrogen Sulfide a Novel Therapeutic for Cancer?
}

Xu Cao,' Lei Ding,, Zhi-zhong Xie,, Yong Yang,,3 Matthew Whiteman,

Philip K. Moore, and Jin-Song Bian ${ }^{1}$

\begin{abstract}
Significance: Hydrogen sulfide $\left(\mathrm{H}_{2} \mathrm{~S}\right)$ has been recognized as the third gaseous transmitter alongside nitric oxide and carbon monoxide. In the past decade, numerous studies have demonstrated an active role of $\mathrm{H}_{2} \mathrm{~S}$ in the context of cancer biology.

Recent Advances: The three $\mathrm{H}_{2} \mathrm{~S}$-producing enzymes, namely cystathionine $\gamma$-lyase (CSE), cystathionine $\beta$ synthase (CBS), and 3-mercaptopyruvate sulfurtransferase (3MST), have been found to be highly expressed in numerous types of cancer. Moreover, inhibition of CBS has shown anti-tumor activity, particularly in colon cancer, ovarian cancer, and breast cancer, whereas the consequence of CSE or 3MST inhibition remains largely unexplored in cancer cells. Intriguingly, $\mathrm{H}_{2} \mathrm{~S}$ donation at high amounts or a long time duration has also been observed to induce cancer cell apoptosis in vitro and in vivo while sparing noncancerous fibroblast cells. Therefore, a bell-shaped model has been proposed to explain the role of $\mathrm{H}_{2} \mathrm{~S}$ in cancer development. Specifically, endogenous $\mathrm{H}_{2} \mathrm{~S}$ or a relatively low level of exogenous $\mathrm{H}_{2} \mathrm{~S}$ may exhibit a pro-cancer effect, whereas exposure to $\mathrm{H}_{2} \mathrm{~S}$ at a higher amount or for a long period may lead to cancer cell death. This indicates that inhibition of $\mathrm{H}_{2} \mathrm{~S}$ biosynthesis and $\mathrm{H}_{2} \mathrm{~S}$ supplementation serve as two distinct ways for cancer treatment. This paradoxical role of $\mathrm{H}_{2} \mathrm{~S}$ has stimulated the enthusiasm for the development of novel CBS inhibitors, $\mathrm{H}_{2} \mathrm{~S}$ donors, and $\mathrm{H}_{2} \mathrm{~S}$-releasing hybrids.

Critical Issues: A clear relationship between $\mathrm{H}_{2} \mathrm{~S}$ level and cancer progression remains lacking. The possibility that the altered levels of these byproducts have influenced the cell viability of cancer cells has not been excluded in previous studies when modulating $\mathrm{H}_{2} \mathrm{~S}$ producing enzymes.

Future Directions: The consequence of CSE or 3MST inhibition in cancer cells need to be examined in the future. Better portrayal of the crosstalk among these gaseous transmitters may not only lead to an in-depth understanding of cancer progression but also shed light on novel strategies for cancer therapy. Antioxid. Redox Signal. 31, 1-38.
\end{abstract}

Keywords: hydrogen sulfide, cancer biology, cancer treatment, CBS inhibitors, $\mathrm{H}_{2} \mathrm{~S}$ donors, $\mathrm{H}_{2} \mathrm{~S}$-releasing hybrids

Reviewing Editors: Jerzy Beltowski, Francois Blachier, Vittorio Calabrese, Martin Diener, Milos Filipovic, Gabriel Gojon, Christopher Kevil, Colin Murdoch, Peter Nagy, and Kenneth Olson.

\footnotetext{
${ }^{1}$ Department of Pharmacology, Yong Loo Lin School of Medicine, National University of Singapore, Singapore, Singapore.

${ }^{2}$ Institute of Pharmacy and Pharmacology, University of South China, Hengyang, China.

${ }^{3}$ State Key Laboratory of Natural Medicines, Jiangsu Key Laboratory of Drug Discovery for Metabolic Disease, Center for New Drug Safety Evaluation and Research, China Pharmaceutical University, Nanjing, China.

${ }^{4}$ University of Exeter Medical School, Exeter, United Kingdom.
} 


\section{Table of Contents}

I. Introduction

II. Biochemistry of $\mathrm{H}_{2} \mathrm{~S}$

A. Physical and chemical properties of $\mathrm{H}_{2} \mathrm{~S}$

B. Endogenous production of $\mathrm{H}_{2} \mathrm{~S}$ in mammals

1. Enzymatic production of $\mathrm{H}_{2} \mathrm{~S}$

a. Cystathionine- $\beta$-synthase

b. Cystathionine- $\gamma$-lyase

c. 3-Mercaptopyruvate sulfurtransferase

2. Non-enzymatic production of $\mathrm{H}_{2} \mathrm{~S}$

C. $\mathrm{H}_{2} \mathrm{~S}$ catabolism

1. Oxidation

2. Methylation

3. Expiration

D. Concentration and quantification methods of $\mathrm{H}_{2} \mathrm{~S}$ in mammals

1. Concentration of $\mathrm{H}_{2} \mathrm{~S}$ in mammals

2. Quantification methods of $\mathrm{H}_{2} \mathrm{~S}$ in mammals

a. Methylene blue method

b. MBB method

c. $\mathrm{S}^{2-}$ sensitive electrodes method

d. Polarographic $\mathrm{H}_{2} \mathrm{~S}$ sensor method

e. GC method

f. Fluorimetric probes

III. $\mathrm{H}_{2} \mathrm{~S}$-Producing Enzymes in Cancer
A. CBS in cancer
B. CSE in cancer
C. 3MST in cancer

IV. Dual Role of $\mathrm{H}_{2} \mathrm{~S}$ in Cancer Biology

A. Cancer-promoting effect of $\mathrm{H}_{2} \mathrm{~S}$

1. $\mathrm{H}_{2} \mathrm{~S}$ is a bioenergetic stimulator

2. $\mathrm{H}_{2} \mathrm{~S}$ is a pro-angiogenic mediator

a. $\mathrm{H}_{2} \mathrm{~S}$-mediated persulfidation of $\mathrm{K}_{\mathrm{ATP}}$ channel 12

b. $\mathrm{H}_{2} \mathrm{~S}$ in hypoxia induces angiogenesis 12

3. $\mathrm{H}_{2} \mathrm{~S}$ activates anti-apoptotic pathways

a. $\mathrm{H}_{2} \mathrm{~S}$-mediated persulfidation of NF- $\kappa \mathrm{B}$ p65

b. $\mathrm{H}_{2} \mathrm{~S}$-mediated persulfidation of Keap1

c. $\mathrm{H}_{2} \mathrm{~S}$-mediated persulfidation of MEK1

4. $\mathrm{H}_{2} \mathrm{~S}$ accelerates cell cycle

B. Anti-cancer effect of $\mathrm{H}_{2} \mathrm{~S}$

1. $\mathrm{H}_{2} \mathrm{~S}$ donors induce uncontrolled cellular acidification

2. $\mathrm{H}_{2} \mathrm{~S}$ suppresses cell survival signaling pathways

3. $\mathrm{H}_{2} \mathrm{~S}$ induces cell cycle arrest

C. Bell-shaped model for the dual role of $\mathrm{H}_{2} \mathrm{~S}$ in cancer

V. Crosstalk of $\mathrm{H}_{2} \mathrm{~S}$ with Other Gaso-Transmitters in Cancer Biology 16

A. Crosstalk of $\mathrm{H}_{2} \mathrm{~S}$ and $\mathrm{NO}$ in cancer 16

1. Endogenous $\mathrm{H}_{2} \mathrm{~S}$ and $\mathrm{NO}$ serve as mutual functional effector molecules 16

2. Bioactive products of $\mathrm{H}_{2} \mathrm{~S}$ and $\mathrm{NO}$ interaction possess anti-cancer effect 17

B. Crosstalk of $\mathrm{H}_{2} \mathrm{~S}$ with $\mathrm{CO}$ in cancer 17

1. $\mathrm{CO}-\mathrm{CBS}-\mathrm{H}_{2} \mathrm{~S}$ axis in cancer regulation 17

VI. The Potential of Targeting $\mathrm{H}_{2} \mathrm{~S}$ for Cancer Treatment 18

A. Treatment of cancer with $\mathrm{H}_{2} \mathrm{~S}$ biosynthesis inhibitors 18

1. CBS inhibitor aminooxyacetic acid shows great potential in cancer therapy 18

2. Advances in the development of selective CBS inhibitors 19

B. Treatment of cancer with $\mathrm{H}_{2} \mathrm{~S}$ donors 20

1. Sulfide salts 20

2. Phosphorodithioate derivatives 20

3. Allium sativum extracts and derivatives 21

4. $\mathrm{H}_{2} \mathrm{~S}$-releasing hybrids 21

a. $\mathrm{H}_{2} \mathrm{~S}$-releasing non-steroid anti-inflammatory drugs 21

(1) $\mathrm{H}_{2} \mathrm{~S}$-releasing non-steroid anti-inflammatory drugs possess anti-cancer activity 21 
(2) Mechanisms of action of $\mathrm{H}_{2} \mathrm{~S}-\mathrm{NS} A I D s$ in cancer inhibition $\quad 21$

b. NOSH compounds as anti-cancer agents

C. The therapeutic potential of $\mathrm{H}_{2} \mathrm{~S}$ donation for cisplatin nephrotoxicity 23

VII. The Novelty and Challenges of $\mathrm{H}_{2} \mathrm{~S}$-Based Cancer Therapy 24

A. The novelty of $\mathrm{H}_{2} \mathrm{~S}$-based cancer therapy 24

B. The challenges of $\mathrm{H}_{2} \mathrm{~S}$-based cancer therapy 24

VIII. Future Directions 25

A. Relationship between $\mathrm{H}_{2} \mathrm{~S}$ level and cancer progression 25

B. Test of drug-like $\mathrm{H}_{2} \mathrm{~S}$ donors in cancer

C. Understand the molecular mechanisms underlying $\mathrm{H}_{2} \mathrm{~S}$ effects 25

D. Confirm $\mathrm{H}_{2} \mathrm{~S}$-linked persulfidation of target proteins 25

E. Crosstalk of $\mathrm{H}_{2} \mathrm{~S}$ with $\mathrm{NO}$ in cancer

F. Inorganic polysulfide accounts for the anti-cancer effect of $\mathrm{H}_{2} \mathrm{~S}$ ? 26

G. A new regulatory circuit of thioredoxin and $\mathrm{H}_{2} \mathrm{~S}$ by controlling persulfidation in cancer? 26

$\mathrm{H}$. $\mathrm{H}_{2} \mathrm{~S}$-mediated immune cell regulation in cancer progression and therapy 26

IX. Concluding Remarks 26

\section{Introduction}

$\mathbf{H}$ YDROGEN SULFIDE $\left(\mathrm{H}_{2} \mathrm{~S}\right)$ is a colorless gas characterized with a strong rotten egg smell under standard conditions of temperature and pressure. It has been more than 300 years since the first description of $\mathrm{H}_{2} \mathrm{~S}$ as a poisonous molecule (18). For instance, it has been recorded that heavy exposure to $\mathrm{H}_{2} \mathrm{~S}(>500 \mathrm{ppm})$ causes unconsciousness and death in humans (238). Usually, the intoxication of $\mathrm{H}_{2} \mathrm{~S}$ is ascribed to its strong suppressive effect on several critical enzymes in humans such as cytochrome $c$ oxidase $(238), \mathrm{Na}^{+} / \mathrm{K}^{+}$ ATPase (238), carbonic anhydrase (205), and monoamine oxidase (299).

Nonetheless, the physiological importance of $\mathrm{H}_{2} \mathrm{~S}$ is suggested by the fact that mammalian cells are able to actively produce this gaseous molecule $(71,240,264)$. This was first demonstrated by Abe and Kimura in 1996 (1) showing that $\mathrm{H}_{2} \mathrm{~S}$ is an endogenous modulator in the central nervous system. Subsequently, $\mathrm{H}_{2} \mathrm{~S}$ has been revealed to participate in the regulation of various physiological and pathological conditions within mammalian systems, including central nervous (1), cardiovascular (89), renal (284), reproductive (293), respiratory (83), and digestive systems (64). It is now well recognized as a third endogenous gaso-transmitter along with nitric oxide (NO) and carbon monoxide (CO).

Intriguingly, very recent evidence has accumulated to show that $\mathrm{H}_{2} \mathrm{~S}$ has a previously unrecognized role in cancer biology. In this review, the roles of $\mathrm{H}_{2} \mathrm{~S}$ in cancer development and the underlying mechanisms will be surveyed. Moreover, our review will also discuss the progress and the therapeutic potential of $\mathrm{H}_{2} \mathrm{~S}$-based molecules for cancer therapy.

\section{Biochemistry of $\mathrm{H}_{2} \mathrm{~S}$}

\section{A. Physical and chemical properties of $\mathrm{H}_{2} \mathrm{~S}$}

Under ambient temperature and pressure, $\mathrm{H}_{2} \mathrm{~S}$ is a colorless and flammable gas with a strong rotten egg smell. Acute exposure to high amounts of $\mathrm{H}_{2} \mathrm{~S}(>500 \mathrm{ppm})$ can lead to human death (238). $\mathrm{H}_{2} \mathrm{~S}$ is readily dissolved in water with a solubility of about $80 \mathrm{~m} M$ at $37^{\circ} \mathrm{C}$ (121). In aqueous solutions, $\mathrm{H}_{2} \mathrm{~S}$ is a weak acid and quickly reaches the equilibrium of $\mathrm{H}_{2} \mathrm{~S} / \mathrm{HS}^{-} / \mathrm{S}^{2-}$ species. It is estimated that $14 \%$ of the sulfide will be $\mathrm{H}_{2} \mathrm{~S}$ and nearly $86 \%$ will be $\mathrm{HS}^{-}$in plasma where the $\mathrm{pH}$ value is around 7.4 (311). Nevertheless, changes of $\mathrm{pH}$ value can readily alter the equilibrium of $\mathrm{H}_{2} \mathrm{~S} / \mathrm{HS}^{-} / \mathrm{S}^{2-}$ species. Unless elsewhere specified, in this review, we use the term $\mathrm{H}_{2} \mathrm{~S}$ to reflect the sum of the species $\mathrm{H}_{2} \mathrm{~S} / \mathrm{HS}^{-} / \mathrm{S}^{2-}$ and intermediates formed from these, present at physiological pH (306).

Due to the volatile nature of $\mathrm{H}_{2} \mathrm{~S}$, it can be easily predicted that the equilibrium will constantly shift to the left, which results in the formation of $\mathrm{H}_{2} \mathrm{~S}$ evading from the solution $\left(\mathrm{H}_{2} \mathrm{~S} \leftrightarrow \mathrm{H}^{+}+\mathrm{HS}^{-} \leftrightarrow \mathrm{H}^{+}+\mathrm{S}^{2-}\right)$. In fact, there are published reports showing that half of $\mathrm{H}_{2} \mathrm{~S}$ can escape from medium in $5 \mathrm{~min}$ in tissue culture wells and in an even shorter time in a bubbled tissue bath $(62,101,208)$. This may have partially contributed to the miraculous variations on the reported concentration of $\mathrm{H}_{2} \mathrm{~S}$ in tissues, plasma, and certain experiments $(84,249,311)$. In addition, it is notable to point out that $\mathrm{H}_{2} \mathrm{~S}$, as a low-molecular-weight lipophilic gaseous molecule, is freely diffusible across cell membranes without the need of a specific transporter $(109,176)$.

Sulfur is a multifaceted atom with multiple oxidation states such as -2 in $\mathrm{H}_{2} \mathrm{~S}, 0$ in $\mathrm{S}_{8},+2$ in $\mathrm{SO},+4$ in $\mathrm{SO}_{3}{ }^{2-}$ and +6 in $\mathrm{SO}_{4}{ }^{2-}$. As clearly seen from the earlier described fact that -2 in $\mathrm{H}_{2} \mathrm{~S}$ is the lowest oxidation state of sulfur, therefore $\mathrm{H}_{2} \mathrm{~S}$ is a reductant and can only be oxidized. As a result, $\mathrm{H}_{2} \mathrm{~S}$ (and/or intermediates derived from it) can readily modify biological pathways and elicit biological effects via the following reactions. The reactions between $\mathrm{H}_{2} \mathrm{~S}$ and the reactive oxygen species (ROS) or reactive nitrogen species (RNS) species have been extensively studied in solutions (306-308). Nevertheless, Olson et al. (211) recently showed that the reaction of $\mathrm{H}_{2} \mathrm{~S}$ with $\mathrm{H}_{2} \mathrm{O}_{2}$ is way too slow to elicit any biological significance in mammalian systems. Therefore, it is unlikely that $\mathrm{H}_{2} \mathrm{~S}$ serves as a direct ROS scavenger in physiological conditions (43). Besides ROS/RNS species, another primary target of $\mathrm{H}_{2} \mathrm{~S}$ in mammalian systems would be biological irons, namely the metal centers on proteins (199).

In recent years, numerous studies revealed a process called persulfidation as the third $\mathrm{H}_{2} \mathrm{~S}$-mediated interaction by which $\mathrm{H}_{2} \mathrm{~S}$ can react with protein thiol groups and forms 
protein persulfides that may induce functional changes of target proteins (194). However, one should bear in mind here that $\mathrm{H}_{2} \mathrm{~S}$ reacts with $\mathrm{R}-\mathrm{SOH}$ rather than free thiols since conversion of $\mathrm{R}-\mathrm{SH}$ to $\mathrm{R}-\mathrm{SSH}$ is associated with oxidation rather than chemical reduction of sulfur. Similar with other modifications of protein thiols such as $S$-nitrosation, $S$-sulfenylation, and $S$-glutathionylation, $\mathrm{H}_{2} \mathrm{~S}$-mediated persulfidation has been found in several proteins and demonstrated to account for the plethora of $\mathrm{H}_{2} \mathrm{~S}$-mediated signaling transduction $(195,225)$. Nevertheless, it should be noted that several critical issues are still awaiting resolution in the field $(41,78)$. For instance, (i) reliable and proper quantification methods are to be developed; (ii) the mechanisms underlying such modification needs to be thoroughly studied; and (iii) it is required to understand the actual impact of persulfidation on cellular functions.

Interestingly, a fourth $\mathrm{H}_{2} \mathrm{~S}$-mediated interaction was recently reported to be the chemical reduction of protein disulfide bonds $(220,289)$, whereas physiological relevance of the reaction still awaits further demonstration. For a thorough description of the chemical basis of the interactions mentioned earlier, it is advised to refer a recent review from Filipovic et al. on the chemical foundation of $\mathrm{H}_{2} \mathrm{~S}$ biology (79).

\section{B. Endogenous production of $\mathrm{H}_{2} \mathrm{~S}$ in mammals}

The first description of $\mathrm{H}_{2} \mathrm{~S}$ production in life can be retrieved back to 1895 in bacteria (215). One hundred years later, the detection of sulfide was first reported in brain tissues (93) and later in other mammalian systems $(107,124)$. Mammalian cells rely on both enzymatic and non-enzymatic pathways to generate $\mathrm{H}_{2} \mathrm{~S}$ (Fig. 1).

By using an enzymatic system, $\mathrm{H}_{2} \mathrm{~S}$ production can be regulated tightly and precisely in mammalian cells, in which $\mathrm{H}_{2} \mathrm{~S}$ may serve as an endogenous signaling molecule. Among the enzymes, cystathionine $\beta$-synthase (CBS) and cystathionine $\gamma$ lyase (CSE) are pyridoxal 5'-phosphate (PLP)-dependent enzymes and are located in the cytosol, whereas PLP-independent

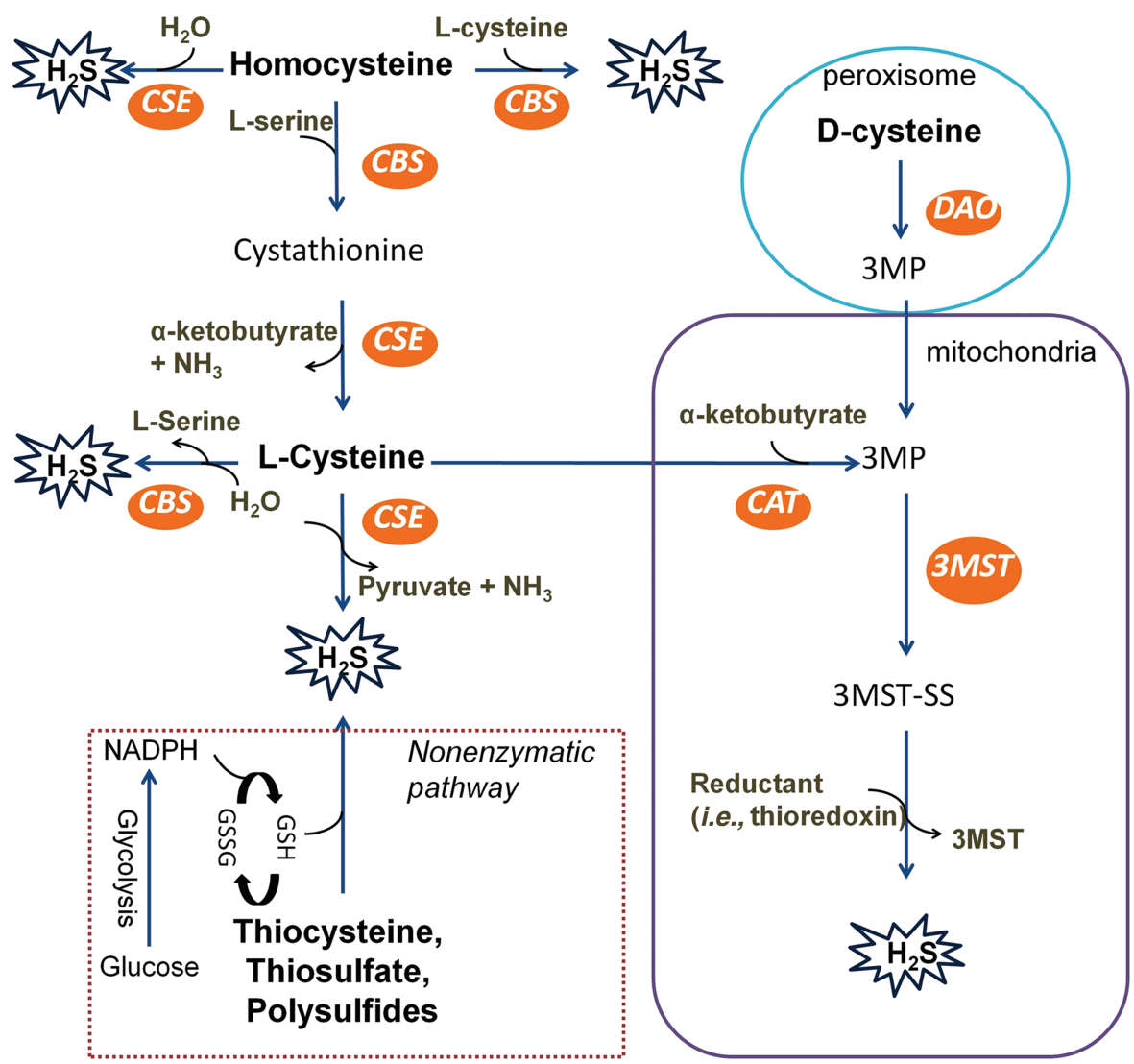

FIG. 1. Endogenous $\mathrm{H}_{2} \mathrm{~S}$ production in mammalian systems. Mammalian cells mainly rely on the enzymatic pathways to generate $\mathrm{H}_{2} \mathrm{~S}$; however, nonenzymatic pathways are also responsible for a small portion of the production. There are four enzymatic pathways for the biosynthesis of $\mathrm{H}_{2} \mathrm{~S}$, including CBS, CSE, 3MST coupled with CAT, and 3MST coupled with DAO. The first three pathways utilize L-cysteine as a main precursor of $\mathrm{H}_{2} \mathrm{~S}$, whereas peroxisome-located DAO (blue circle) can catalyze D-cysteine into 3MP, which can be further transformed into $\mathrm{H}_{2} \mathrm{~S}$ by $3 \mathrm{MST}$. This D-cysteine pathway may exclusively exist in brain and kidney. In addition, CBS and CSE may generate $\mathrm{H}_{2} \mathrm{~S}$ in the cytosol whereas $3 \mathrm{MST}$ mainly resides and synthesizes $\mathrm{H}_{2} \mathrm{~S}$ in mitochondria (purple rectangle). A small portion of endogenous $\mathrm{H}_{2} \mathrm{~S}$ is derived via nonenzymatic reduction (dotted green rectangle). In the presence of reducing equivalents such as NADPH and NADH, reactive sulfur species in persulfides, thiosulfate, and polysulfides are reduced into $\mathrm{H}_{2} \mathrm{~S}$ and other metabolites. 3MP, 3mercaptopyruvate; 3MST, 3-mercaptopyruvate sulfurtransferase; CAT, cysteine aminotransferase; CBS, cystathionine $\beta$ synthase; CSE, cystathionine $\gamma$-lyase; DAO, D-amino acid oxidase; $\mathrm{H}_{2} \mathrm{~S}$, hydrogen sulfide; NADH, nicotinamide adenine dinucleotide; NADPH, nicotinamide adenine dinucleotide phosphate. Color images are available online. 
3-mercaptopyruvate sulfurtransferase (3MST) mainly resides and generates $\mathrm{H}_{2} \mathrm{~S}$ within mitochondria. Nevertheless, CBS and CSE can translocate into mitochondria when the activity of 3MST is significantly suppressed in oxidative conditions such as hypoxia $(82,276)$. CBS and CSE also play a role in transsulfuration and reverse trans-sulfuration pathways that are responsible for homocysteine metabolism.

Moreover, it is worth pointing out that the mechanisms underlying the regulation of these enzymes such as the expression and activities remain largely unsettled regardless of physiological or pathophysiological conditions. Interestingly, Olson et al. (212) recently showed that $\mathrm{H}_{2} \mathrm{~S}$ may be generated from thioredoxin by catalase using nicotinamide adenine dinucleotide phosphate (NADPH) in hypoxia in vitro but this has yet to be demonstrated in vivo or in mammalian cells. This could be very relevant to solid tumors where $\mathrm{O}_{2}$ is low and NADPH is elevated (23).

\section{Enzymatic production of $\mathrm{H}_{2} \mathrm{~S}$}

a. Cystathionine- $\beta$-synthase. CBS (EC 4.2.1.22) was first identified in 1969 by Braunstein et al. (28) and was later found to be able to produce $\mathrm{H}_{2} \mathrm{~S}$ mainly through catalyzing L-homocysteine and L-cysteine to form L-cystathionine and $\mathrm{H}_{2} \mathrm{~S}$, a reaction analogous to that catalyzed by this enzyme in the trans-sulfuration pathway (29). In the presence of L-cysteine, CBS generates $\mathrm{H}_{2} \mathrm{~S}$ via a $\beta$-replacement reaction along with the production of $\mathrm{L}$-serine. When Lhomocysteine is available, the rate of $\mathrm{H}_{2} \mathrm{~S}$ generation can be accelerated by 23 -fold compared with that from $\mathrm{L}$ cysteine alone (257). In addition, CBS is also well known to catalyze the condensation of homocysteine and $\mathrm{L}$-serine, which results in the formation of L-cystathionine and $\mathrm{H}_{2} \mathrm{O}$ (118). This reaction is a critical step for the biosynthesis of L-cysteine, which can be further used as an $\mathrm{H}_{2} \mathrm{~S}$-producing substrate.

The activity of CBS is found to be mainly regulated by three sites on the protein, including a heme group at the $\mathrm{N}$-terminus, an $S$-adenosyl-L-methionine (SAM)-binding domain at the Cterminus, and an $S$-glutathionylation site at cysteine 346 . For instance, the modification of CBS carrying the Fe (II) form of heme by $\mathrm{CO}$ inhibits $\mathrm{CBS}$ activity and $\mathrm{H}_{2} \mathrm{~S}$ generation (274) and is discussed in section V, Crosstalk of $\mathrm{H}_{2} \mathrm{~S}$ with Other GasoTransmitters in Cancer Biology. In contrast, both SAM and $S$ glutathionylation lead to the activation of CBS and enhanced production of $\mathrm{H}_{2} \mathrm{~S}(206,247)$. In addition, Agrawal and Banerjee have shown that purified CBS protein can be targeted by SUMO in vitro and the resulting SUMOylation of CBS leads to the reduction of its activity (2). However, the presence and possible functional consequences of this SUMOylation are still not clear within cells and mammalian systems. The combination of these modulations may allow the quick adjustment of the endogenous $\mathrm{H}_{2} \mathrm{~S}$ level to cope with various cellular conditions. However, the molecular mechanisms underlying these modulations remain to be addressed in future.

$\mathrm{CBS}$ is regarded as the predominant $\mathrm{H}_{2} \mathrm{~S}$ synthase in the central nervous system, although its expression has also been observed in various types of other organs such as kidney, liver, lymphocytes, uterus, placenta, and pancreas islets (1, $125,224)$. Recently, this notion seems to be challenged by a report that brain homogenates of CBS-knockout mice produce a similar level of $\mathrm{H}_{2} \mathrm{~S}$ to that obtained from wide-type mice (253). However, we propose that the conflict may result from compensatory expression of 3MST in the brain when CBS is knocked out, which may help maintain the endogenous level of $\mathrm{H}_{2} \mathrm{~S}$ for neuronal cell survival. As a result, CBS knockout mice-derived brain lysates produce a comparable level of $\mathrm{H}_{2} \mathrm{~S}$ with that obtained from wide-type mice. Therefore, the data perhaps do not necessarily contradict with the existing notion that CBS is predominant for $\mathrm{H}_{2} \mathrm{~S}$ production in the brain, particularly in physiological conditions. In this case, more experiments are needed to test the hypothesis whether such possible compensatory mechanisms among $\mathrm{H}_{2} \mathrm{~S}$-producing enzymes cause the contradiction.

b. Cystathionine- $\gamma$-lyase. CSE (EC 4.4.1.1), similar to $\mathrm{CBS}$, utilizes homocysteine as a substrate to generate $\mathrm{H}_{2} \mathrm{~S}$ along with $\alpha$-ketobutyrate and ammonia. Alternatively, CSE can also catalyze L-cysteine to produce $\mathrm{H}_{2} \mathrm{~S}$ and other byproducts such as pyruvate, and ammonia. Using the dithiobisnitrobenzene assay, Chiku et al. (53) have found that at a physiological concentration of L-cysteine and homocysteine, around $70 \%$ of $\mathrm{H}_{2} \mathrm{~S}$ is produced from CSE-mediated $\alpha$ - and $\beta$-elimination of L-cysteine whereas CSE-catalyzed $\alpha, \gamma$ elimination of homocysteine contributes merely about $29 \%$ to the total $\mathrm{H}_{2} \mathrm{~S}$ content. However, about $90 \%$ of $\mathrm{H}_{2} \mathrm{~S}$ is derived from $\alpha, \gamma$-elimination of homocysteine when homocysteine level is increased to the amount comparable with that of hyperhomocysteinemia (53). These suggest that the relative concentration of homocysteine and L-cysteine may determine the main substrate used by CSE for the production of $\mathrm{H}_{2} \mathrm{~S}$ in mammalian cells.

The activity of CSE is known to be influenced by intracellular $\mathrm{Ca}^{2+}$ concentration $(182,343)$. Specifically, low levels of intracellular $\mathrm{Ca}^{2+}$ constitutively induce the production of $\mathrm{H}_{2} \mathrm{~S}$ by CSE whereas CSE activity is suppressed on the rise of intracellular $\mathrm{Ca}^{2+}$ by cell stimulation even in the presence of PLP. Further study has revealed that the regulation is independent of calmodulin as neither calmodulin nor its selective inhibitor $\mathrm{W}-7$ alters the level of $\mathrm{H}_{2} \mathrm{~S}$ derived from purified CSE from the liver (182). Nevertheless, the precise mechanism underlying $\mathrm{Ca}^{2+-}$ mediated regulation of CSE activity remains to be defined in future.

In comparison to $\mathrm{CBS}, \mathrm{CSE}$ distributes more widely in mammalian tissues. It is abundantly expressed in the cardiovascular system and respiratory system (107, 344). CSE may also be the dominant $\mathrm{H}_{2} \mathrm{~S}$-producing enzyme in tissues such as liver, kidney, uterus, and pancreatic islets $(135,327,344)$. A detectable level of CSE mRNA has been reported in the brain $(71,89)$; however, it seems that the presence of CSE may not be related to $\mathrm{H}_{2} \mathrm{~S}$ production in the organ because CSE inhibitors do not alter the production of $\mathrm{H}_{2} \mathrm{~S}$ in the brain (1).

c. 3-Mercaptopyruvate sulfurtransferase. 3MST is the most recently discovered $\mathrm{H}_{2} \mathrm{~S}$-producing enzyme (253). With this enzyme system (Fig. 1), L-cysteine has to be first converted into 3-mercaptopyruvate (3MP) by cysteine aminotransferase (CAT). Thereafter, 3MST transfers a sulfur atom from $3 \mathrm{MP}$ onto itself, which leads to the formation of persulfide. $\mathrm{H}_{2} \mathrm{~S}$ is then released from the persulfide in the presence of a reductant such as thioredoxin (197, 248, 323). Recently, another source of 3MP was found in mammals by Shibuya et al., D-cysteine (251). Specifically, D-cysteine is 
transformed into 3MP by peroxisome-located D-amino acid oxidase (DAO). Metabolite exchanges between peroxisome and mitochondria can import 3-MP into mitochondria where it is further catalyzed into $\mathrm{H}_{2} \mathrm{~S}$ by $3 \mathrm{MST}$. Because of the exclusive location of DAO in the brain and kidney, this $\mathrm{H}_{2} \mathrm{~S}$ generating pathway is currently believed to uniquely exist in the two organs.

Distinct from CBS and CSE, the activity of 3MST appears to be regulated intrinsically by its redox state rather than interactions with other factors. Based on its crystal structure, three redox-sensitive cysteines (Cys154, Cys247, Cys263) have been identified on its catalytic site (196). In line with this, oxidative stress significantly suppresses the activity of 3MST and, therefore, $\mathrm{H}_{2} \mathrm{~S}$ production probably by oxidation of these protein thiols $(36,133)$. Moreover, modulation of CAT or DAO activity can also apparently affect the generation of $\mathrm{H}_{2} \mathrm{~S}$ by $3 \mathrm{MST}$. For instance, extensive evidence has shown that aspartate, an inhibitor of CAT, largely inhibits $\mathrm{H}_{2} \mathrm{~S}$ biosynthesis and is commonly used as a pharmacological tool to study the function of $3 \mathrm{MST}$-derived $\mathrm{H}_{2} \mathrm{~S}(4,252,253)$ whereas one should bear in mind that aspartate is not a selective 3MST inhibitor. Therefore, special caution should be given when studying 3MST-mediated cellular $\mathrm{H}_{2} \mathrm{~S}$ production due to the fact that multiple enzymes are participating in the process, particularly in organs such as the brain and kidney. In addition, increased intracellular $\mathrm{Ca}^{2+}$ has been shown to suppress the activity of CAT and the subsequent $\mathrm{H}_{2} \mathrm{~S}$ synthesis independently of calmodulin (134, 181). However, the precise molecular mechanism underlying this regulation is unknown.

3MST, similar to CBS and CSE, is expressed in many tissues with particularly high activity in cardiac cells, pericentral hepatocytes in the liver, and the proximal tubular epithelium of the kidney $(252,253,312)$. Recent evidence shows that 3MST may be crucial for $\mathrm{H}_{2} \mathrm{~S}$ generation in the brain as brain homogenates of CBS-knockout mice produce a similar level of $\mathrm{H}_{2} \mathrm{~S}$ to that of wide-type mice (253). Within mammalian cells, 3MST is mainly located in mitochondria, although a detectable level of 3MST has also been reported in the cytoplasm (134). Nevertheless, it is believed that the occurrence of $\mathrm{H}_{2} \mathrm{~S}$ generation by $3 \mathrm{MST}$ is mainly in mitochondria, because the concentration of L-cysteine is three times higher in the mitochondria than that in the cytoplasm (197).

2. Non-enzymatic production of $\mathrm{H}_{2} \mathrm{~S}$. A portion of endogenous $\mathrm{H}_{2} \mathrm{~S}$ is derived from sulfane sulfur via non-enzymatic chemical reduction. In general, the process requires reducing equivalents such as NADPH and nicotinamide adenine dinucleotide (NADH), which are supplied by oxidation of glucose via glycolysis or from phosphogluconate via NADPH oxidase (244). In the presence of such equivalents, reactive sulfur species in persulfides, thiosulfate, and polysulfides can be reduced into $\mathrm{H}_{2} \mathrm{~S}$ and other metabolites (210). Essentially, all the components of this non-enzymatic route are available in mammals including reducible sulfur, suggesting the necessity of this pathway in mammalian systems. In accordance with this, hyperglycemia is demonstrated to promote $\mathrm{H}_{2} \mathrm{~S}$ generation by enhancing this pathway (296).

\section{C. $\mathrm{H}_{2} \mathrm{~S}$ catabolism}

Along with the production of endogenous $\mathrm{H}_{2} \mathrm{~S}$, it has to be disposed very quickly as the accumulation of $\mathrm{H}_{2} \mathrm{~S}$ may result in organ toxicity. In comparison to the biosynthesis of $\mathrm{H}_{2} \mathrm{~S}$, the catabolism of this gaseous transmitter is not well studied and most evidence was obtained by using exogenous $\mathrm{H}_{2} \mathrm{~S}$. Therefore, further validation is needed in experimental settings of physiological conditions. Herein, we will discuss three catabolic routes of $\mathrm{H}_{2} \mathrm{~S}$ in mammalian systems, namely oxidation, methylation, and expiration. It is worth mentioning that hemoglobin also interacts with $\mathrm{H}_{2} \mathrm{~S}$, resulting in the formation of bound sulfur in plasma as sulfhemoglobin (45); however, this may serve as an internal storage of sulfide rather than its catabolism and is, therefore, not included here in this review.

1. Oxidation. The vast majority of $\mathrm{H}_{2} \mathrm{~S}$ is disposed via the kidney in the form of sulfate. In the process of sulfate formation, oxidized $\mathrm{H}_{2} \mathrm{~S}$ combines with another molecule of $\mathrm{H}_{2} \mathrm{~S}$ and forms one molecule of thiosulfate in mitochondria. This step does not require any enzyme and has been demonstrated within isolated rat kidneys and livers $(13,165) . \mathrm{H}_{2} \mathrm{~S}$ can also be oxidized by sulfide quinine oxidoreductase (SQOR) in mitochondria to generate persulfide, which is then catalyzed into thiosulfate by rhodanese $(115,116)$. Recently, Bostelar et al. (26) discovered that ferric hemoglobin is also able to oxidize sulfide to thiosulfate, whereas the physiological significance of this reaction still awaits further exploration. Subsequently, conversion of thiosulfate into sulfate and/ or sulfite occurs in the presence of sulfide-detoxifying enzymes such as rhodanese (228). The produced sulfite is also quickly oxidized into sulfate (152). To this end, sulfate can be excreted via urine as a main product of $\mathrm{H}_{2} \mathrm{~S}$ catabolism.

However, it should be noted that the urinary concentration of sulfate does not serve as an accurate marker for endogenous $\mathrm{H}_{2} \mathrm{~S}$ level; sulfate in urine can also be derived from the direct oxidation of L-cysteine $(143,158)$. Although the oxidation of $\mathrm{H}_{2} \mathrm{~S}$ may occur in all types of mammalian cells, the primary site of this oxidation is postulated to be in the liver (85).

2. Methylation. Unlike $\mathrm{H}_{2} \mathrm{~S}$ oxidation, the methylation of $\mathrm{H}_{2} \mathrm{~S}$ mainly occurs in the cytosol rather than mitochondria. In the process, $\mathrm{H}_{2} \mathrm{~S}$ is methylated into methanethiol, which can be further methylated into non-toxic dimethylsulfide by thiol S-methyltransferase (305). Compared with sulfide oxidation, the methylation of sulfide is shown to be $\sim 10,000$ times slower in colonic mucosa (152). Therefore, it may dispose minimal amounts of $\mathrm{H}_{2} \mathrm{~S}$ in physiological conditions.

3. Expiration. $\mathrm{H}_{2} \mathrm{~S}$ can also escape from mammalian lungs. The amounts of exhaled $\mathrm{H}_{2} \mathrm{~S}$ can be readily detected along with administration of sodium sulfide $\left(\mathrm{Na}_{2} \mathrm{~S}\right)$ (113) or inhibition of endogenous NO synthesis (229). Therefore, it seems that expiration may provide a disposal route of $\mathrm{H}_{2} \mathrm{~S}$ when large amounts of $\mathrm{H}_{2} \mathrm{~S}$ are generated. In support of this notion, the exhalation of $\mathrm{H}_{2} \mathrm{~S}$ is detectable in pathological conditions such as septic shock, hemorrhagic shock, and chronic obstructive pulmonary disease when $\mathrm{H}_{2} \mathrm{~S}$ is generated excessively $(110,189,263)$. However, it remains unknown how much $\mathrm{H}_{2} \mathrm{~S}$ is lost through lungs in healthy conditions since there is not enough to pick up for measurement. Considering that the free level of $\mathrm{H}_{2} \mathrm{~S}$ is extremely low in mammalian blood $(84,209)$, the loss of $\mathrm{H}_{2} \mathrm{~S}$ via this route should be very minimal if there is any. 


\section{Concentration and quantification methods of $\mathrm{H}_{2} \mathrm{~S}$ in mammals}

1. Concentration of $\mathrm{H}_{2} \mathrm{~S}$ in mammals. In spite of definitive evidence showing the presence of $\mathrm{H}_{2} \mathrm{~S}$ in mammalian systems, the exact concentration of $\mathrm{H}_{2} \mathrm{~S}$ in vivo has been in debate for a long time due to conflicting data reported. Using the methylene blue method, initial literatures reported that the concentration of $\mathrm{H}_{2} \mathrm{~S}$ is above $35 \mu \mathrm{M}$ and 50-160 $\mu \mathrm{M}$ in mammalian plasma and brain, respectively (93, 242, 344, 349). However, later studies have shown that the high concentration of $\mathrm{H}_{2} \mathrm{~S}$ may be caused by the usage of a strong acid in the measurement $(114,311)$, because $\mathrm{H}_{2} \mathrm{~S}$ is released from acid-labile sulfur in the presence of a strong acid when using the methylene blue method.

With the exclusion of a strong acid, $0.7-3 \mu M$ sulfide has been reported in the mammalian plasma utilizing monobromobimane (MBB) method with or without dithiothreitol $(111,249,282,315)$ by more robust analytical techniques such as high-performance liquid chromatography (HPLC). Nevertheless, one should bear in mind that MBB reacts and removes $\mathrm{HS}^{-}$from solution, which may result in the release of more $\mathrm{HS}^{-}$ from some proteins ionized by $\mathrm{HS}^{-}$at cationic sites (99).

In contrast, the polarographic sensor method can be used to measure $\mathrm{H}_{2} \mathrm{~S}$ concentration without sequestrating it by which a low nano-molor range of $\mathrm{H}_{2} \mathrm{~S}$ concentration has been observed in rodent plasma $(311,315)$. In line with this, it has recently been shown that the concentration of $\mathrm{H}_{2} \mathrm{~S}$ is about $15 \mathrm{n} M$ in mouse plasma by a newly developed gas chromatography (GC) method (151). Taken together, the concentration of sulfide is suggested to be in the range of nanomolar to submicromolar in mammalian plasma in spite of controversy.

Although the concentration of $\mathrm{H}_{2} \mathrm{~S}$ in mammalian plasma is demonstrated to be rather low, it may be substantially increased in certain microenvironments. This may be due to three possible mechanisms, including: (i) $\mathrm{H}_{2} \mathrm{~S}$ release from bound sulfur. For example, it has been demonstrated that activation of neurons causes the release of sulfide from the bound sulfur of nearby astrocytes, which stimulates the activity of $\mathrm{Na}^{+}$/ $\mathrm{HCO}_{3}{ }^{-}$cotransporter and alkalinizes the astrocytes (114). It is likely that other tissues or organs embrace a similar mechanism as the brain considering the spread of bound sulfur across the mammalian body. (ii) Upregulation of $\mathrm{H}_{2} \mathrm{~S}$ biosynthesis. It has been shown that tissue $\mathrm{H}_{2} \mathrm{~S}$ biosynthesis is enhanced in conditions such as streptozotocin-induced diabetes (334). In such conditions, it is expected that $\mathrm{H}_{2} \mathrm{~S}$ will be temporarily concentrated in the microenvironment, particularly around $\mathrm{H}_{2} \mathrm{~S}$-producing enzymes before its diffusion or oxidation. (iii) Suppression of $\mathrm{H}_{2} \mathrm{~S}$ catabolism. During hypoxia, $\mathrm{O}_{2}$ reduction leads to suppression of $\mathrm{H}_{2} \mathrm{~S}$ oxidation and subsequent accumulation of $\mathrm{H}_{2} \mathrm{~S}$, which has been demonstrated in various tissues/systems such as blood vessels, carotid body, kidney etc. $(21,25,36)$.

2. Quantification methods of $\mathrm{H}_{2} \mathrm{~S}$ in mammals. As reviewed earlier, the concentration of $\mathrm{H}_{2} \mathrm{~S}$ does not always remain constant and it may fluctuate in particular conditions. Therefore, the accurate measurement of $\mathrm{H}_{2} \mathrm{~S}$ level is crucial for a precise portrayal of the role of $\mathrm{H}_{2} \mathrm{~S}$ in individual circumstances. Herein, the commonly used quantification methods of $\mathrm{H}_{2} \mathrm{~S}$ will be briefly overviewed with emphasis on their sensitivity and reliability for measuring the level of
$\mathrm{H}_{2} \mathrm{~S}$ in biological samples. The readers are also advised to refer to the review by Kevil and coworkers (140) and another review article from Nagy et al. (200) discussing in detail the pitfalls that are associated with sulfide quantification.

a. Methylene blue method. In this method, sulfide is first trapped with a metal (usually zinc acetate). The resultant complex reacts with $N, N$-dimethyl- $p$-phenylenediamine and leads to the formation of methylene blue in the presence of $\mathrm{Fe}^{3+}$ under acidic conditions. Subsequently, methylene blue is measured at $670 \mathrm{~nm}$ with a spectrophotometer. The methylene blue method was initially developed by Fischer (80) for the quantification of $\mathrm{H}_{2} \mathrm{~S}$ in natural water and thereafter adapted for analyzing non-biological samples such as sewage, food, and gas $(6,117,231)$. Ever since the demonstration of $\mathrm{H}_{2} \mathrm{~S}$ as an endogenous signaling molecule, it has been extensively employed to measure $\mathrm{H}_{2} \mathrm{~S}$ concentration in blood, tissues, and other biological specimens perhaps due to its easy protocol for usage $(1,77,209)$.

However, it is currently believed that this method is not suitable for these biological samples due to the release of $\mathrm{H}_{2} \mathrm{~S}$ from acid labile sulfide pools under acidic conditions (114, 311 ), though it may be useful in estimating total sulfide pools. Nevertheless, it may still serve well as an acceptable assay to measure the activity of $\mathrm{H}_{2} \mathrm{~S}$-producing enzymes with proper control groups. Furthermore, it is essential to make the standard curves for sulfide calculation under exactly the same conditions (i.e., pH) with the sample solutions (200).

b. $M B B$ method. In the assay, $\mathrm{MBB}$ derivates $\mathrm{H}_{2} \mathrm{~S}$ into sulfide-diamine product in basic conditions, which is subsequently determined with HPLC equipped with a fluorescence detector. The detection limit of this method is $2 \mathrm{n} M$ at optimum conditions, and the good stability of the sulfide-diamine product allows batch storage and analysis (249). Thus, this method is regarded as a highly useful method for sulfide quantification. Nonetheless, examination of publication revealed that the concentration of $\mathrm{H}_{2} \mathrm{~S}$ measured under $\mathrm{pH} 9.5$ seems to be higher than that under $\mathrm{pH} 8.0(249,315)$. We speculate that this discrepancy may be caused by the release of $\mathrm{H}_{2} \mathrm{~S}$ from some bound sulfide under basic conditions. Thus, special caution should be given for $\mathrm{pH}$ control when employing this method to compare $\mathrm{H}_{2} \mathrm{~S}$ levels among different experimental groups. It is worth mentioning that this method can measure the conversion of sulfide into polysulfide, another potential endogenous signaling molecule, as suggested by Nagy and Winterbourn (201).

c. $S^{2-}$-sensitive electrodes method. In this method, $\mathrm{S}^{2-}$ -sensitive electrodes are used to measure the electronic voltage, which can be further calculated as sulfide concentration. It is able to detect $\mathrm{H}_{2} \mathrm{~S}$ concentration in $1 \mathrm{~min}$ with a detection range of $1-100 \mu M$ and is now widely used for the quantification of $\mathrm{H}_{2} \mathrm{~S}$ in biological samples $(328,344)$. Since this method does not require sulfide derivation, it, therefore, allows the kinetic measurement of free sulfide concentration (200). Moreover, a polarographic sulfide sensor was developed to overcome the interference of biomolecules and frequent reconditioning (65), which has shown its feasibility to measure free sulfide levels in in vivo models $(62,65)$.

d. Polarographic $\mathrm{H}_{2} \mathrm{~S}$ sensor method. This method employs polarographic $\mathrm{H}_{2} \mathrm{~S}$ sensors for the measurement of $\mathrm{H}_{2} \mathrm{~S}$ 
level with $\mathrm{Na}_{2} \mathrm{~S}$ or sodium hydrosulfide $(\mathrm{NaSH})$ as a standard. The assay is sensitive with a detection limit of nanomolar range under anoxic conditions and is able to provide a realtime measurement of $\mathrm{H}_{2} \mathrm{~S}$ from biological samples $(65,139)$. Though the method is well documented as a reliable method for the measurement of $\mathrm{H}_{2} \mathrm{~S}$ levels by various studies (139, 209), Whitfield et al. (311) have recently reported that they cannot detect any sulfide in plasma derived from various animal species. Later, it was suggested that the earlier on successful studies had constructed electrodes with a unique silicone polycarbonate blend membrane that is not commercially available any longer (140). Intriguingly, Faccenda et al. (73) recently showed that polydimethylsiloxane membrane is successful in construction of $\mathrm{H}_{2} \mathrm{~S}$ electrodes and after measurement of $\mathrm{H}_{2} \mathrm{~S}$. However, it can be clearly seen that the sensitivity of the method is apparently affected by the materials of $\mathrm{H}_{2} \mathrm{~S}$ electrodes. In addition, how to preserve the sulfide content for later measurement remains to be settled when using this method.

e. GC method. The method uses an alkylation technique to extract $\mathrm{H}_{2} \mathrm{~S}$ followed by $\mathrm{GC}$ measurement of the $\mathrm{H}_{2} \mathrm{~S}$-derived substance. Shigetoshi et al. (254) first established the method and successfully detected the sulfide level in rat blood exposed to $\mathrm{H}_{2} \mathrm{~S}$. Recently, Furne et al. (84) have improved the method via combing GC with a chemiluminescence sulfur detector by which the concentration of free $\mathrm{H}_{2} \mathrm{~S}$ in mouse blood is later reported to be around $15 \mathrm{n} M$ (151). Both studies showed that the detection limit of the improved method is at nanomolar range. Though it may be not as user friendly as aforementioned techniques, this method is evidently sensitive and specific. Nevertheless, it is notable that the method may primarily facilitate quantification of the species of $\mathrm{H}_{2} \mathrm{~S}$ alone over other species of sulfide, including HS $^{-}$.

f. Fluorimetric probes. In the method, the reducing ability of $\mathrm{H}_{2} \mathrm{~S}$ serves as the chemical basis for the synthesis of such probes. Compared with the techniques mentioned earlier, fluorescence probes have tremendous advantages on the sensitive and real-time $\mathrm{H}_{2} \mathrm{~S}$ detection within specific tissues and cellular compartments. Due to this, the development of $\mathrm{H}_{2} \mathrm{~S}$-sensitive fluorescence probes is one of the most rapid growing areas in the field of $\mathrm{H}_{2} \mathrm{~S}$ biology. As a result, numerous such probes have been reported, such as sulfidefluor-1/2 (SF-1/ 2 ), dansylazide azide, sulfide-selective fluorescent probe- $1 / 2$, and 7-Azido-4-methylcoumarin (96, 166, 227, 236).

However, they, indeed, have some limitations that should be noted when employing these probes: (i) Some of the probes may have limited sensitivity, and, therefore, long time exposure may be needed to catch the changes of $\mathrm{H}_{2} \mathrm{~S}$ levels; (ii) tissue antofluorescence may disturb the use of some probes that have a similar excitation/emission wavelength (175); (iii) some of the probes may have non-specific interaction with other reducing biological thiols such as cysteine and glutathione $(311,315)$, which may limit their use, particularly in in vivo settings; and (iv) they actually measure the amount of $\mathrm{H}_{2} \mathrm{~S}$ produced over the duration of exposure as the chemical reactions of $\mathrm{H}_{2} \mathrm{~S}$ with these fluorophores are essentially irreversible (99).

\section{III. $\mathrm{H}_{2} \mathrm{~S}$-Producing Enzymes in Cancer}

$\mathrm{H}_{2} \mathrm{~S}$ is produced in mammalian cells by three major enzymes, including CSE, CBS, and 3MST. Among these en- zymes, CSE and CBS are located in the cytosol whereas 3MST resides and generates $\mathrm{H}_{2} \mathrm{~S}$ in mitochondria. Numerous studies have shown altered expression of the enzyme(s) in the progression of various types of cancer cells, which have been reviewed next and summarized in Table 1.

\section{A. CBS in cancer}

The pro-cancer effect of CBS has been thoroughly demonstrated in colon cancer. Tu et al. first observed the correlation of $\mathrm{CpG}$ island methylation in CBS promoter with the occurrence and progression of colon cancer (285), implying a possible role of CBS in the tumorigenesis. After this, the expression level of CBS has been measured in human colon cancer biopsies, colon cancer cell lines, and normal margin mucosa by Szabo et al. (266) and Szabo and Hellmich (267). They found that in comparison to normal tissues the expression levels of CBS rather than those of CSE and 3MST are selectively upregulated in colon cancer biopsies and colon cancer cell lines $(266,267)$. Intriguingly, the proliferation of colon cancer cell line HCT116 was further accelerated on the activation of CBS with SAM (185) or supplementation of $\mathrm{NaSH}$ (although $<100 \mu M$ ) (32). Conversely, genetic silencing or pharmacological inhibition of CBS lessened the proliferation of colon cancer cell lines along with the reduced migration and invasion $(266,267)$.

These anti-cancer effects of CBS blockage in colon cancer have been further substantiated in several mouse xenograft models $(48,102)$. Recently, Pagliara et al. (219) reported that 5fluorouracil treatment induces the downregulation of CBS, which may contribute to the following apoptosis in colon cancer cells. Taken together, these results indicate that CBS is a procancer factor in colon cancer development and its inhibition may serve as a promising strategy for colon cancer therapy.

Accumulating evidence also suggests a pro-cancer role of CBS in human ovarian cancer and breast cancer. The expression of CBS is commonly found in primary serous ovarian carcinoma (24) and also ovarian cancer cell lines (47); however, minimal expression of CBS is detected in the non-malignant ovarian surface epithelial cell line OSE (24). siRNA silencing of CBS abrogates tumor growth $(24,47)$ and increases the sensitivity of ovarian cancer cell lines to chemotherapeutic drug cisplatin (24). The outcome of CBS silencing might be the disruption of mitochondrial ROS production and adenosine triphosphate (ATP) generation, which may result in the inhibitory effect in ovarian cancer cells (24).

In human breast cancer, a more subtle impact of CBS has been suggested. When CBS is silenced with siRNA, it does not alter breast cancer cell proliferation in in vitro culture but significantly reduces tumor growth in xenograft models (246). Further study has shown that CBS silencing inhibits breast cancer cell growth in the presence of activated microphages (246), suggesting that CBS-derived $\mathrm{H}_{2} \mathrm{~S}$ might protect breast cancer cells from the attack of microphage instead of directly promoting cell growth. The pro-cancer effect of CBS in human breast cancer has been further consolidated by a recently reported association between the 844 ins68 polymorphism in the CBS gene and the occurrence of breast cancer (87).

In contrast, shRNA knockdown of CBS has been reported to cause rapid growth of human glioma tumor cells both in vitro and in vivo (270). However, the expression level of other $\mathrm{H}_{2} \mathrm{~S}$ - 
Table 1. Changes in the Expression of Various Hydrogen Sulfide-Producing Enzymes in Various Types of CANCER

\begin{tabular}{|c|c|c|c|c|c|c|}
\hline \multirow[b]{2}{*}{ Cancer type } & \multirow[b]{2}{*}{ Cell line/tissues } & \multirow{2}{*}{$\begin{array}{l}\text { mRNA or } \\
\text { protein level } \\
\text { measured }\end{array}$} & \multicolumn{3}{|c|}{$\mathrm{H}_{2} \mathrm{~S}$ producing enzymes } & \multirow[b]{2}{*}{ Ref. } \\
\hline & & & CSE & $C B S$ & $3 M S T$ & \\
\hline \multirow[t]{3}{*}{ Prostate cancer } & LNCaP cell & Protein level & Upregulation & Upregulation & Not tested & (95) \\
\hline & PC3 cell & Protein level & Upregulation & Upregulation & Not tested & $(226)$ \\
\hline & $\begin{array}{l}\text { LNCaP-B cell; human } \\
\text { prostate cancer tissues }\end{array}$ & Protein level & Downregulation & No change & Not tested & $(342)$ \\
\hline \multirow[t]{2}{*}{ Melanoma } & A375, WM35 cells & $\begin{array}{l}\text { mRNA and } \\
\text { protein level }\end{array}$ & Upregulation & Not tested & Upregulation & $(120)$ \\
\hline & $\begin{array}{l}\text { A375, Sk-Mel-5, } \\
\text { Sk-Mel-28, PES } 43 \text { cells }\end{array}$ & Protein level & Upregulation & No change & No change & $(222)$ \\
\hline \multirow[t]{2}{*}{ Gastric cancer } & SGC-7901 cell & Protein level & Upregulation & Not tested & Not tested & (123) \\
\hline & $\begin{array}{l}\text { Human gastric carcinoma } \\
\text { tissues; SGC-7901 cell }\end{array}$ & $\begin{array}{l}\text { mRNA and } \\
\text { protein level }\end{array}$ & Upregulation & Upregulation & Not tested & (338) \\
\hline \multirow[t]{2}{*}{ Colon cancer } & $\begin{array}{l}\text { Human cancer specimens; } \\
\text { LoVo, HCT116, } \\
\text { HT29 cells }\end{array}$ & Protein level & $\begin{array}{l}\text { No change (Human } \\
\text { specimens; LoVo) } \\
\text { Downregulation } \\
\text { (HCT116, HT29) }\end{array}$ & Upregulation & No change & $(266)$ \\
\hline & SW480 cell & Protein level & Upregulation & Not tested & Not tested & (74) \\
\hline $\begin{array}{l}\text { Urothelial } \\
\text { carcinomas }\end{array}$ & $\begin{array}{l}\text { Human urothelial } \\
\text { carcinomas }\end{array}$ & Protein level & Upregulation & Not tested & Not tested & (86) \\
\hline \multirow[t]{3}{*}{$\begin{array}{l}\text { Ovarian } \\
\text { carcinomas }\end{array}$} & $\begin{array}{l}\text { Human ovarian cancer } \\
\text { samples; OV202, } \\
\text { SKOV3, A2780 cells }\end{array}$ & $\begin{array}{l}\text { mRNA and } \\
\text { protein level }\end{array}$ & No change & Upregulation & Not tested & (24) \\
\hline & $\begin{array}{l}\text { OV202, A2780, SKOV3, } \\
\text { OVCAR3, OVCAR4, } \\
\text { OVCAR5 cells }\end{array}$ & Protein level & $\begin{array}{l}\text { No change } \\
\text { (OVCAR3; } \\
\text { OVCAR5); }\end{array}$ & Upregulation & No change & $(47)$ \\
\hline & & & $\begin{array}{l}\text { Downregulation } \\
\text { (OV202;A2780; } \\
\text { SKOV3;OVCAR4) }\end{array}$ & & & \\
\hline \multirow[t]{2}{*}{$\begin{array}{l}\text { Hepatocellular } \\
\text { carcinomas }\end{array}$} & $\begin{array}{l}\text { Hepatocellular carcinomas } \\
\text { specimens }\end{array}$ & mRNA level & Not tested & Downregulation & Not tested & $(132)$ \\
\hline & HepG2, PLC/PRF/5 cells & Protein level & Upregulation & Not tested & Not tested & $(222)$ \\
\hline Breast cancer & $\begin{array}{l}\text { Human breast cancer } \\
\text { samples; Hs578T, MCF7, } \\
\text { MDA-MB-468 cells }\end{array}$ & $\begin{array}{l}\text { mRNA and } \\
\text { protein level }\end{array}$ & Not tested & Upregulation & Not tested & (246) \\
\hline Astrocytoma & U373 cell & Protein level & Not tested & Not tested & Upregulation & $(120)$ \\
\hline Neuroblastoma & SH-SY5Y cell & Protein level & Not tested & Not tested & Upregulation & (120) \\
\hline Gliomas & $\begin{array}{l}\text { Human brain } \\
\text { gliomas sample }\end{array}$ & Protein level & Not tested & Not tested & Upregulation & $(316)$ \\
\hline
\end{tabular}

3MST, 3-mercaptopyruvate sulfurtransferase; CBS, cystathionine $\beta$-synthase; CSE, cystathionine $\gamma$-lyase; $\mathrm{H}_{2} \mathrm{~S}$, hydrogen sulfide.

producing enzyme has not been examined in the study. As recent evidence has shown that 3MST is a crucial enzyme for $\mathrm{H}_{2} \mathrm{~S}$ production in brain cells, particularly when CBS is genetically deleted (253), therefore it is possible that compensatory $\mathrm{H}_{2} \mathrm{~S}$ generated from 3MST may have promoted the growth of glioma cells on CBS silencing. The expression of CBS is downregulated in human hepatocellular carcinoma and associated with high tumor grade and high Edmondson grade (132); however, further studies are required to clarify the role of CBS in the progression of this type of cancer.

\section{B. CSE in cancer}

CSE might be the dominant $\mathrm{H}_{2} \mathrm{~S}$-producing enzyme in peripheral tissues as indicated by experiments with mice lacking CSE (328). Increasing evidence suggests that CSE plays a role in the survival of various types of cancers. In prostate cancer, the abundance of CSE is first found in the LNCaP cell (95), which was later confirmed in other cell lines such as PC-3 (226) and LNcaP-B (342). Overexpression of
CSE or $\mathrm{H}_{2} \mathrm{~S}$ supplementation with $\mathrm{NaSH}$ (although 50 $200 \mu M)$ apparently induces cancer cell proliferation (226, 342 ), suggesting a role of the $\mathrm{CSE} / \mathrm{H}_{2} \mathrm{~S}$ pathway in the survival of prostate cancer. A similar effect of CSE has also been observed in melanoma (222) and gastric cancer $(123,338)$, as either CSE overexpression or $\mathrm{H}_{2} \mathrm{~S}$ donors leads to cell apoptosis in both of the cancer types. However, whether CSE promotes or inhibits cancer cell survival remains to be determined, since none of the studies examined the consequences of CSE inhibition or deletion in these cell lines.

Nevertheless, CSE has been found to support cell survival in hepatocellular carcinoma $(221,332)$. Yin et al. (332) has shown that the expression of CSE is under the control of the phosphoinositide-3-kinase/protein kinase B (PI3K/AKT) pathway in hepatoma cell lines QGY-7703 and SMMC-7721. CSE knockdown by siRNA significantly inhibits the proliferation of both cell lines, which has been further echoed in HepG2 cells by another group (221). In colon cancer cells, the expression of CSE is under the regulation of the $\mathrm{Wnt} / \beta$ catenin pathway (74), which is an essential player in this type 
of cancer. Moreover, either siRNA knockdown or pharmacological inhibition of CSE leads to cell death in SW480 and HCT116 (74), suggesting a possible pro-cancer effect of CSE in colon cancer. This has been further supported by the evidence that NaSH $(200 \mu M)$ stimulated cancer cell proliferation by activating extracellular signal-regulated kinase (ERK) and AKT pathways in HCT116 and SW480 (32). Recent evidence has also shown that the expression level of CSE is positively associated with urothelial cell carcinoma of the bladder (86). However, the exact role of CSE remains to be investigated in bladder cancer development.

\section{3MST in cancer}

$3 \mathrm{MST}$ is the third enzyme that is responsible for $\mathrm{H}_{2} \mathrm{~S}$ production in mammals. Distinct from aforementioned cytosol resident CSE and CBS, it locates and produces $\mathrm{H}_{2} \mathrm{~S}$ in cellular mitochondria (318). Provided mitochondria can use $\mathrm{H}_{2} \mathrm{~S}$ as an electron donor for ATP production $(82,276)$, it may be interesting to postulate that $3 \mathrm{MST}$-derived $\mathrm{H}_{2} \mathrm{~S}$ might be a direct source of energy in certain tumors if the $\mathrm{O}_{2}$ supply is sufficient. In accordance with this, high levels of 3MST have been discovered in numerous cancer cell lines or tissues, including astrocytoma cell U373 (120), neuroblastoma cell SHSY5Y (120, 262), melanoma cell A375 and WM35 (120), and gliomas tissue (316). However, no study has shown the consequence of 3MST modulation in cancer. Therefore, the exact role of 3MST in cancer development still remains uninvestigated but will be an interesting area open to explore in the future.

\section{Dual Role of $\mathrm{H}_{2} \mathrm{~S}$ in Cancer Biology}

On the discovery of altered expression of $\mathrm{H}_{2} \mathrm{~S}$-producing enzymes, the possible role of $\mathrm{H}_{2} \mathrm{~S}$ was extensively studied in cancer cells with genetic or chemical approaches to modulate the level of $\mathrm{H}_{2} \mathrm{~S}$. Existing evidence tends to show a dual role of $\mathrm{H}_{2} \mathrm{~S}$ in cancer progression (summarized below and in Table 2). Nevertheless, before this, one should bear three facts in mind when interpreting the data, including (i) modulation of $\mathrm{H}_{2} \mathrm{~S}$-producing enzymes can alter not only the level of $\mathrm{H}_{2} \mathrm{~S}$ but also other byproducts such as pyruvate, glutathione, and L-homocysteine (169); (ii) some of these inhibitors are not very specific and their effects could result from mechanisms other than inhibiting these enzymes (297); and (iii) use of high micromolar ranges of $\mathrm{H}_{2} \mathrm{~S}$ concentration is not physiologically relevant (169).

\section{A. Cancer-promoting effect of $\mathrm{H}_{2} \mathrm{~S}$}

This section provides a summary of cancer-promoting effects of $\mathrm{H}_{2} \mathrm{~S}$, including stimulation of bioenergetics, proangiogenesis, activation of anti-apoptotic pathways, and acceleration of cell cycle. Moreover, $\mathrm{H}_{2} \mathrm{~S}$-linked protein persulfidation that is relevant to cancer biology is also overviewed.

1. $\mathrm{H}_{2} \mathrm{~S}$ is a bioenergetic stimulator. Historically, $\mathrm{H}_{2} \mathrm{~S}$ was well known as a suppressor of the mitochondrial respiratory chain due to its inhibitory effect on cytochrome c oxdiase (56). However, the fact that some bacteria utilize sulfide for energy production has urged to test whether this scenario also exists in mammals (30). Currently, several layers of evidence suggest that $\mathrm{H}_{2} \mathrm{~S}$ at low doses serves as a bioenergetic stimulator in mammalian cells. Goubern et al. (94) have shown a very high affinity for mammalian mitochondria with sulfide, which allows the use of sulfide as an energetic substrate at low micromolar concentrations. Subsequently, the enzyme consuming $\mathrm{H}_{2} \mathrm{~S}$ has been identified to be mitochondrial SQOR, which is an independent parallel

Table 2. Possible Molecular Mechanisms Relevant to the Dual Role of Hydrogen Sulfide IN CANCER Biology

\begin{tabular}{|c|c|c|c|c|}
\hline Role of $\mathrm{H}_{2} \mathrm{~S}$ & Molecular mechanisms & Possible target proteins/pathways & Interaction mechanisms & Ref. \\
\hline \multirow{12}{*}{$\begin{array}{l}\text { Cancer } \\
\quad \text { promoting }\end{array}$} & \multirow[t]{4}{*}{ Stimulation of bioenergetics } & Sulfide quinine reductase & $\mathrm{H}_{2} \mathrm{~S}$ as a substrate & $(145,186)$ \\
\hline & & Mitochondrial ATP synthase & Persulfidation & (187) \\
\hline & & Lactate dehydrogenase A & Persulfidation & $(286)$ \\
\hline & & Glucose transporter & Unknown & $(163)$ \\
\hline & \multirow[t]{3}{*}{ Pro-angiogenesis } & $\mathrm{K}_{\mathrm{ATP}}$ channel activation & Persulfidation & $(195,223)$ \\
\hline & & PI3K/Akt activation & Unknown & (159) \\
\hline & & MAPKs activation & Persulfidation of MEK1? & $(341)$ \\
\hline & \multirow[t]{3}{*}{ Anti-apoptosis } & $\mathrm{NF}-\kappa \mathrm{B}$ pathway activation & Persulfidation of p65 & $(245)$ \\
\hline & & Keap1-Nrf2 pathway activation & Persulfidation of Keap1 & (329) \\
\hline & & MEK1-ERK activation & Persulfidation of MEK1 & $(341)$ \\
\hline & \multirow[t]{2}{*}{ Acceleration of cell cycle } & ERK activation & Persulfidation of MEK1 & $(32,341)$ \\
\hline & & PI3K/Akt activation & Unknown & $(172,174)$ \\
\hline \multirow[t]{8}{*}{ Anti-cancer } & \multirow{3}{*}{$\begin{array}{l}\text { Induction of uncontrolled } \\
\text { cellular acidification }\end{array}$} & Glucose transporter & Unknown & $(149,163)$ \\
\hline & & Anion exchanger & Unknown & (149) \\
\hline & & Sodium/proton exchanger & Unknown & (149) \\
\hline & \multirow[t]{3}{*}{ Suppression of cell survival } & Suppression of NF- $\kappa \mathrm{B}$ pathway & Unknown & $(222)$ \\
\hline & & Suppression of STAT3 & Unknown & $(171)$ \\
\hline & & $\begin{array}{l}\text { Reduction of pleckstrin } \\
\text { homology-like domain-A1 }\end{array}$ & Unknown & (193) \\
\hline & \multirow[t]{2}{*}{ Induction of cell cycle arrest } & Upregulation of $\mathrm{p} 21^{\mathrm{Cip} 1}$ & Unknown & $(321)$ \\
\hline & & Downregulation of cyclin D1 & Unknown & $(150)$ \\
\hline
\end{tabular}

AKT, protein kinase B; ATP, adenosine triphosphate; ERK, extracellular signal-regulated kinase; $\mathrm{K}_{\mathrm{ATP}}$, ATP-sensitive potassium; MAPK, mitogen-activated protein kinase; MEK1, ERK activator kinase 1; NF- $\kappa \mathrm{B}$, nuclear factor kappa-light-chain enhancer of activated B cells; Nrf2, transcription factor NF-E2-related nuclear factor 2; PI3K, phosphoinositide-3-kinase; STAT3, signal transducer and activator of transcription 3. 
electron donor to coenzyme $\mathrm{Q}$, in addition to complexes I and II $(145,186)$.

Endogenous $\mathrm{H}_{2} \mathrm{~S}$ derived by $3 \mathrm{MST}$ plays a pivotal role in supporting the physiological cellular bioenergetic functions, as basal bioenergetic parameters are reduced on siRNA knockdown of 3MST $(186,269)$. However, they can be enhanced by $3 \mathrm{MP}(186)$, the substrate of 3MST. Although stress conditions such as hypoxia were reported to induce the translocation of CSE and CBS into mitochondria to sustain energy production (82), yet the deprivation of $\mathrm{O}_{2}$ should reduce the production of ATP from $\mathrm{H}_{2} \mathrm{~S}$ as $\mathrm{O}_{2}$ serves as the terminal electron acceptor. Furthermore, it has been shown that $\mathrm{H}_{2} \mathrm{~S}$ metabolism is progressively reduced as $\mathrm{PO}_{2}$ falls in isolated mitochondria and this occurs at physiologically relevant $\mathrm{PO}_{2}$ (213). Therefore, $\mathrm{H}_{2} \mathrm{~S}$-mediated mitochondrial respiration may be only useful to cancer development when $\mathrm{O}_{2}$ supply is still sufficient.

Other than serving as a substrate in mitochondrial respiration, $\mathrm{H}_{2} \mathrm{~S}$ may also stimulate cellular bioenergetics by elevating intra-mitochondrial cAMP levels (188), inducing the persulfidation of mitochondrial ATP synthase (187) and lactate dehydrogenase A (286). Besides mitochondrial respiration, $\mathrm{H}_{2} \mathrm{~S}$ has also been implicated in the regulation of glycolysis, which is well recognized as the main energy source that cancer cells rely on (287). For instance, an inorganic source of $\mathrm{H}_{2} \mathrm{~S}$ (using the salt $\mathrm{NaSH}$ ) enhanced glucose uptake and glycolysis efficiency in cardiomyocytes likely via stimulating the activity of glucose transporter (GluT). Subsequently, this finding has been paralleled in a panel of cancer cell lines (163).
In line with these, CBS knockdown significantly diminishes the bioenergetic parameters such as oxygen consumption and ATP production in both colon cancer $(102,266)$ and ovarian cancer cells (24). Nonetheless, the elaboration of whether and how $\mathrm{H}_{2} \mathrm{~S}$ enhances the activity of GluT is still required, particularly in cancer cells. Taken together, $\mathrm{H}_{2} \mathrm{~S}$ stimulates mitochondrial respiration and glycolysis, thereby supporting the energy required by cancer development (Fig. 2).

2. $\mathrm{H}_{2} \mathrm{~S}$ is a pro-angiogenic mediator. Angiogenesis plays a critical role in cancer development given that it promotes new blood vessel formation, which provides tumors with oxygen and nutrients (44). The pro-angiogenic function of $\mathrm{H}_{2} \mathrm{~S}$ was initially found in the late $2000 \mathrm{~s}$. NaSH, a commonly used experimental source of $\mathrm{H}_{2} \mathrm{~S}$, accelerates cell proliferation, migration, and tubule-like structure formation in cultured endothelial cells $(31,223)$. In addition, exposure of chicken chorioallantoic membrane to $\mathrm{NaSH}$ promoted the growth and branching of blood vessels (223). The proangiogenic effect of $\mathrm{H}_{2} \mathrm{~S}$ has further been confirmed in rat models (223). Moreover, either pharmacological inhibition or genetic deletion of CSE blocked vascular endothelial growth factor (VEGF)-induced angiogenesis (223, 233), suggesting that $\mathrm{H}_{2} \mathrm{~S}$ may act as as a physiological angiogenic mediator.

Further studies revealed that the signaling pathways underlying the pro-angiogenic effect of $\mathrm{H}_{2} \mathrm{~S}$ may involve the PI3K/AKT pathway, the mitogen-activated protein kinase pathway, and ATP-sensitive potassium $\left(\mathrm{K}_{\mathrm{ATP}}\right)$ channels (31, $70,159,223)$. The pro-angiogenic effect of $\mathrm{H}_{2} \mathrm{~S}$ has recently

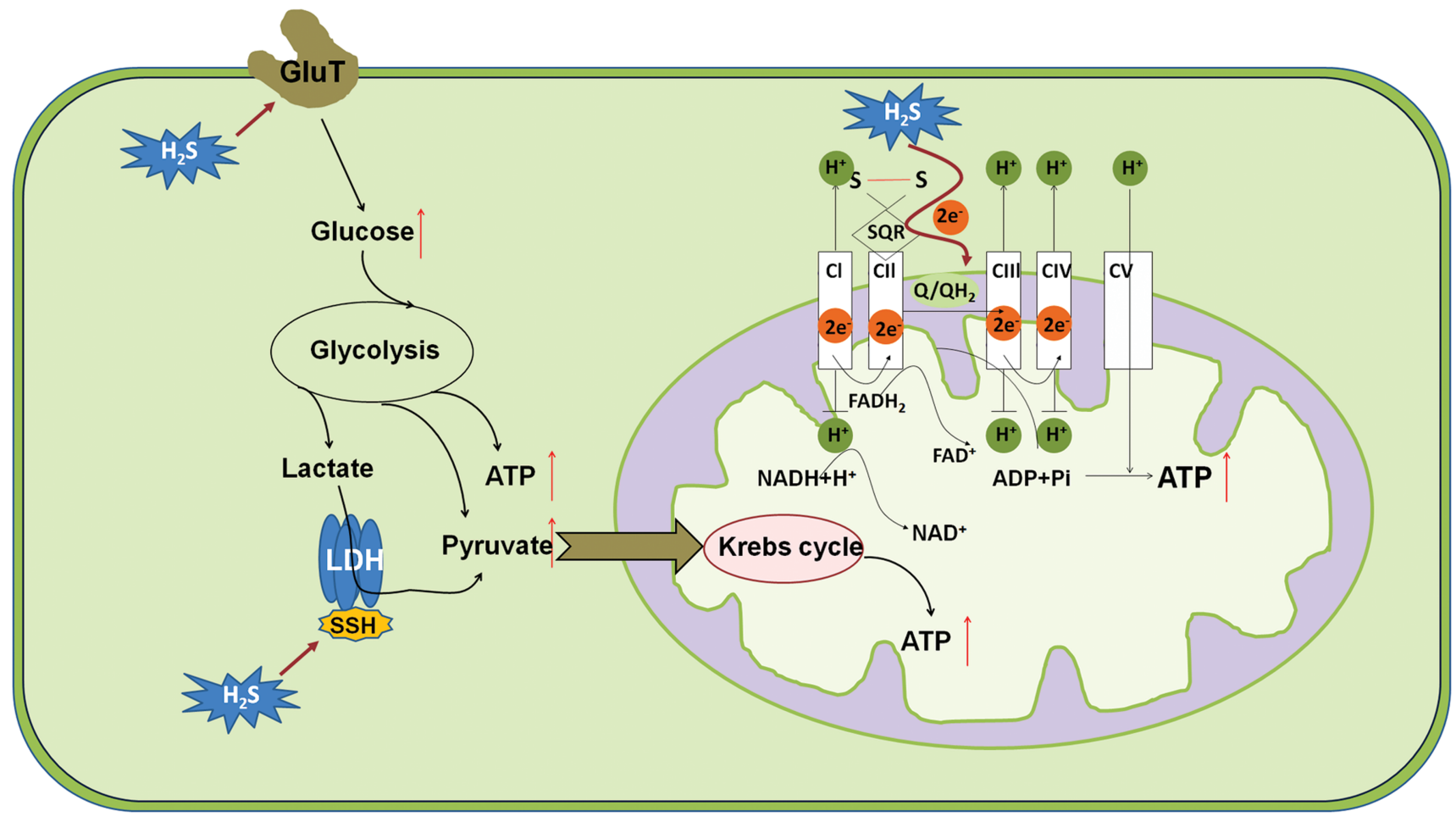

FIG. 2. $\mathrm{H}_{2} \mathrm{~S}$ as a bioenergetic stimulator. $\mathrm{H}_{2} \mathrm{~S}$ enhances glucose uptake probably by stimulating the activity of GluT and thereby increasing the rate of glycolysis. Meanwhile, $\mathrm{H}_{2} \mathrm{~S}$ can be consumed by mitochondrial SQR to generate electrons for the mitochondrial respiratory chain. By doing these, $\mathrm{H}_{2} \mathrm{~S}$ may enhance the production of intracellular ATP and support cancer cell proliferation. ATP, adenosine triphosphate; GluT, glucose transporter; SQR, sulfide quinone reductase. Color images are available online. 


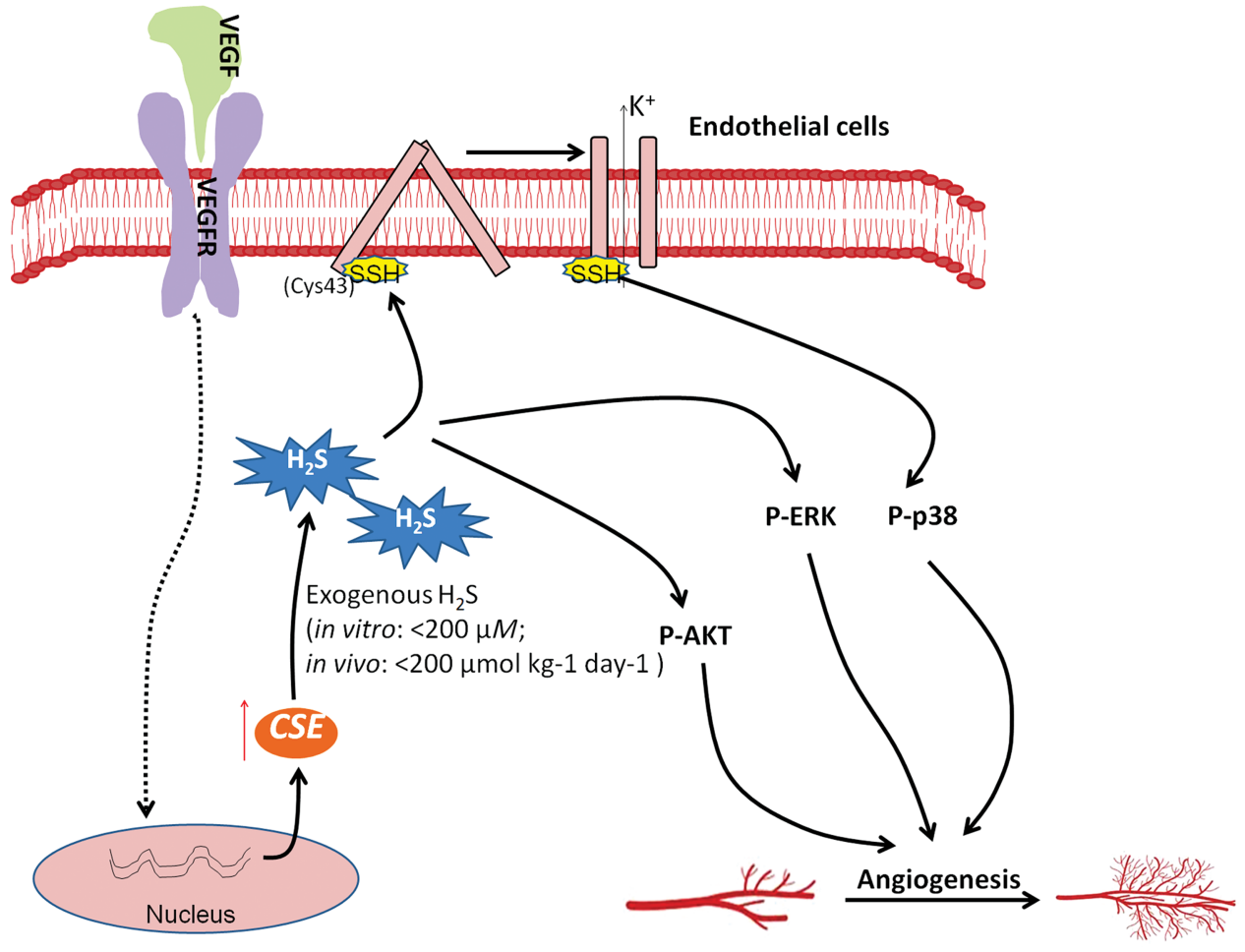

FIG. 3. $\mathrm{H}_{2} \mathrm{~S}$ as a proangiogenic mediator. VEGF increases $\mathrm{H}_{2} \mathrm{~S}$ level by upregulating the expression of CSE in endothelial cells. Both endogenous and exogenous $\mathrm{H}_{2} \mathrm{~S}$ (in vitro: $<200 \mu M$; in vivo: $<200 \mu \mathrm{mol} / \mathrm{kg} /$ day) serve as stimulators of angiogenesis by activating multiple signaling pathways. For instance, $\mathrm{H}_{2} \mathrm{~S}$ mediated persulfidation of the $\mathrm{K}_{\mathrm{ATP}}$ channel (cysteine-43) leads to its activation and downstream phosphorylation of p38, which causes angiogenesis. In addition, the activation of ERK and AKT is also implicated in the angiogenic effect of $\mathrm{H}_{2} \mathrm{~S}$ in endothelial cells. AKT, protein kinase B; ERK, extracellular signalregulated kinase; $\mathrm{K}_{\mathrm{ATP}}$, ATPsensitive potassium; VEGF, vascular endothelial growth factor. Color images are available online. been observed in endothelial cells of tumors. With a wellestablished model of tumor angiogenesis, namely endothelial cells obtained from breast carcinomas (B-TECs), Pupo et al. (233) found that $\mathrm{NaSH}(1-10 \mu M)$ enhances the migration of B-TECs whereas inhibition of CSE suppresses VEGFinduced migration of B-TECs, suggesting that both exogenous and endogenous $\mathrm{H}_{2} \mathrm{~S}$ promote angiogenesis in breast cancer. In addition, genetic silencing of CBS diminished the neovessel density and tumor growth in rat models of colon cancer (266) and ovarian cancer (24). These results suggest that $\mathrm{H}_{2} \mathrm{~S}$ may be beneficial for tumor growth by promoting angiogenesis, thereby delivering nutrients and oxygen to cancer cells (Fig. 3).

Nevertheless, it is still noteworthy that $\mathrm{NaSH}$ at high concentrations or doses (in vitro: $>200 \mu M$; in vivo: $>200 \mu \mathrm{mol} / \mathrm{kg} /$ day) may also exhibit a suppressive effect on angiogenesis $(31,317)$, suggesting that the pro-angiogenic activity occurs only with endogenous $\mathrm{H}_{2} \mathrm{~S}$ and/or exposure of low amounts of exogenous $\mathrm{H}_{2} \mathrm{~S}$ in the context of cancer biology.

a. $\mathrm{H}_{2} \mathrm{~S}$-mediated persulfidation of $K_{A T P}$ channel. $\mathrm{K}_{\mathrm{ATP}}$ channel has long been recognized as a potential target of $\mathrm{H}_{2} \mathrm{~S}$, accounting for its cardiovascular effects such as vasorelaxation, cardioprotection, and hyperpolarization $(119,272$, $340,344)$. Interestingly, the $\mathrm{K}_{\mathrm{ATP}}$ channel antagonist glibenclamide attenuates $\mathrm{H}_{2} \mathrm{~S}$-induced p38 phosphorylation and migration of endothelial cells (223), suggesting that $\mathrm{H}_{2} \mathrm{~S}-$ $\mathrm{K}_{\mathrm{ATP}}$ channel-p38 axis may partially mediate the proangiogenic effect of $\mathrm{H}_{2} \mathrm{~S}$.

An elegant study from Mustafa et al. has recently unclosed that $\mathrm{H}_{2} \mathrm{~S}$-mediated persulfidation activates $\mathrm{K}_{\mathrm{ATP}}$ channel and induces the downstream effects (195). In the study, they have shown that $\mathrm{NaSH}$ induces persulfidation of $\mathrm{K}_{\mathrm{ATP}}$ channels in
$\mathrm{K}_{\text {ATP }}$ channel overexpressed HEK293 cells. The persulfidation can also be detected in cells overexpressing CSE but not in those lacking CSE, indicating that endogenous $\mathrm{H}_{2} \mathrm{~S}$ induces the persulfidation of the $\mathrm{K}_{\mathrm{ATP}}$ channel. Importantly, the physiological relevance of the persulfidation is further demonstrated by the observation that cholinergic stimulation of mouse aorta increases persulfidation of the $\mathrm{K}_{\mathrm{ATP}}$ channel in wild-type but not CSE-deficient mice. In addition, mutation of cysteine 43 that lies close to the surface of the $\mathrm{K}_{\mathrm{ATP}}$ channel completely abolished the persulfidation and $\mathrm{H}_{2} \mathrm{~S}$ mediated vasorelaxation, indicating that Cysteine 43 is the principal target of persulfidation in $\mathrm{K}_{\mathrm{ATP}}$ channel.

b. $\mathrm{H}_{2} \mathrm{~S}$ in hypoxia induces angiogenesis. Hypoxia is recognized as a primary physiological regulator of angiogenesis. Tumor hypoxia occurs when a tumor rapidly grows, resulting in limited supply of oxygen. This leads to the induction of the transcriptional factor hypoxia inducible factor $1 \alpha(\mathrm{HIF}-1 \alpha)$ and subsequent angiogenesis, which helps bring nutrients and oxygen to the tumor. One is advised to refer to Liao and Johnson's article for a detailed description of the process (164). Notably, hypoxia can profoundly evaluate the level of $\mathrm{H}_{2} \mathrm{~S}$ because it inhibits the catabolism of $\mathrm{H}_{2} \mathrm{~S}$ (37) and induces the expression of CSE (294), which is the main $\mathrm{H}_{2} \mathrm{~S}$ producer in endothelial cells. Interestingly, a series of recent studies also provides strong evidence showing that $\mathrm{H}_{2} \mathrm{~S}$ promotes ischemia-induced angiogenesis by augmenting the expression of HIF- $1 \alpha(25,168,268)$. Therefore, it is highly likely that $\mathrm{H}_{2} \mathrm{~S}$ may partially mediate hypoxia-induced angiogenesis in cancer progression, though direct demonstration of this notion remains lacking.

3. $\mathrm{H}_{2} \mathrm{~S}$ activates anti-apoptotic pathways. Apoptosis is critical for the maintenance of tissue homeostasis in 
multicellular organism; however, it is suppressed in cancer cells, which affords tumor cells the capability of surviving under various stresses. The anti-apoptotic role of $\mathrm{H}_{2} \mathrm{~S}$ is clearly manifested by several aspects, including (i) mouse embryonic fibroblasts and endothelial cells derived from CSE deficiency mice display accelerated cellular senescence compared with the counterparts from wild-type mice (329, 341); (ii) $\mathrm{H}_{2} \mathrm{~S}$ supplementation reverses CSE deficiencyinduced senescence $(329,341)$; (iii) inhibition of $\mathrm{H}_{2} \mathrm{~S}$ biosynthesis induces apoptotic responses in various types of cells (102, 103); and (iv) $\mathrm{H}_{2} \mathrm{~S}$ shows a protective effect against various apoptotic stimuli $(250,275,331,339,346)$.

In the context of cancer biology, the anti-apoptotic effect has also been demonstrated in numerous types of cancer cells such as colon cancer (241), hepatomas cancer (345), and neuroblastoma (281). Further studies have revealed the possible underlying mechanisms such as activation of nuclear factor kappa-light-chain enhancer of activated B cells (NF- $\kappa \mathrm{B})(245)$, Keap1-transcription factor NF-E2-related nuclear factor 2 (Nrf2) (329), and ERK activator kinase 1 (MEK1)-ERK pathways (341) mediated by $\mathrm{H}_{2} \mathrm{~S}$-linked persulfidation (Fig. 4).

a. $\mathrm{H}_{2} \mathrm{~S}$-mediated persulfidation of $\mathrm{NF}-\kappa B$ p65. The NF$\kappa \mathrm{B}$ pathway mediates its anti-apoptotic function by inducing the expression of several anti-apoptotic proteins such as TNFR-associated factor (TRAF)-1, TRAF-2, caspase-8-cFLP, and cellular inhibitor of apoptosis (207). The activation of the pathway requires the nucleus translocation of p65 (19), whose lacking induces the death of mice at the embryonic stage due to extensive liver apoptosis (20). Tumor necrosis factor (TNF) $\alpha$, an activator of the NF- $\kappa$ B pathway, stimulated CSE expression, thereby tripling $\mathrm{H}_{2} \mathrm{~S}$ generation. CSE gen-

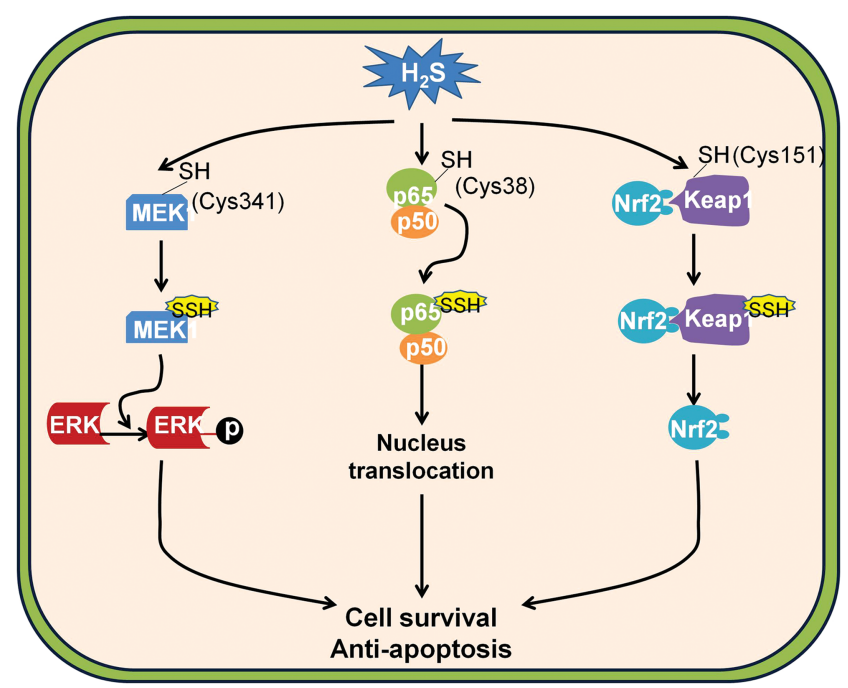

FIG. 4. $\mathrm{H}_{2} \mathrm{~S}$ activates anti-apoptotic pathways. $\mathrm{H}_{2} \mathrm{~S}$ is able to activate multiple anti-apoptotic pathways by $\mathrm{H}_{2} \mathrm{~S}$ linked persulfidation. For example, $\mathrm{H}_{2} \mathrm{~S}$ persulfidates cysteine-38 of the NF- $\kappa \mathrm{B}$ p65 subunit and results in its activation (middle); $\mathrm{H}_{2} \mathrm{~S}$ persulfidates cysteine-151 of Keap1 and induces Nrf2 translocation into the nucleus; and $\mathrm{H}_{2} \mathrm{~S}$ persulfidates cysteine-341 of MEK1 and induces subsequent phosphorylation of ERK1/2. MEK1, ERK activator kinase 1; NF- $\kappa \mathrm{B}$, nuclear factor kappa-light-chain enhancer of activated B cells; Nrf2, transcription factor NF-E2related nuclear factor 2 . Color images are available online. erated $\mathrm{H}_{2} \mathrm{~S}$-enhanced DNA binding of p65 and the downstream gene expression, which is absent in mice lacking CSE. As a result, the anti-apoptotic function of the NF- $\kappa$ B pathway is largely diminished in CSE-deleted mice (245).

Sen et al. have recently revealed that $\mathrm{H}_{2} \mathrm{~S}$ promoted the binding of p65 to the promoters of downstream genes by persulfidation cysteine- 38 on $\mathrm{p} 65$, as the mutation of cysteine- 38 abolishes the effect of $\mathrm{H}_{2} \mathrm{~S}$ on p65 persulfidation and NF- $\kappa$ B activation (245). Importantly, the persulfidation is verified by several methods, including biotin switch assay, maleimide assay, and liquid chromatography-mass spectrometry (245). In line with this finding, $\mathrm{H}_{2} \mathrm{~S}$ has long been suggested to be an endogenous mediator of inflammation by augmenting NF- $\kappa$ B pathway activity $(154,310,336)$. Similarly, inhibition of CSE may diminish cell proliferation of melanoma cells via suppression of the NF- $\kappa$ B pathway (222). Despite this, one should bear in mind that exogenous $\mathrm{H}_{2} \mathrm{~S}$ may actually be able to suppress the activation of the NF- $\kappa \mathrm{B}$ pathway in inflammatory conditions $(36,38,83,92,155)$.

b. $\mathrm{H}_{2} \mathrm{~S}$-mediated persulfidation of Keapl. The importance of the Keap1-Nrf2 pathway in tumorigenesis can be evidenced by the finding that somatic mutations of Nrf2 or Keap1 are frequently detected in cancer cells with overactivation of Nrf2mediated transcription (130), which may afford malignant cells the growth advantage by promoting tumor growth and enhancing cancer chemoresistance (146, 344).

Intriguingly, a recent study from Wang et al. suggested that $\mathrm{H}_{2} \mathrm{~S}$ may be an endogenous stimulator of the Keap1Nrf2 pathway by persulfidation Keap1 at cysteine-151 (329). In the study, they have shown that in comparison with mouse embryonic fibroblasts from wild-type mice the cells obtained from CSE knockout mice display increased oxidative stress and accelerated cellular senescence, which can be reversed by the supplementation of NaSH (329). In addition, they have shown that NaSH can persulfidate Keap1 and the persulfidation can be fully abolished by the mutation of cysteine- 151 of Keap1, but not cysteine-288 (329). This indicates that $\mathrm{H}_{2} \mathrm{~S}$ may persulfidate Keap1 at cysteine 151, which induces the release of Nrf2. Importantly, in CSE wild-type cells, the persulfidation of Keap1 is detectable and can be further enhanced by the $\mathrm{H}_{2} \mathrm{~S}$-producing substrate cysteine; however, it is absent in CSE knockout cells (329), suggesting that $\mathrm{H}_{2} \mathrm{~S}$ may serve as an endogenous activator of the Keap1/Nrf2 pathway.

By activating the Keap1-Nrf2 pathway, $\mathrm{H}_{2} \mathrm{~S}$ may induce the downstream expression of a battery of cytoprotective genes called vitagens such as glutathione $S$-transferases, epoxide hydrolase, and ferritin, which may afford cancer cells the adaption for chronic oxidative stress during their progression (33-35). Nevertheless, how persulfidation of Keap1 triggers the release of Nrf2 remains unclear and further study is, therefore, needed.

c. $\mathrm{H}_{2} \mathrm{~S}$-mediated persulfidation of MEK1. Somatic mutation is one of the most pervasive characteristics of human tumors (106). To overcome the devastating effect of genetic instability, cancer cells activate a batch of responses, including activation of DNA repair pathways $(14,39)$. Among these pathways, the overactivation of MEK1-ERK-poly [ADP-ribose] polymerase 1 (PARP1) pathway is commonly detected in a broad spectrum of cancer cells whose inhibition serves as a promising strategy for cancer therapy (300). 
An interesting article from Zhao et al. suggested that $\mathrm{H}_{2} \mathrm{~S}$ may facilitate DNA repair by activating the MEK1-ERKPARP1 pathway (341). In the study, they found that the activity of PARP1 is significantly lower in CSE knockout kidney, liver, and endothelial cells compared with their wildtype counterparts (341). NaSH treatment apparently activates PARP1 and enhances the capability of DNA damage repair, which can be inhibited by two inhibitors of MEK1 (U0126 and PD98059) that can suppress ERK1/2 phosphorylation (341), suggesting the involvement of MEK1 in $\mathrm{H}_{2} \mathrm{~S}$ stimulated ERK1/2 phosphorylation and PARP1 activity. Moreover, the persulfidation of MEK1 is clearly observed in kidney lysates from wild-type mice, which can be further enhanced by the treatment of NaSH (341). The mutation of cysteine-341 not only fully abolishes $\mathrm{NaSH}$-induced persulfidation of MEK1 but also suppresses the phosphorylation of ERK1/2 (341), indicating that $\mathrm{H}_{2} \mathrm{~S}$ selectively persulfidates MEK1 at cysteine-341 and induces the downstream effects. However, whether cancer cells have higher levels of MEK1 persulfidation is still not clear.

4. $\mathrm{H}_{2} \mathrm{~S}$ accelerates cell cycle. Cancer cells gain the capability of infinitive proliferation through evading cell cycle arrest (100). Recent evidence indicates that $\mathrm{H}_{2} \mathrm{~S}$ is able to accelerate cell cycle in various types of cells such as endothelial cells, cardiomyocytes, and cancer cells $(15,63,326)$. For instance, exogenous application of $\mathrm{H}_{2} \mathrm{~S}$ (NaSH, 200$500 \mu M$ ) reduces the expression of cell cycle regulatory genes such as replication protein A70 and retinoblastoma protein 1 but increases the expression of proliferating cell nuclear antigen and cyclin-dependent kinase 4, thereby promoting cell proliferation in several oral squamous cell carcinoma cell lines (172).

The acceleration effect of $\mathrm{H}_{2} \mathrm{~S}$ on cell cycle has also been found in colon cancer cells (32) and hepatoma cells (221). The signaling mechanism underlying the action might be attributed to the activation of the ERK and AKT pathway (32, $172,174,221)$ because inhibition of either ERK or AKT phosphorylation has been revealed to partially abolish the cell cycle accelerating effect of $\mathrm{H}_{2} \mathrm{~S}$ on squamous cell carcinomas cell lines and colon cancer cell lines $(32,172)$. Although not directly demonstrated, the underlying mechanisms of $\mathrm{H}_{2} \mathrm{~S}$-induced ERK activation may be ascribed to the persulfidation of MEK1 as discussed earlier. However, the molecular mechanism underlying $\mathrm{H}_{2} \mathrm{~S}$-induced AKT phosphorylation remains unclear. Considering the crucial role of AKT in human cancer development (216), the deciphering of this will be of great value.

\section{B. Anti-cancer effect of $\mathrm{H}_{2} \mathrm{~S}$}

In spite of the earlier mentioned evidence that $\mathrm{H}_{2} \mathrm{~S}$ is beneficial for cancer development, recent studies have also disclosed that $\mathrm{H}_{2} \mathrm{~S}$ donation especially at high doses or long time duration leads to cancer cell death without affecting the viability of normal fibroblast cells. In this section, the possible mechanisms underlying the anti-cancer effects of $\mathrm{H}_{2} \mathrm{~S}$ have been reviewed in the context of cancer development (Fig. 5).

1. $\mathrm{H}_{2} \mathrm{~S}$ donors induce uncontrolled cellular acidification. One hallmark of cancer cells is the utilization of glycolysis as the main pathway for energy production (97). Thus, they tend

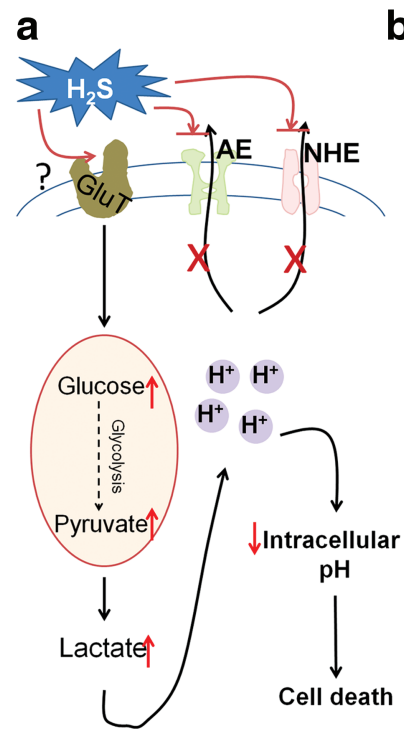

b

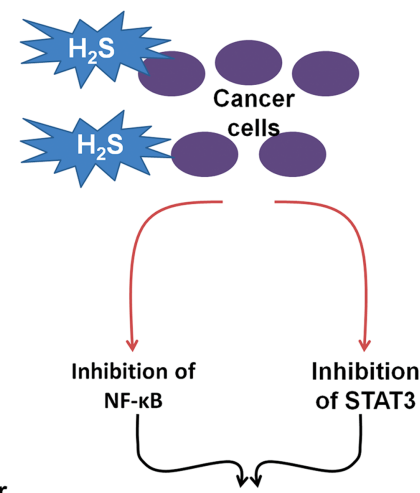

Pro-apoptotic protein $\uparrow$ Anti-apoptotic protein $\downarrow$
C

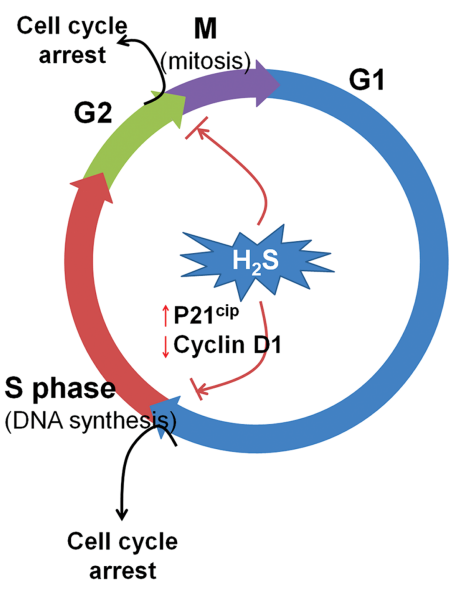

FIG. 5. Detrimental effects of $\mathrm{H}_{2} \mathrm{~S}$ donation against cancer development. (a) $\mathrm{H}_{2} \mathrm{~S}$ induces uncontrolled cellular acidification. $\mathrm{H}_{2} \mathrm{~S}$ stimulates the rate of glycolysis by enhancing the uptake of glucose, which leads to the accumulation of lactate and intracellular acid. Due to the inhibitory effect of $\mathrm{H}_{2} \mathrm{~S}$ on the activity of $\mathrm{AE}$ and NHE, the intracellular acid cannot be efficiently exported out of cells, which causes cancer cell death. (b) $\mathrm{H}_{2} \mathrm{~S}$ suppresses the cell survival signaling pathway. $\mathrm{H}_{2} \mathrm{~S}$ has been found to suppress the activity of cell survival pathways such as NF- $\kappa \mathrm{B}$ and STAT3 and, therefore, downregulates the downstream anti-apoptotic proteins, which leads to cancer cell death. (c) $\mathrm{H}_{2} \mathrm{~S}$ induces cell cycle arrest. $\mathrm{H}_{2} \mathrm{~S}$ induces cell cycle arrest at G1/S by upregulating the expression of $\mathrm{p} 21^{\mathrm{Cip} 1}$ and downregulating expression of cyclin D1. Besides, $\mathrm{H}_{2} \mathrm{~S}$ was also found to induce cell cycle arrest at $\mathrm{G} 2 / \mathrm{M}$; however, the underlying mechanism has not been studied. AE, anion exchanger; NHE, sodium/proton exchanger; STAT3, signal transducer and activator of transcription 3. Color images are available online. 
to have enhanced capacity for glucose uptake and its conversion into lactate. Lactate accumulation results in cellular acidification and stress. However, cancer cells can efficiently export intracellular acid out of cells, which helps form an acidic microenvironment promoting angiogenesis and tumor metastasis $(90,243)$. Therefore, targeting regulators of intracellular $\mathrm{pH}$ is recognized to be a promising strategy for cancer treatment (301).

It was found that a slow-release $\mathrm{H}_{2} \mathrm{~S}$ donor GYY4137 (200-1000 $\mu M$ ) enhances glycolysis of cancer cells by increasing the uptake of glucose, meanwhile it disrupts the exporting of intracellular acid possibly by suppressing the activity of anion exchanger (AE) and sodium/proton exchanger (NHE) (149) (Fig. 5a). Nevertheless, it should not be neglected that the catabolism of $\mathrm{H}_{2} \mathrm{~S}$ to $\mathrm{H}_{2} \mathrm{SO}_{4}$ may also contribute to the subsequent intracellular acidification. As a result, this causes uncontrolled intracellular acidification and subsequent cell death in a panel of cancer cell lines (149). ZYJ1122, a control compound for GYY4137 that cannot release $\mathrm{H}_{2} \mathrm{~S}$ as it has no sulfur, had no such effect $(149,150)$, suggesting that the aforementioned activity of GYY4137 may be exclusively derived from $\mathrm{H}_{2} \mathrm{~S}$. Intriguingly, GYY4137 exhibits strong anti-tumor effect in mice models (150).

The effect of GYY4137 has also been studied in fibroblast cells such as Wi-38 and MCF10A in their study (149, 150) and GYY4137 did not cause intracellular acidification in these non-cancerous cells. In contrast to this, $\mathrm{NaSH}(10 \mu M-$ $1 \mathrm{~m} M$ ) was found to decrease the intracellular $\mathrm{pH}$ of vascular muscle cells by stimulating the activity of $\mathrm{Cl}^{-} / \mathrm{HCO}_{3}{ }^{-}$ transporter (148). Thereafter, this effect has been reproduced in primary cultured glia cells, yet not in the neuroblastoma cell line SH-SY5Y (170). Therefore, the controversy among these studies needs to be resolved in the future; for instance, whether the discrepancy can be ascribed to (i) the distinct releasing manner of $\mathrm{H}_{2} \mathrm{~S}$ between $\mathrm{NaSH}$ and GYY4137; (ii) the different levels of $\mathrm{AE}, \mathrm{NHE}$, and $\mathrm{Cl}^{-} / \mathrm{HCO}_{3}{ }^{-}$among different types of cells; and/or (iii) non- $\mathrm{H}_{2} \mathrm{~S}$ effects derived from GYY4137.

2. $\mathrm{H}_{2} \mathrm{~S}$ suppresses cell survival signaling pathways. Cancer cells disrupt the balance between apoptosis and survival through sustained activation of pro-survival signaling pathways, leading to the constant increase of cancer cell numbers (60). The NF- $\kappa \mathrm{B}$ pathway acts as such a signaling pathway and its abnormal activation has been commonly found in various types of cancers, including non-small lung cancer, breast cancer, prostate cancer, etc. (237).

Despite that $\mathrm{H}_{2} \mathrm{~S}$ may stimulate the NF- $\kappa \mathrm{B}$ pathway as mentioned earlier by persulfidating the p65 subunit, $\mathrm{H}_{2} \mathrm{~S}$ has been demonstrated to inhibit $\mathrm{TNF} \alpha$ and lipopolysaccharidesstimulated NF- $\kappa \mathrm{B}$ activation $(92,309)$. Therefore, it is not surprising to find that constant exposure of cancer cells to $\mathrm{H}_{2} \mathrm{~S}$ (222) or its donating hybrids (127) suppresses NF- $\kappa \mathrm{B}$ activity and causes cancer cell apoptosis. However, the molecular target for the inhibitory effect of $\mathrm{H}_{2} \mathrm{~S}$ on NF- $\kappa \mathrm{B}$ activity has not been identified. In addition, other pro-survival signaling molecules have been reported to account for the anti-cancer effect of $\mathrm{H}_{2} \mathrm{~S}$. For instance, GYY4137 causes the apoptosis of hepatocellular carcinoma cell lines by suppression of signal transducer and activator of transcription 3 (STAT3) activation and downregulation of STAT3-mediated downstream proteins such as B cell lymphoma 2, survivin, and VEGF (171). In addition, constant exposure to $\mathrm{H}_{2} \mathrm{~S}$ causes oral cancer cell apoptosis, possibly by reducing the expression of pleckstrin homology-like domain-A1, an apoptotic suppressor in this type of cancer (193). In the future, the target proteins of $\mathrm{H}_{2} \mathrm{~S}$ in cell survival pathways need to be unveiled and studied in detail.

3. $\mathrm{H}_{2} \mathrm{~S}$ induces cell cycle arrest. Dysregulation of cell cycle has been proved to be involved in cancer progression (72). Thus, induction of cell cycle arrest is effective to treat cancer (173). The suppressive effect of $\mathrm{H}_{2} \mathrm{~S}$ on cell cycle transition has been reported by numerous studies (Fig. 5c). $S$ proargyl-cysteine (SPRC), an $\mathrm{H}_{2} \mathrm{~S}$ donor, causes cell cycle arrest at the G1/S phase in the gastric cancer cell line SGC-7901 and subsequent apoptosis both in vitro and in vivo (123). NaSH $(0.4-1 \mathrm{~m} M)$ leads to cell cycle arrest at G1/S, possibly by upregulating cyclin-dependent kinase inhibitor $\mathrm{p} 21^{\mathrm{Cip} 1}$ in a panel of colon cancer cell lines (HT-29, SW116, and HCT116) (321).

The inductive effect of GYY4137 on cell cycle arrest has also been proposed in various cancer types $(150,171)$. For instance, Lu et al. (171) found that GYY4137 suppressed G1/S cell cycle transition by downregulating the expression of cyclin D1 and the tumor growth is inhibited in the subcutaneous HepG2 xenograft model as a result. It was also reported that GYY4137 caused partial G2/M arrest in breast cancer cell line MCF7 whereas the underlying mechanism has not been studied (150). Attractively, $\mathrm{H}_{2} \mathrm{~S}$ seems to specifically induce cell cycle arrest in cancer cells, as neither NaSH nor GYY4137 caused cell cycle arrest in normal fibroblast cells in the aforementioned studies $(150,321)$. However, the molecular targets of $\mathrm{H}_{2} \mathrm{~S}$ eliciting these effects remain unclear.

Due to its pleiotropic effect on biological processes, there are more potential mechanisms likely underlying $\mathrm{H}_{2} \mathrm{~S}$-mediated anti-cancer activity. For example, $\mathrm{H}_{2} \mathrm{~S}$ may increase the level of E-Cadherin possessing anti-metastatic effect (108); and $\mathrm{H}_{2} \mathrm{~S}$ has also been found to downregulate the level of histone deacetylases that may result in the epigenetic reactivation of tumor suppressor genes (204). These have been summarized elsewhere in an excellent review by Predmore et al. (232).

\section{Bell-shaped model for the dual role of $\mathrm{H}_{2} \mathrm{~S}$ in cancer}

The role of $\mathrm{H}_{2} \mathrm{~S}$ in cancer development seems to be controversial. Therefore, an appropriate model system is highly desirable to explain why $\mathrm{H}_{2} \mathrm{~S}$ exerts diametrically opposite effects in cancer cells, in different laboratories. Recently, Hellmich et al. (102) proposed a reasonable bell-shaped model to illustrate the effects of $\mathrm{H}_{2} \mathrm{~S}$ in cancer cells. In the model (Fig. 6), a bell-shaped curve is employed to describe the effects of $\mathrm{H}_{2} \mathrm{~S}$ on cancer cell proliferation. In general, endogenous $\mathrm{H}_{2} \mathrm{~S}$ or a relatively low level of exogenous $\mathrm{H}_{2} \mathrm{~S}$ exhibits procancer effect. In contrast, exposure to $\mathrm{H}_{2} \mathrm{~S}$ with high amounts leads to cancer cell death. This is consolidated by the fact that CBS inhibition not only leads to the inhibition of cell growth but also limits the toxic effect of either $3 \mathrm{~m} M \mathrm{NaSH}$ or $3 \mathrm{~m} M$ GYY4137 in the colon cancer line HCT116 (102).

Supportively, Wu et al. (317) recently showed that $\mathrm{NaSH}$ $(25-100 \mu M)$ facilitated vessel formation and tumor growth of hepatocellular carcinomas, both of which were significantly suppressed when the concentration of $\mathrm{NaSH}$ was 


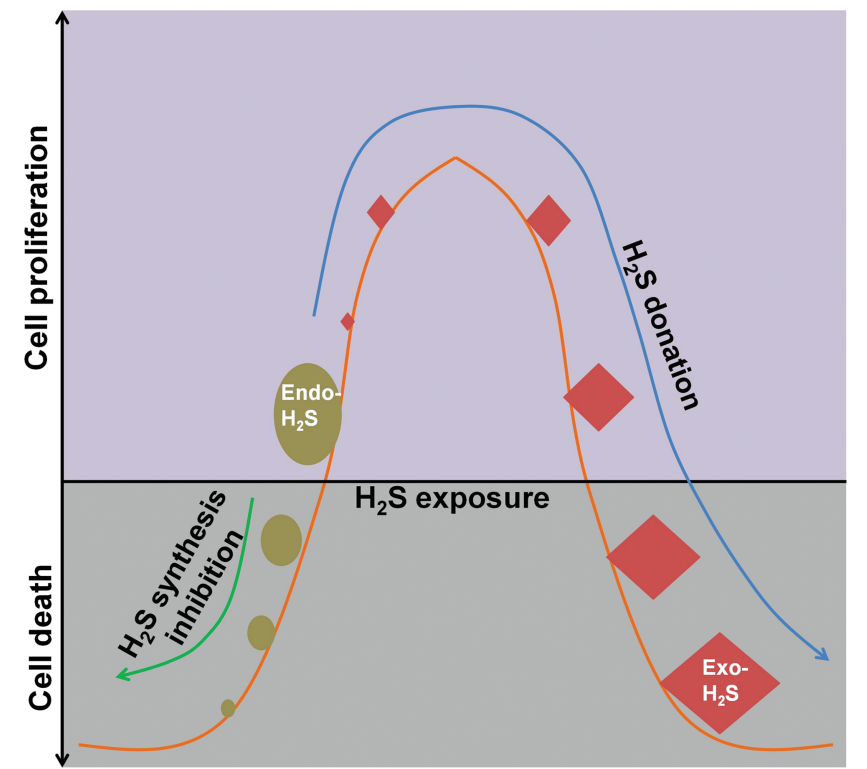

FIG. 6. The bell-shaped model for the dual role of $\mathrm{H}_{2} \mathrm{~S}$ in cancer development. A bell-shaped curve is employed to describe the exposure-dependent effect of $\mathrm{H}_{2} \mathrm{~S}$ on cancer cell proliferation. In general, endogenous $\mathrm{H}_{2} \mathrm{~S}$ or a relatively low level of exogenous $\mathrm{H}_{2} \mathrm{~S}$ exhibits pro-cancer effects. In contrast, exposure of $\mathrm{H}_{2} \mathrm{~S}$ at high amounts or long-time exposure leads to cancer cell death. The models suggest that $\mathrm{H}_{2} \mathrm{~S}$ biosynthesis inhibition and $\mathrm{H}_{2} \mathrm{~S}$ donation serve as two distinct ways for cancer treatment. Color images are available online.

increased to $800 \mu M$. Nonetheless, it is notable that the study relies on a hypothesis that modulating endogenous $\mathrm{H}_{2} \mathrm{~S}$ production is similar to exogenous $\mathrm{H}_{2} \mathrm{~S}$ donation, which may still be plausible considering the unknown intracellular and subcellular $\mathrm{H}_{2} \mathrm{~S}$ concentration after these modulations. Moreover, SAM, a putative allosteric CBS activator, promoted cancer cell proliferation at a lower concentration range $(0.1-0.3 \mathrm{mM})$. However, it inhibited cell proliferation at higher concentrations $(1-3 \mathrm{~m} M)$ and this effect was partially blocked by CBS silencing (102), suggesting that overactivation of $\mathrm{H}_{2} \mathrm{~S}$-producing enzymes can also suppress cancer cell proliferation.

Interestingly, this biphasic dose response of $\mathrm{H}_{2} \mathrm{~S}$ in cancer cells well reflects a hormetic response that was recently proposed by Calabrese et al. (34). Specifically, $\mathrm{H}_{2} \mathrm{~S}$ at low concentrations may activate endogenous cellular defense mechanisms that lead to cell death at high concentrations due to its toxic effects. In addition, continuous supplementation of $\mathrm{NaSH},(5-20 \mu M$; every $2 \mathrm{~h})$, induced cancer cell death while sparing non-cancerous cells such as MCF10A and Wi38 after 5 days (150). This effect was well reflected with the slowly releasing $\mathrm{H}_{2} \mathrm{~S}$ donor GYY4137 $(42,150)$. These results suggest that long time exposure to $\mathrm{H}_{2} \mathrm{~S}$, even at low doses, can also cause cancer cell death.

Taken together, the bell-shaped models may provide a valuable framework to harmonize the controversies regarding the seemingly controversial role of $\mathrm{H}_{2} \mathrm{~S}$ in cancer development. Meanwhile, it is suggested that $\mathrm{H}_{2} \mathrm{~S}$ biosynthesis inhibition and $\mathrm{H}_{2} \mathrm{~S}$ donation serve as two distinct ways for cancer treatment. Nonetheless, further studies are warranted to precisely define what the exact levels of sulfide exposure are with respect to carcinogenesis in the bell-shaped curve.

\section{Crosstalk of $\mathrm{H}_{2} \mathrm{~S}$ with Other Gaso-Transmitters in Cancer Biology}

\section{A. Crosstalk of $\mathrm{H}_{2} \mathrm{~S}$ and $\mathrm{NO}$ in cancer}

There is plenty of evidence showing that $\mathrm{H}_{2} \mathrm{~S}$ and $\mathrm{NO}$ actually share some similar actions such as relaxing smooth muscle and interacting with heme groups in protein molecules $(271,290,296)$. Intriguingly, these molecules are also demonstrated to crosstalk with each other, even in physiological conditions. Herein, the crosstalk of $\mathrm{H}_{2} \mathrm{~S}$ with $\mathrm{NO}$ is reviewed with an emphasis in the context of cancer biology.

1. Endogenous $\mathrm{H}_{2} \mathrm{~S}$ and $\mathrm{NO}$ serve as mutual functional effector molecules. The similarities in the function of $\mathrm{H}_{2} \mathrm{~S}$ and NO have urged the investigation whether these two molecules serve as each other's downstream signaling molecule. Up to date, there is adequate evidence to suggest that they may accomplish this by mutually affecting each other's biosynthesis in mammalian cells (Fig. 7). NO is able to induce CSE expression $(298,344)$ and facilitate the cellular uptake of $\mathrm{H}_{2} \mathrm{~S}$-producing substrate L-cysteine (153), thereby enhancing the production of endogenous $\mathrm{H}_{2} \mathrm{~S}$.

Conversely, $\mathrm{H}_{2} \mathrm{~S}$ also enhances the production of NO. For example, CSE deficiency in mice causes endothelial nitric oxide synthase (eNOS) dysfunction, NO reduction, and aggravated myocardial ischemia/reperfusion injury (137). When $\mathrm{H}_{2} \mathrm{~S}$ is supplemented, $\mathrm{NO}$ level increases by the induction of eNOS expression $(55,142,180)$. In addition, NO production is also prompted on the persulfidation of eNOS induced by

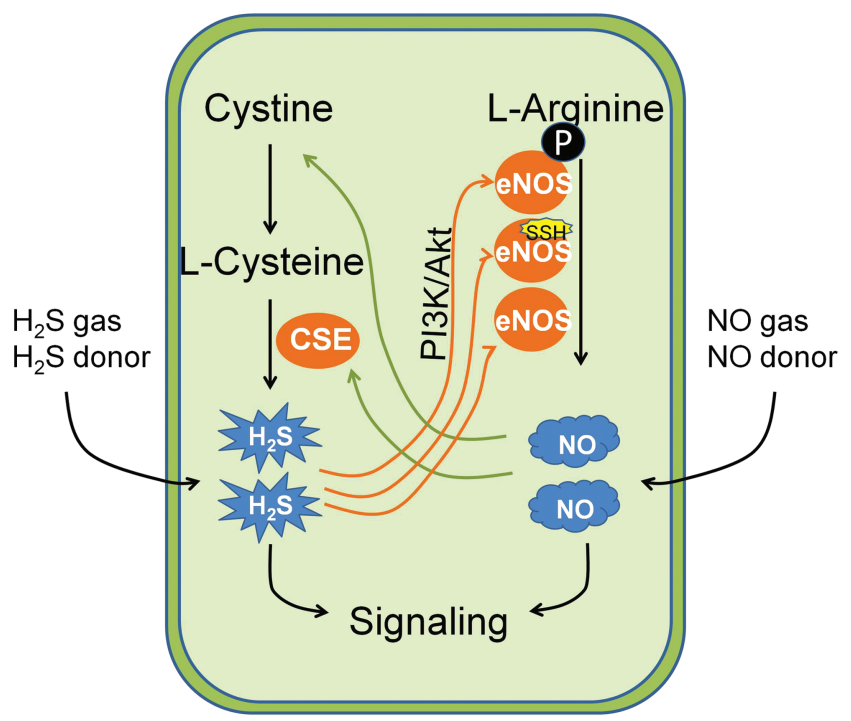

FIG. 7. Endogenous $\mathrm{H}_{2} \mathrm{~S}$ and NO serve as mutual functional effector molecules. $\mathrm{H}_{2} \mathrm{~S}$ and $\mathrm{NO}$ mutually enhance each other's biosynthesis in mammalian cells. NO is able to induce the biosynthesis of $\mathrm{H}_{2} \mathrm{~S}$ by stimulating CSE expression and facilitating the cellular uptake of $\mathrm{H}_{2} \mathrm{~S}$ producing substrate cysteine. Conversely, $\mathrm{H}_{2} \mathrm{~S}$ also enhances the production of NO by stimulating the activity and expression of eNOS. eNOS, endothelial nitric oxide synthase; NO, nitric oxide. Color images are available online. 
$\mathrm{H}_{2} \mathrm{~S}(7,131)$. As a result, it was found that suppression of eNOS lessens $\mathrm{H}_{2} \mathrm{~S}$-mediated vasorelaxation and genetic knockdown of CSE attenuates NO-stimulated angiogenesis (55). In the context of cancer biology, both endogenous $\mathrm{H}_{2} \mathrm{~S}$ and NO are suggested to be beneficial for cancer progression $(265,314)$. Therefore, it is likely that NO partially mediates the pro-cancer effect of $\mathrm{H}_{2} \mathrm{~S}$ and vice versa. This implies that simultaneous inhibition of $\mathrm{H}_{2} \mathrm{~S}$ and $\mathrm{NO}$ biosynthesis may afford synergic effects on the suppression of cancer cell growth, which should be tested in the future.

2. Bioactive products of $\mathrm{H}_{2} \mathrm{~S}$ and $\mathrm{NO}$ interaction possess anti-cancer effect. For a long period, $\mathrm{H}_{2} \mathrm{~S}$ and NO signaling pathways have been also observed to be intimately intertwined with mutual potentiation of responses, particularly in the cardiovascular system $(69,198)$. For instance, Yong et al. (333) have reported that a combination of $\mathrm{H}_{2} \mathrm{~S}$ and $\mathrm{NO}$ produces positive inotropic and lusitropic effects likely via formation of a thiol-sensitive molecule that is suggested to be nitroxyl (HNO) in the study. This is further confirmed by studies published by Filipovic et al. (78) and Zhou et al. (347). However, the possible interaction between these two gaseous transmitters remains unexplored in the context of cancer biology.

A recent study from Whiteman et al. (308) suggests that thionitrous acid (HSNO) is spontaneously formed when $\mathrm{H}_{2} \mathrm{~S}$ and $\mathrm{NO}$ gases are mixed at room temperature in the presence of metallic surfaces. And a further reaction of HSNO with $\mathrm{H}_{2} \mathrm{~S}$ may lead to the formation of $\mathrm{HNO}$ and inorganic polysulfides such as $\mathrm{H}_{2} \mathrm{~S}_{2}$ (202). Subsequently, Cortese-Krott

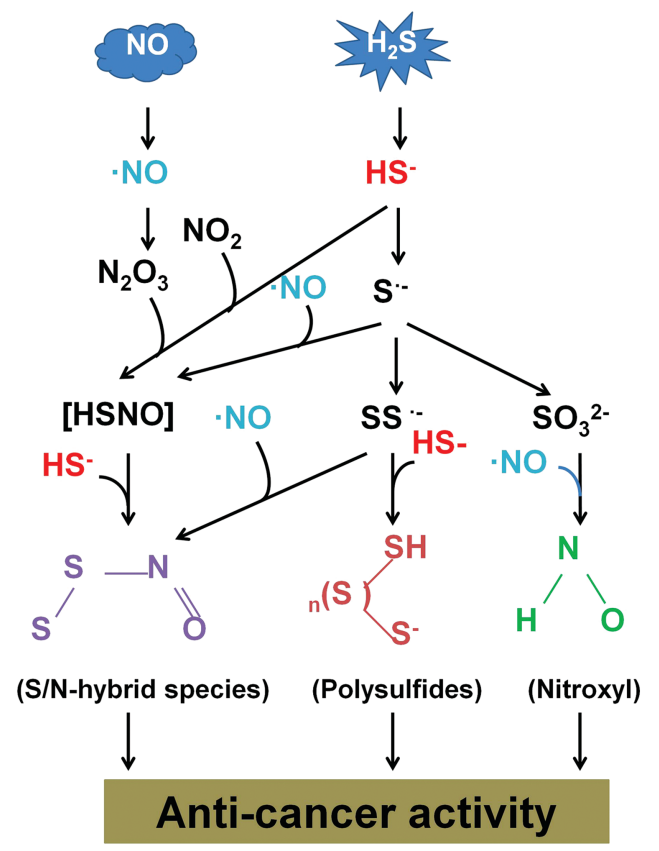

FIG. 8. Direct interaction between $\mathrm{H}_{2} \mathrm{~S}$ and NO generates bioactive anti-cancer products. The interaction between $\mathrm{H}_{2} \mathrm{~S}$ and $\mathrm{NO}$ occurs even in physiological conditions and the key bioactive reaction products of the interaction are $\mathrm{S} /$ $\mathrm{N}$-hybrid species, polysulfides, and HNO. Interestingly, all these species have been shown to possess anti-tumor effects by previous studies. HNO, nitroxyl; HSNO, thionitrous acid. Color images are available online. et al. (59) have identified that the chemical reaction between $\mathrm{H}_{2} \mathrm{~S}$ and $\mathrm{NO}$ occurs even in physiological conditions and the key bioactive reaction products of the interaction are $\mathrm{S} / \mathrm{N}$ hybrid species, inorganic polysulfides, and HNO (Fig. 8).

Chemical studies on some of those S/N-hybrid species, however, have strongly questioned the formation of these intermediates in the cells, and more so in vivo. For example, Koppenol and Bounds (141) showed that it would take more than 1 day to generate a maximum of $1 \mathrm{n} M$ of SSNO- from $1 \mu M \mathrm{H}_{2} \mathrm{~S}$ based on the values reported by Cortese-Krott et al. (59). Thus, studies are warranted to resolve this conflict in the future. Nonetheless, all these species have been shown to possess anti-tumor effects by previous studies $(46,51$, $255 a)$, indicating the potential of a direct interaction between the two gaseous transmitters in cancer biology. Further studies are, therefore, needed to validate the interaction that may lead to the discovery of novel strategies for cancer therapy.

\section{B. Crosstalk of $\mathrm{H}_{2} \mathrm{~S}$ with $\mathrm{CO}$ in cancer}

The direct reaction between $\mathrm{H}_{2} \mathrm{~S}$ and $\mathrm{CO}$ has not yet been reported so far; however, emerging evidence suggests that the axis of CO-CBS- $\mathrm{H}_{2} \mathrm{~S}$ may be important in cancer regulation, which has been discussed next.

1. $\mathrm{CO}-\mathrm{CBS}-\mathrm{H}_{2} \mathrm{~S}$ axis in cancer regulation. $\mathrm{CO}$ is a gaso-transmitter generated from heme oxygenase (HO) by catalyzing the oxidative degradation of heme, a process highly relying on the availability of cellular $\mathrm{O}_{2}(313,319)$. So far, there is plenty of evidence suggesting that $\mathrm{CO}$ is an intrinsic modulator of $\mathrm{H}_{2} \mathrm{~S}$ biosynthesis by inhibiting $\mathrm{CBS}$ activity. For example, an increase of $\mathrm{CO}$ level in liver leads to the reduction of $\mathrm{H}_{2} \mathrm{~S}$ concentration and a subsequent increase of bile excretion, both of which are shown to be absent in CBS heterozygous knockout mice (255). In line with this, hypoxia increases CBS-mediated $\mathrm{H}_{2} \mathrm{~S}$ production through inhibition of HO-2 activity and $\mathrm{CO}$ biosynthesis, which may contribute to vasodilation of precapillary arterioles (190). It is worth mentioning that hypoxia can also lead to the suppression of $\mathrm{H}_{2} \mathrm{~S}$ oxidation, thereby augmenting $\mathrm{H}_{2} \mathrm{~S}$ signaling $(210,213)$, which could be very relevant to the development of solid tumors.

Moreover, the inhibitory effect of CO on CBS activity has been ascribed to its irreversible binding to the heme group of CBS (122, 234, 256). Currently, accumulative studies suggest that this regulation may be relevant to cancer development. As a tumor grows, it rapidly outgrows its blood supply, leading to a significantly lower concentration of $\mathrm{O}_{2}$ in tumor tissues compared with that of normal tissues $(104,105)$. Such a low level of $\mathrm{O}_{2}$ could lead to the reduction of $\mathrm{CO}$ biosynthesis and $\mathrm{H}_{2} \mathrm{~S}$ overproduction, which may be supportive for tumor growth through the beneficial effects of $\mathrm{H}_{2} \mathrm{~S}$ in cancer development as reviewed earlier. In accordance with this, the low enzymatic activity of HO-1 is found in moderately differentiated prostate tumors, which correlates with relatively worse clinical outcomes (303).

In addition, exposure to a low level of $\mathrm{CO}$ diminishes the rate of glycolysis in cancer cells and sensitizes them to chemotherapy with enhanced growth arrest and apoptosis (303), which are very similar to that after CBS inhibition $(266,267)$. Moreover, overexpression of HO-1 in cancer cells attenuates 


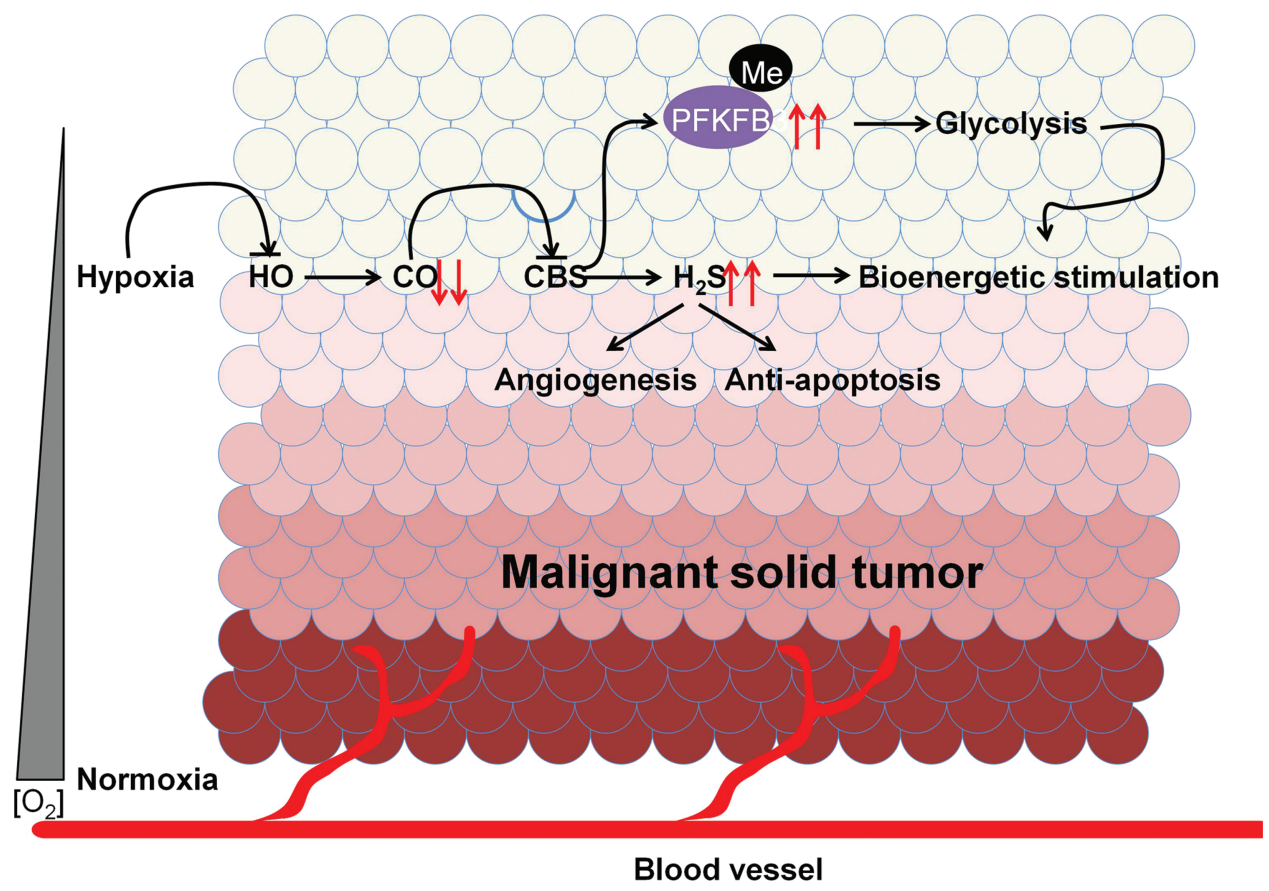

FIG. 9. CO-CBS- $\mathrm{H}_{2} \mathrm{~S}$ axis in cancer regulation. In malignant solid tumors, hypoxia suppresses the activity of CO generating the enzyme $\mathrm{HO}$, which leads to the reduction of $\mathrm{CO}$ level. This reduction can stimulate the activity of CBS and result in the upregulation of endogenous $\mathrm{H}_{2} \mathrm{~S}$ synthesis since $\mathrm{CO}$ serves as an intrinsic inhibitor of CBS. The increase of endogenous $\mathrm{H}_{2} \mathrm{~S}$ can be beneficial for cancer cell growth by promoting angiogenesis, activating anti-apoptotic pathways, and stimulating bioenergetic process. In addition, the activation of CBS itself is able to stimulate the methylation of PFKFB3, which enhances glycolysis and also contributes to bioenergetic stimulation. CO, carbon monoxide; HO, hemo oxygenase; PFKFB3, 6-phosphofructo-2-kinase/fructose-2,6-bis-phosphatase 3. Color images are available online.

the growth of lung carcinoma xenografts in mice $(203,258$, 277). However, it is notable that although the reduction of $\mathrm{H}_{2} \mathrm{~S}$ caused by CBS inhibition may be, at least partially, involved in this CO-mediated cancer inhibition, a direct demonstration of such involvement is still lacking.

Other than the decrease of $\mathrm{H}_{2} \mathrm{~S}, \mathrm{CBS}$ inhibition by $\mathrm{CO}$ has also been found to cause demethylation of proteins such as 6 phosphofructo-2-kinase/fructose-2,6-bis-phosphatase 3 (PFKFB3) (325). The demethylation of PFKFB3 results in the attenuation of glycolysis in cancer cells (261). Therefore, it can be proposed that CBS activation on $\mathrm{CO}$ reduction in hypoxic conditions such as a tumor microenvironment may contribute to the maintenance of glycolysis partially by enhancing PFKFB3 methylation. The possible mechanisms underlying $\mathrm{CO}-\mathrm{CBS}-\mathrm{H}_{2} \mathrm{~S}$ axis in cancer regulation have been illustrated in Figure 9.

\section{The Potential of Targeting $\mathrm{H}_{2} \mathrm{~S}$ for Cancer Treatment}

\section{A. Treatment of cancer with $\mathrm{H}_{2} \mathrm{~S}$ biosynthesis inhibitors}

All the three $\mathrm{H}_{2} \mathrm{~S}$ synthesizing enzymes, namely CSE, CBS, and $3 \mathrm{MST}$, might be involved in cancer development, as shown in section III, however, only CBS has been demonstrated as a potential therapeutic target for cancer treatment, particularly in colon cancer $(48,102,103,266,267)$ and ovarian cancer $(24,47)$. As a result, the discovery of CBS inhibitors has attracted more attention compared with their counterparts. In this section, we summarize the current CBS inhibitors and their usage, particularly in cancer treatment. The chemical structures of these CBS inhibitors have been illustrated in Figure 10.

1. CBS inhibitor aminooxyacetic acid shows great potential in cancer therapy. Aminooxyacetic acid (AOAA) (Fig. 10a) is a traditional CBS inhibitor and has been extensively used in the field of $\mathrm{H}_{2} \mathrm{~S}$ biology. In colon cancer cell lines, AOAA treatment inhibits $\mathrm{H}_{2} \mathrm{~S}$ production, cell migration, and cell growth, closely mimicking the effect of CBS silencing (266, 267). A similar effect was observed in other cancer cell lines, including ovarian cancer cells (24), breast cancer cells (278), and pancreatic adenocarcinoma cells (259). In vivo, AOAA exhibits remarkable inhibition of HCT116 cell xenografts (267) and the proliferation of patient-derived colon tumor xenografts (102). Moreover, the inhibitory effect on breast cancer has also been shown in a xenograft mouse model (278). However, it is noticed that non-cancerous cells have not been included in most studies mentioned earlier. Therefore, it remains unclear whether AOAA has sufficient therapeutic window for cancer treatment.

Recently, Chao et al. (48) found that addition of a methyl ester group on AOAA enhances the cellular uptake of AOAA and the new molecule YD0171 (Fig. 10a) exerts higher potency on the growth inhibition of colon cancer cell line HCT116 both in vitro and in vivo. In addition, YD0171 reduces tumor growth in the patient-derived tumor xenograft model and causes no systemic toxicity in a 5-day safety study, indicating the value of the molecule for cancer treatment. On 


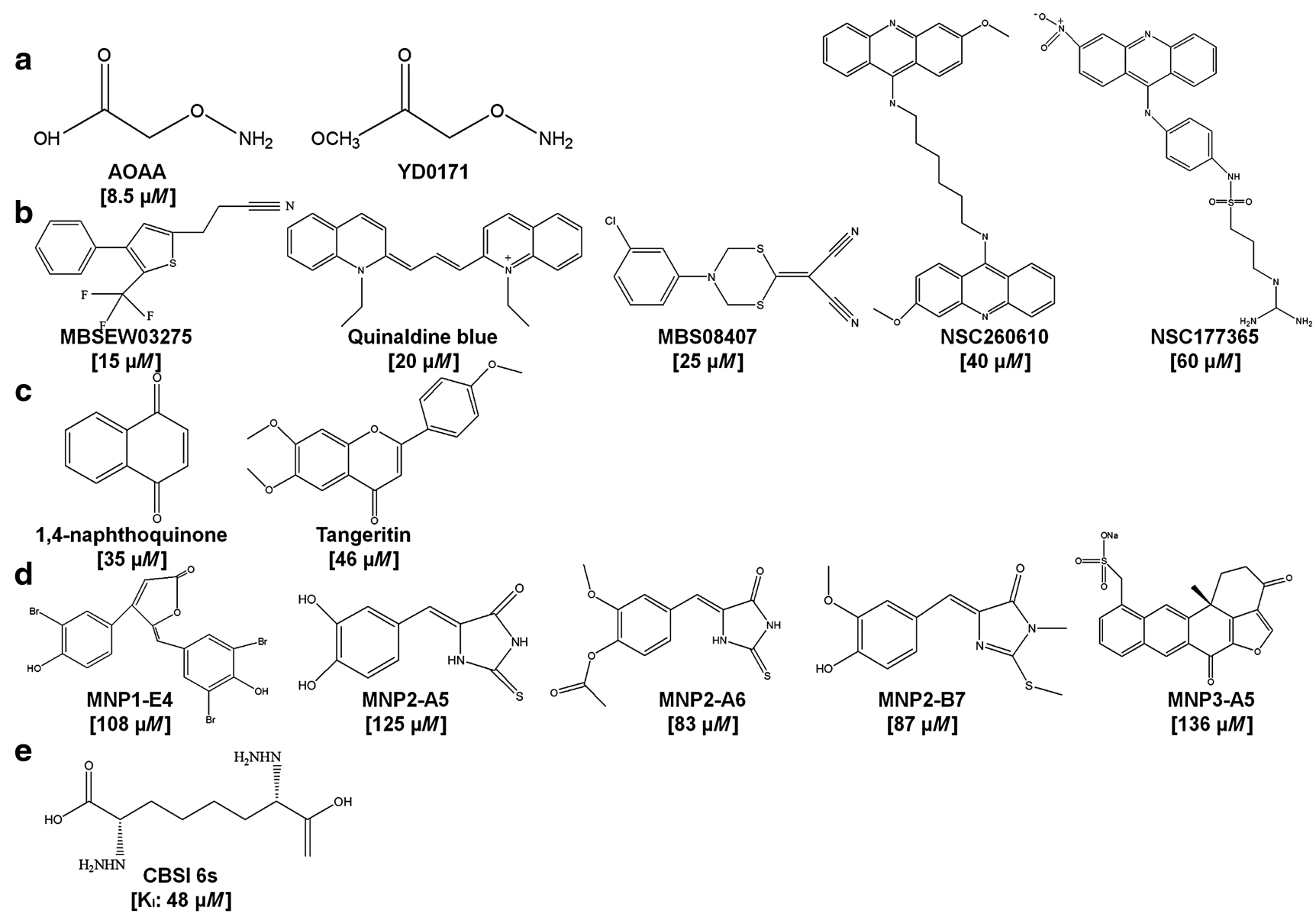

FIG. 10. Pharmacological inhibitors of CBS. (a) Traditionally used CBS inhibitor and its derivative YD0171. Addition of a methyl ester group on AOAA enhanced the cellular uptake of AOAA, and the new molecule YD0171 exerted higher potency on the growth inhibition of colon cancer cells both in vitro and in vivo. The IC50 was determined by Asimakopoulou et al. (9). (b) CBS inhibitors screened by Zhou et al. (348) from a chemical library containing 21,599 compounds. This is the first high-throughput screen with the effort to identify specific CBS inhibitors. (c) CBS inhibitors obtained from a 1900 chemical library by Thorson et al. (279). The two compounds suppress the activity of CBS without affecting that of CSE. (d) CBS inhibitors screened from a library of marine natural products (MICL-240 library) by Thorson et al. (279). (e) CBS inhibitor synthesized by McCune et al. (177). The inhibitor was synthesized based on the structure of the enzymatic product rather than the cofactor PLP, therefore it shows rather high specificity over other PLP-dependent enzymes. The IC50 is not comparable among studies due to the differences in assay format. AOAA, aminooxyacetic acid; PLP, pyridoxal 5 -phosphate.

top of these, one should bear in mind that the selectivity of AOAA for CBS over CSE or other PLP-dependent enzymes is limited as it targets the PLP cofactor, which is commonly used by this class of enzyme (102). In line with this, a study has indicated that AOAA is three times less potent for CBS than CSE (9). Therefore, selective CBS inhibitors are of high demand.

2. Advances in the development of selective CBS inhibitors. To obtain novel selective CBS inhibitors, Zhou et al. (348) initiated the first high-throughput assay for the identification of potent and selective inhibitors of CBS in 2013. With a tandem-microwell assay, 21,599 agents from various libraries have been screened against recombinant human CBS (hCBS). As a result, 35 compounds have been confirmed as hits with an IC50 of $<50 \mu M$ for the inhibition of hCBS. Among them, five compounds, namely MBSEW03275, JHU-8555/Quinaldine blue, MBS08407, NSC260610, and
NSC177365 (Fig. 10b), have shown a preference to inhibit hCBS over human CSE with MBS08407 and Quinaldine blue as the most selective ones. Interestingly, quinaldine blue is an anti-tumor drug approved by FDA; however, its molecular mechanism is not clear (75). This study implies that quinaldine blue may inhibit tumor growth by selectively suppressing the activity of CBS.

Later, Barrios and colleagues (279) conducted another screen of a small chemical library containing 1900 compounds with an $\mathrm{H}_{2} \mathrm{~S}$ probe-based assay. Eventually, two compounds, namely 1,4-naphthoquinone and tangeritin (Fig. 10c), were yielded that selectively suppress the activity of CBS without affecting that of CSE. Intriguingly, both the compounds have been suggested as potential anti-cancer molecules, especially for colon cancer in other studies (129, 191). Using a library of marine natural products (MICL-240 library), Barrios and colleagues (280) have recently performed another screen to identify novel CBS inhibitors. They 
identified five hits (IC50<150 $\mu M$; Fig. 10d) as CBS inhibitors; however, the selectivity of these compounds remains elusive, as the effect of these compounds on CSE has not been tested. Nevertheless, these scaffolds may serve as useful starting points for the synthesis of selective CBS-targeted molecules in the future.

Apart from the earlier mentioned high-throughput strategy, McCune et al. (177) recently reported a novel way to synthesize selective CBS inhibitors. They chose the enzymatic product $(\mathrm{L}, \mathrm{L})$-cystathionine, instead of the cofactor PLP, as a scaffold for the synthesis of inhibitor candidates. In the study, half of the inhibitor was constructed and then fused by olefin cross-matathesis. Among the inhibitors, CBSI 6S (Fig. 10e) exhibits the highest potency for CBS and reduces infarct volume in a rat transient middle cerebral artery occlusion model. Significantly, CBSI 6S shows 12fold higher inhibition of CBS than that of gammaaminobutyric acid aminotransferase, one of the best studied PLP dependent enzymes, indicating its good selectivity. Further studies are needed to test the effect of CBSI 6S on cancer cell proliferation.

\section{B. Treatment of cancer with $\mathrm{H}_{2} \mathrm{~S}$ donors}

$\mathrm{H}_{2} \mathrm{~S}$ donors with different properties have been developed and tested in various disease models. Herein, we review three categories of $\mathrm{H}_{2} \mathrm{~S}$ donors, including sulfide salts, phosphorodithioate derivatives, and allium sativum extracts and derivatives, with an emphasis on their application in cancer treatment (Fig. 11).
1. Sulfide salts. Sulfide salts (Fig. 11a), namely $\mathrm{NaSH}$ and $\mathrm{Na}_{2} \mathrm{~S}$, are the most commonly used $\mathrm{H}_{2} \mathrm{~S}$ donors in the field of $\mathrm{H}_{2} \mathrm{~S}$ biology. They readily dissolve in physiological solution buffers and water and form $\mathrm{HS}^{-}$and $\mathrm{H}_{2} \mathrm{~S}$ (157). As they do not have any backbone structures, it is believed that the biological effects derived from these molecules are solely from $\mathrm{H}_{2} \mathrm{~S}$. In the context of cancer biology, the effect of salt sulfides appears to be concentration dependent. Specifically, it promotes cancer cell proliferation at low doses and inhibits cancer cell growth at high concentrations (102). Perhaps due to the distinct effects caused by concentrations, no studies have been performed to show their efficacy for cancer inhibition within in vivo models. In addition, the concentrationdependent effect of these $\mathrm{H}_{2} \mathrm{~S}$ donors has also been observed in non-cancerous cells such as heart cells and smooth muscle cells (15), indicating a possible marginal therapeutic index of these compounds in cancer treatment. The other concern of utilizing sulfide salts is that they release $\mathrm{H}_{2} \mathrm{~S}$ at an uncontrolled manner and may cause acute toxicity to organs.

Taken together, sulfide salts serve as great tool compounds to illustrate $\mathrm{H}_{2} \mathrm{~S}$-mediated biological effects and the underlying mechanisms whereas the feasibility is rather low to translate them as a therapeutic drug, especially for cancer treatment.

2. Phosphorodithioate derivatives. GYY4137 (Fig. 11b) is the first phosphinodithioate-derived $\mathrm{H}_{2} \mathrm{~S}$-releasing compound that was synthesized in 2008 (162). It slowly releases $\mathrm{H}_{2} \mathrm{~S}$ in aqueous solution via a two-step process and after intravenous or intraperitoneal injection in animals, closely

a

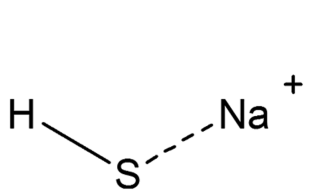

Sodium hydrosulfide

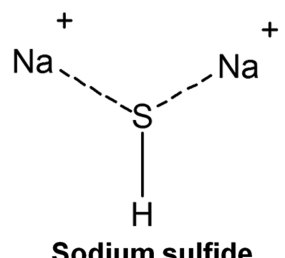

Sodium sulfide

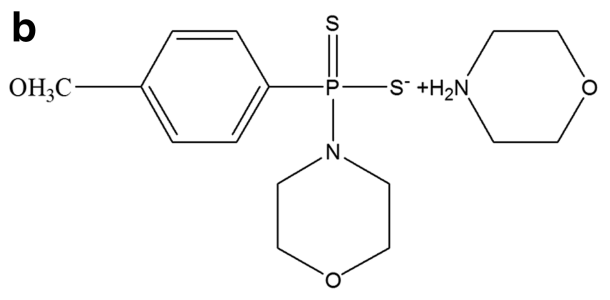

GYY4137

C
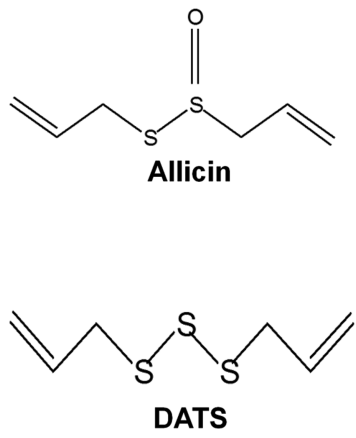

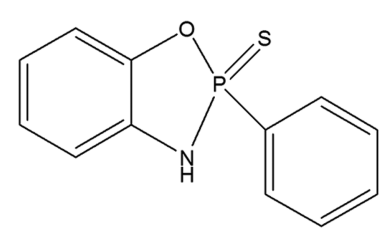

FW1256

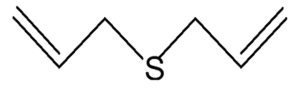

DAS

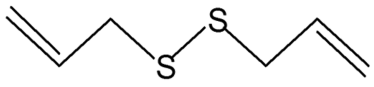

DADS
FIG. 11. Structural components of $\mathrm{H}_{2} \mathrm{~S}$ donors with anti-tumor activity. (a) Chemical structure of sulfide salts, including sodium hydrosulfide and sodium sulfide. (b) Chemical structure of phosphorodithioate derivatives donating $\mathrm{H}_{2} \mathrm{~S}$. FW1256, derivative of GYY4137, has a higher $\mathrm{H}_{2} \mathrm{~S}$-releasing rate and higher potency of anti-tumor activity compared with GYY4137. (c) Chemical structure of Allium sativum extracts and derivatives, including Allicin, DAS, DADS, and DATS. DADS, diallyl disulfide; DAS, diallyl sulfide; DATS, diallyl trisulfide.

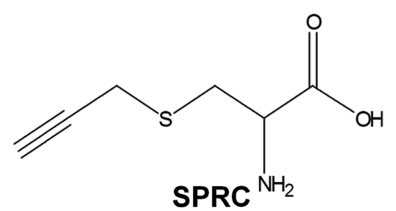


mirroring the physiological releasing manner of $\mathrm{H}_{2} \mathrm{~S}$ from mammalian cells $(5,162)$. Therefore, it has been extensively used to study both physiological and therapeutic effects of $\mathrm{H}_{2} \mathrm{~S}$. The anti-cancer effect of GYY4137 has been demonstrated both in vitro and in vivo $(149,150,162,171)$. Importantly, GYY4137 induces cell apoptosis in cancer cell lines without affecting the cell viability of noncancerous fibroblast cells $(149,150)$, indicating the potential value of the molecule for cancer treatment. However, examination of published data $(149,150)$ clearly indicates that the concentrations and/or doses of GYY4137 employed to exert the anti-cancer effect are high (400-1000 $\mu M$ for in vitro; 100 $300 \mathrm{mg} / \mathrm{kg}$ for in vivo), indicating its marginal potency. However, $\mathrm{H}_{2} \mathrm{~S}$ production from GYY4137 is inefficient (5), and very little $\mathrm{H}_{2} \mathrm{~S}$ is produced, necessitating its use at high concentrations/doses.

To improve the anti-cancer potency of GYY4137, Feng et al. (76) have recently synthesized a series of compounds based on the structure of GYY4137. Among these compounds, FW1256 (Fig. 11b) has shown superior potency in MCF7 tumor spheroids compared with GYY4137 (IC50: $5.7 \mu M$ for FW1256 vs. $368 \mu M$ for GYY4137) and caused cancer cell death through apoptosis by activating PARP and caspase-7. At a concentration inhibiting cancer cell proliferation, no toxic effect is observed in noncancerous fibroblast cell Wi-38. Further analysis with a series of these compounds shows a positive correlation between the anti-cancer potency and $\mathrm{H}_{2} \mathrm{~S}$-releasing rate, which may provide a guide for the future development of such compounds. However, the study did not show the anti-tumor activity of FW1256 in vivo, which needs to be done in the future.

3. Allium sativum extracts and derivatives. Allium sativum (garlic) has been extensively used for numerous diseases, including cardiovascular disease and cancer in traditional Chinese medicine (324). It is abundant with sulfur-containing compounds that can be easily recognized with a smell. Among these compounds, allicin (diallyl thiosulfinate; Fig. 11c) has been extracted and studied thoroughly. Intriguingly, compiling evidence suggests that allicin possesses anticancer effects in various types of cancer both in vitro and in vivo $(17,218,273)$. For instance, allicin significantly inhibits cell proliferation of several colon cancer cell lines such as Caco-2, HT-29, and HCT116 (17).

In addition, allicin administration apparently inhibits tumor growth in L5178Y lymphoma-bearing mice (218). Allicin is very unstable and decomposes quickly into several compounds, including diallyl sulfide, diallyl disulfide, diallyl trisulfide, and allyl methyl sulfide (Fig. 11c). Therefore, these individual compounds have also been synthesized and tested in various disease models. The results have shown that the number of sulfur atoms well reflects the efficacy of these molecules not only in cancer inhibition (192) but also in vasodilation (22), which positively correlates with the $\mathrm{H}_{2} \mathrm{~S}$ releasing capacity. In spite of this, further studies are still needed to investigate whether the effects are derived from other reactive sulfur species or $\mathrm{H}_{2} \mathrm{~S}$ directly, as suggested by a recent study (61).

In addition, SPRC (Fig. 11c), a novel stimulator of endogenous $\mathrm{H}_{2} \mathrm{~S}$, is a structural analogue of $S$-allycysteine that is derived from garlic component $S$-alkyl cysteine sulfoxides. It has been shown to stimulate $\mathrm{H}_{2} \mathrm{~S}$ production continuously in mammalian cells (295). Recently, SPRC was found to cause cell cycle arrest at the G1/S phase in gastric cancer cell line SGC-7901 and subsequent apoptosis both in vitro and in vivo (123). Intriguingly, the anti-cancer effect of SPRC can be blocked by CSE inhibition (123), indicating that the effect can be at least partially attributed to the production of $\mathrm{H}_{2} \mathrm{~S}$. However, the marginal potency (IC50 $\approx 5 \mathrm{mM}$ ) may be an issue to use this compound as cancer therapy, which needs to be improved in the future.

\section{4. $\mathrm{H}_{2} \mathrm{~S}$-releasing hybrids \\ a. $\mathrm{H}_{2} \mathrm{~S}$-releasing non-steroid anti-inflammatory drugs}

(1) $\mathrm{H}_{2} \mathrm{~S}$-releasing non-steroid anti-inflammatory drugs possess anti-cancer activity. The finding that $\mathrm{H}_{2} \mathrm{~S}$ is able to enhance ulcer healing (291) has impelled the synthesis of $\mathrm{H}_{2} \mathrm{~S}$ releasing non-steroid anti-inflammatory drugs (HS-NSAIDs) to limit NSAIDs caused gastrointestinal side effect. Usually, 5-(4-hydroxyphenyl)-3H-1, 2-dithiole-3-thione (ADT-OH) is covalently conjugated with an NSAID to form a hybrid (128). So far, a number of HS-NSAIDs have been developed, including HS-Sulindac, HS-Ibuprofen, HS-Mesalamine, HSNaproxen, HS-Diclofenac, HS-Aspirin (HS-ASA), and HSIndomethacin (127). Most of these drugs have shown less damage to the gastrointestinal tract compared with their respective NSAID (127), which favors the initial hypothesis. Besides inflammation, NSAIDs, in general, also serve as potential chemopreventive agents against cancer as indicated by Kune et al. (144) that subjects taking NSAIDs have a significantly lower incidence of colon cancer.

Recently, four HS-NSAIDs, including HS-Sulindac, HSIbuprofen, HS-naproxen, and HS-ASA (Fig. 12), have been tested within 11 cancer cell lines from six tissue origins across from solid tumor to leukemia (50). Remarkably, all the HS-NSAIDs tested exert inhibitory effects on the growth of the 11 cancer cell lines. To achieve the same extent inhibition, the parental NSAID treatment alone requires 38- to 1300 -fold higher concentration (50), indicating a synergic effect of $\mathrm{H}_{2} \mathrm{~S}$ and NSAID on cancer inhibition. The antitumor effect of HS-NSAIDs was further demonstrated in several in vivo models (50). Taken together, HS-NSAIDs not only increase the therapeutic index but also enhance the antitumor activity of NSAIDs, showing their potential value as novel anti-cancer agents. Nonetheless, though existing data showed that some $\mathrm{H}_{2} \mathrm{~S}$-NSAIDs such as HS-Diclofenac can release $\mathrm{H}_{2} \mathrm{~S}$ in plasma and their effects can be mimicked by an injection of ADT-OH and corresponding NSAID (160), however, whether these compounds release $\mathrm{H}_{2} \mathrm{~S}$ and NSAIDs simultaneously that account for the subsequent anti-cancer effect was not established in many cases.

(2) Mechanisms of action of $\mathrm{H}_{2} \mathrm{~S}-\mathrm{NSAIDs}$ in cancer inhibition. Along with the recognition of the remarkably anticancer potential of HS-NSAIDs, the mechanisms underlying such effects have also been thoroughly studied, which has been summarized in Figure 13. Chattopadhyay et al. (50) have found that the four HS-NSAIDs (HS-Sulindac, HSIbuprofen, HS-naproxen, and HS-ASA) induce apoptosis in HT-29 colon cancer cells accompanied by cell cycle arrest in the G0/G1 phase, which has been further paralleled in breast cancer MDA MB-231 (98). In addition, also using MDA-MB 231 cells, it is suggested by studies from Kashfi et al. that HS- 


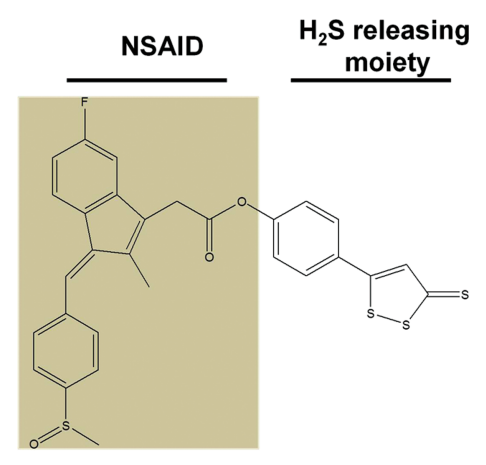

HS-Sulindac

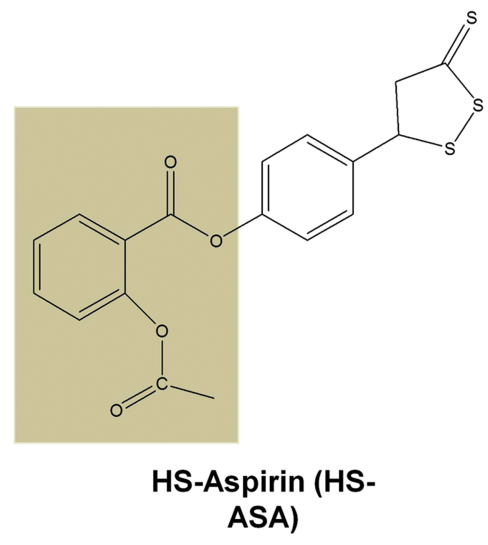

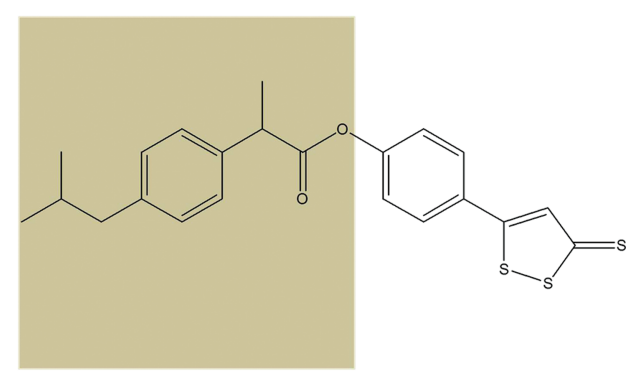

HS-Ibuprofen

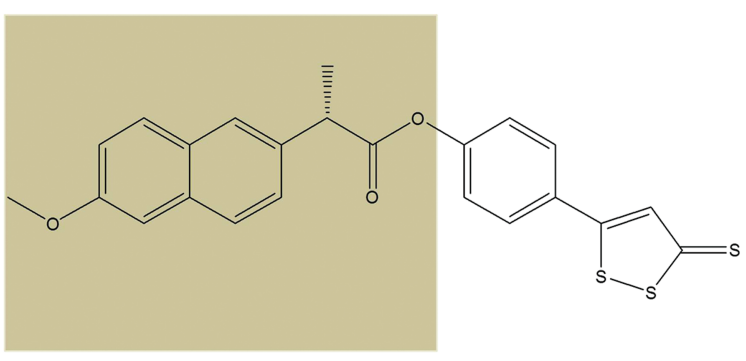

HS-Naproxen
FIG. 12. Structural components of $\mathrm{H}_{2} \mathrm{~S}$-releasing NSAIDs with anti-tumor activity. ADT-OH is covalently conjugated with an NSAID to form a hybrid that releases $\mathrm{H}_{2} \mathrm{~S}$ and NSAID simultaneously. The traditional NSAIDs are shown in the shaded box. ADT$\mathrm{OH}, 5-(4-h y d r o x y p h e n y l)-3 \mathrm{H}-$ 1, 2-dithiole-3-thione; NSAID, non-steroid anti-inflammatory drug. Color images are available online.
ASA may inhibit cancer cell growth by suppression of the $\mathrm{NF}-\kappa \mathrm{B}$ signaling pathway via preventing the phosphorylation of the $\mathrm{I} \kappa \mathrm{B}$ kinases $(12,49)$. Moreover, it has been shown that HS-ASA concentration dependently results in the cellular ROS formation, which may also contribute to the following cancer cell apoptosis $(50,54)$. Though the mechanisms underlying HS-ASA-mediated ROS production remain elusive, it is worth mentioning that $\mathrm{H}_{2} \mathrm{~S}$, in fact, can behave as a pro- oxidant through the interaction with dioxygen to produce sulfur-centered and oxygen-centered free radicals $(10,260)$. This could induce a redox shift over the redox set points of cancer cells (i.e., redlines) and result in cancer cell death (232).

Intriguingly, the suppression of the wnt/ $\beta$-catenin pathway is suggested to be the mechanism underlying the anti-cancer effect of HS-ASA in T cell acute lymphoblastic leukemia (52, 88). Other than these, modulation of thioredoxin/thioredoxin

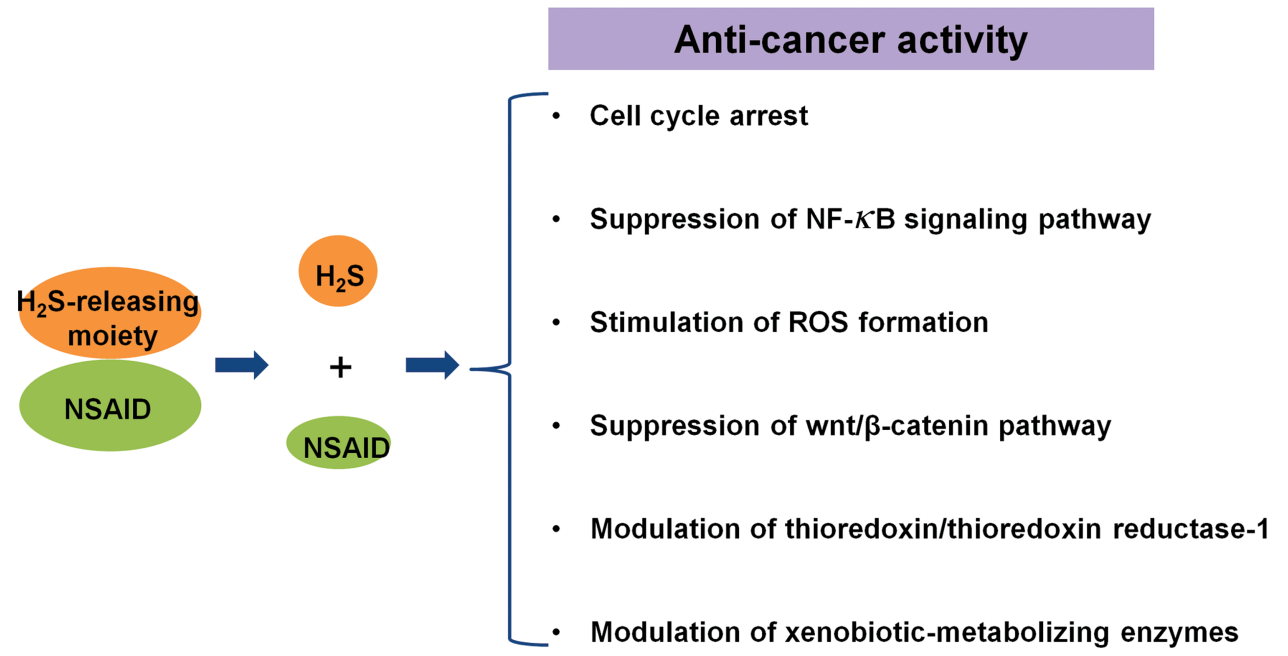

FIG. 13. Mechanisms of action of HS-NSAIDs in cancer inhibition. Multiple mechanisms have been suggested to underlie the anti-cancer effect of HS-NSAIDs. These mechanisms include, but are not limited to, cell cycle arrest, Suppression of the NF- $\kappa \mathrm{B}$ signaling pathway, stimulation of ROS formation, suppression of the wnt/ $\beta$-catenin pathway, modulation of thioredoxin/thioredoxin reductase-1, and modulation of xenobiotic-metabolizing enzymes. HS-NSAID, $\mathrm{H}_{2} \mathrm{~S}$ releasing non-steroid anti-inflammatory drug; ROS, reactive oxygen species. Color images are available online. 

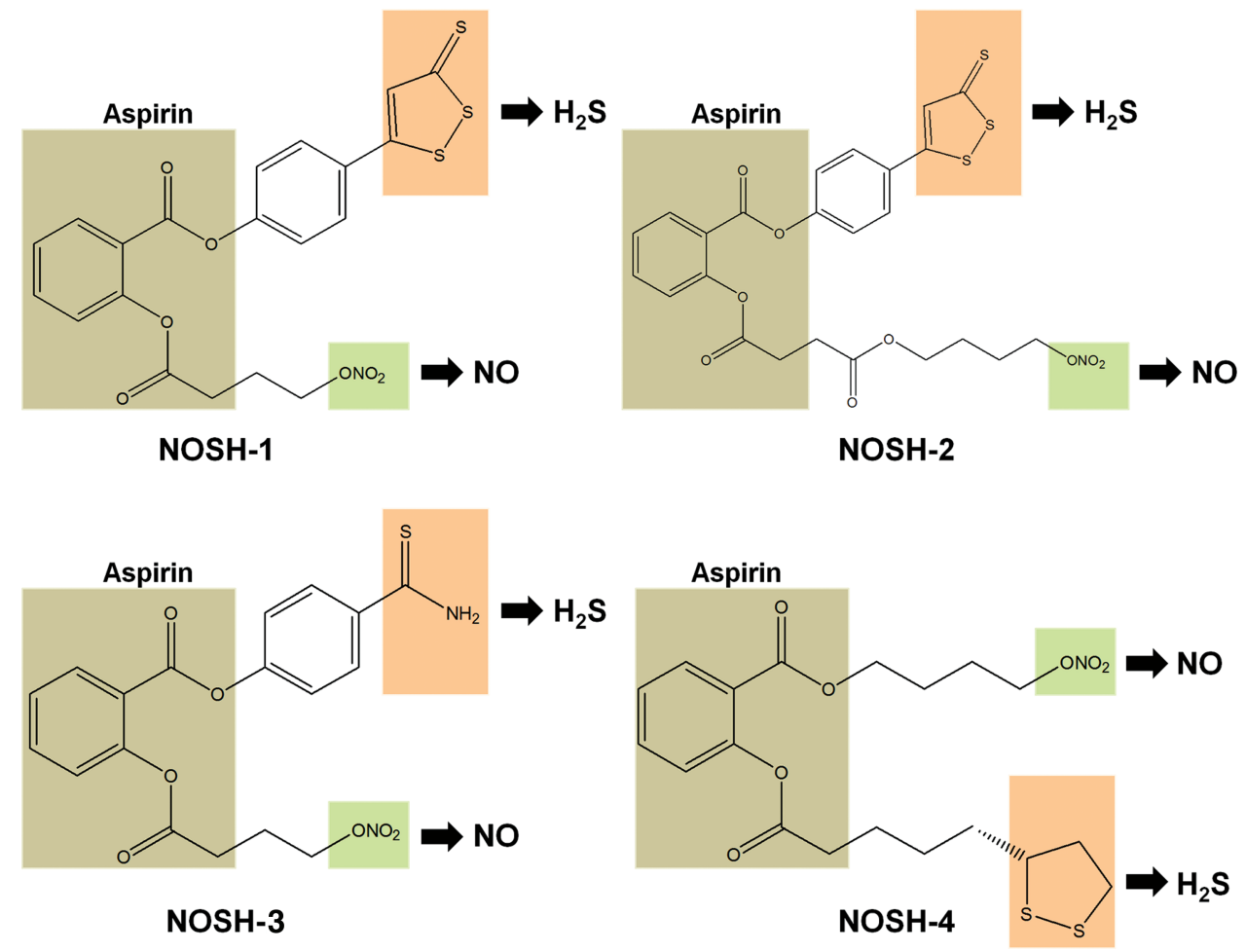

FIG. 14. The chemical structures of NOSH compounds possessing anti-cancer activity. The mother compound aspirin is shaded in gray; $\mathrm{H}_{2} \mathrm{~S}$-releasing moiety is shaded in pink; and NO-releasing moiety is shaded in green. NOSH-1, (4-(3thioxo-3H-1, 2-dithiol-5-yl) phenyl 2-((4-(nitrooxy)butanoyl)oxy)benzoate); NOSH-2, (4-(nitrooxy)butyl (2-((4-(3-thioxo-3H1,2-dithiol-5-yl)phenoxy)carbonyl)phenyl)); NOSH-3, (4-carbamothioylphenyl 2-((4-(nitrooxy)butanoyl)oxy)benzoate); NOSH-4, (4-(nitrooxy)butyl 2-(5-((R)-1,2-dithiolan-3-yl)pentanoyloxy)benzoate). Color images are available online.

reductase- 1 and/or xenobiotic-metabolizing enzymes may also contribute to the anti-cancer effect of HS-NSAIDs, as suggested by various studies $(16,50)$. As clearly seen from what has been described earlier, HS-NSAIDs exert their anti-cancer effect through multiple mechanisms. Nevertheless, why HSNSAIDs possess anti-cancer activity with such a higher potency than their parental drugs is not yet revealed.

Therefore, it would be better to compare the efficacy and mechanism of action among $\mathrm{H}_{2} \mathrm{~S}$ donor, NSAID, $\mathrm{H}_{2} \mathrm{~S}$ donor together with NSAID, and HS-NSAID hybrid to obtain a better understanding of the possible interactions between $\mathrm{H}_{2} \mathrm{~S}$ and NSAIDs in the treatment of cancer.

b. NOSH compounds as anti-cancer agents. Due to the anti-inflammatory effects of exogenous $\mathrm{NO}$ and $\mathrm{H}_{2} \mathrm{~S}$, it is hypothesized that compounds simultaneously donating NO and $\mathrm{H}_{2} \mathrm{~S}$ may achieve higher potency in the suppression of inflammation. This class of compounds is termed NOSH compounds $(51,138)$. Currently, four such NOSH compounds have been reported, including NOSH-1 [(4-(3-thioxo-3H-1,2-dithiol-5-yl) phenyl 2-((4-(nitrooxy)butanoyl)oxy)benzoate)], NOSH-2 [(4(nitrooxy)butyl (2-((4-(3-thioxo-3H-1, 2-dithiol-5-yl)phenoxy) carbonyl)phenyl))], NOSH-3 [(4-carbamothioylphenyl 2-((4(nitrooxy)butanoyl)oxy)benzoate)], and NOSH-4 [(4-(nitrooxy) butyl 2-5-((R)-1,2-dithiolan-3-yl)pentanoyloxy)benzoate)] (Fig. 14), all of which use aspirin as a scaffold coupled with NO and $\mathrm{H}_{2} \mathrm{~S}$-releasing moieties (138). As expected, these compounds show great potential in inflammatory inhibition (128, 147, 235). Remarkably, all of the four NOSH compounds exhibit extreme effectiveness in the growth inhibition of cancer cells, including colon cancer (HT-29, HCT15, and SW480), breast cancer (MCF7, MDA MD-231, and SKBR3), T cell leukemia (Jurkat), pancreatic cancer (BxPC3 and MIAPaCa-2), prostate cancer (LNCaP), and lung cancer (A549) (138). Among these compounds, NOSH-1 was shown to be the most potent one with IC50 ranging from 48 to $240 \mathrm{n} M$ for inhibition of cancer cell growth at $24 \mathrm{~h}$ (138).

Compared with its parental ASA, the potency for inhibition of cancer cell growth is increased by 100,000-fold, 60,000-fold, 600-fold, and 16,000-fold for NOSH-1, -2, -3, and -4 , respectively, in HT-29 colon cancer cells (138). Significantly, the anti-tumor effect of NOSH-1 has been demonstrated in a human colon cancer xenograft model, which shows an $85 \%$ reduction in tumor volume after treatment for 18 days (51). Although the underlying mechanisms of NOSH compounds have not well understood yet, it is highly likely that they may include the aforementioned mechanisms of HS-NSAIDs and also the interaction between $\mathrm{NO}$ and $\mathrm{H}_{2} \mathrm{~S}$, which needs to be tested in the future.

\section{The therapeutic potential of $\mathrm{H}_{2} \mathrm{~S}$ donation for cisplatin nephrotoxicity}

Cisplatin is a widely used chemotherapeutic drug for cancer treatment (335). Due to the remarkable ability to treat various forms of cancers, it has gained the reputation as "the penicillin of cancer" (320). However, its effective usage for cancer therapy has been largely limited because of numerous 
adverse effects (81). Among these adverse effects, nephrotoxicity is the most prevalent one as evidence shows that more than $30 \%$ of patients show symptoms of acute kidney injury after the administration of cisplatin (239). This causes either discontinuation of treatment or severe renal damage. After years of efforts, some success has been made to curtail cisplatin nephrotoxicity. For instance, hydration of patients during cisplatin administration appears to reduce the occurrence after renal dysfunction $(11,57)$. Despite this, cisplatin nephrotoxicity remains a crucial factor compromising the use and efficacy of cisplatin in the therapy of cancer.

Very different from traditional chemotherapeutic drugs, $\mathrm{H}_{2} \mathrm{~S}$ exhibits both cell protective effects and anti-cancer effects. Interestingly, $\mathrm{H}_{2} \mathrm{~S}$ donation with GYY4137 inhibits cancer cell growth at doses that exhibit protective effects against oxidative stress and/or inflammation-induced cell injuries $(57,150,155,304)$. Therefore, we proposed that $\mathrm{H}_{2} \mathrm{~S}$ donation may be a promising strategy for the treatment of cisplain nephrotoxicity, which is mainly caused by oxidative stress and inflammation in renal proximal tubule cells (8, 217). By this strategy, we speculate that $\mathrm{H}_{2} \mathrm{~S}$ donation may alleviate cisplatin caused renal toxicity and add on more anticancer activity when combining with cisplatin in cancer cells. This hypothesis is partially supported by recent proofof-concept studies that $\mathrm{NaSH}$ attenuates cisplatin caused renal toxicity in rat models $(3,67)$ whereas whether $\mathrm{NaSH}$ influences the anti-cancer activity of cisplatin is not studied.

However, a recent report from Liu et al. somewhat disfavors the hypothesis because they have shown that $\mathrm{H}_{2} \mathrm{~S}$ slowreleasing donor GYY4137 aggravates cisplatin-induced renal damage by increasing inflammatory response (167). But several defects in using GYY4137 can be identified after clear examination of the study, such as (i) GYY4137 is prepared and stored in dimethyl sulfoxide, which has been shown to be detrimental and to accelerate GYY4137 decomposition $(162,178,179)$; (ii) the study used a rather low dose of GYY4137 $(21 \mathrm{mg} / \mathrm{kg})$. It is likely that $\mathrm{H}_{2} \mathrm{~S}$ might be not provided adequately considering the releasing property of $\mathrm{H}_{2} \mathrm{~S}$ by the compound $(178,179)$; (iii) the chemical analogue of GYY4137, ZYJ1122 (150), was not used in the study, thus the possibility that the chemical backbone of GYY4137 molecule aggravated cisplatin nephrotoxicity cannot be ruled out, particularly at such a low concentration of generated $\mathrm{H}_{2} \mathrm{~S}$. As such, further studies are warranted to unclose the effects of $\mathrm{H}_{2} \mathrm{~S}$ slowly releasing compounds such as GYY4137 on both cisplatin caused renal toxicity and the anti-cancer activity of cisplatin.

Besides, as discussed earlier, the recently developed $\mathrm{H}_{2} \mathrm{~S}$ releasing hybrids such as $\mathrm{H}_{2} \mathrm{~S}$-NSAIDs and NOSH-NSAIDs possess similar effects to those of $\mathrm{H}_{2} \mathrm{~S}$ slowly releasing compounds but with greater potency not only in cellular protection but also in cancer inhibition. Therefore, they may have promising potential in the treatment of cisplatin nephrotoxicity while without influencing its anti-cancer activity even if not potentiating it.

\section{The Novelty and Challenges of $\mathrm{H}_{2} \mathrm{~S}$-Based Cancer Therapy}

\section{A. The novelty of $\mathrm{H}_{2} \mathrm{~S}$-based cancer therapy}

Cancer is one of the main threats to human beings and tremendous efforts have been invested in the treatment of this devastating disease. Traditionally, the discovery of anticancer drugs was led by the identification of cytotoxic compounds. For several decades, these drugs similar to alkylating agents and nitrogen mustard have shown effectiveness against various types of tumors. However, they also induce severe adverse effects because they can hardly discriminate cancer cells and normal cells.

The recent advances in molecular sciences and genomics have recognized the genetic basis of tumorigenesis and generated potential new targets. This has led to a change in the paradigm of anticancer drug discovery toward molecularly targeted therapy (27). The paradigm shows success as indicated by the emergence of molecular targeted drugs, including imatinib, gefitinib, and bortezomib. However, several limitations appear in recent years, such as (i) cancer cells can develop resistance to these drugs; (ii) the treatment can be lost as sometimes the target changes; (iii) drugs may be difficult to be developed for some targets; (iv) one drug can hardly abolish tumor growth due to the heterogenecity of tumor populations; and (v) the drug may be not able to adequately penetrate into solid tumors. This is well reflected by the emergence of a changing paradigm by targeting multiple targets using either drug cocktails or multiple-targeted drugs, particularly for complex diseases such as cancer, diabetes, acquired immune deficiency syndrome, etc. $(58,288)$.

$\mathrm{H}_{2} \mathrm{~S}$ is a potential therapeutic agent with multiple biological targets with unique properties. In contrast to toxic chemotherapeutic drugs, $\mathrm{H}_{2} \mathrm{~S}$ possesses protective effects in multiple organs even in the doses that are able to inhibit tumor growth as shown with the slowly releasing donor GYY4137 (27, 161, 178, 179). Thus, it is likely that the existence of $\mathrm{H}_{2} \mathrm{~S}$ is critical for the maintenance of cellular homeostasis, including both normal cells and cancer cells. This is supported by the evidence that $\mathrm{H}_{2} \mathrm{~S}$ is essential to regulate the homeostasis of redox (322) and thiols (91). Thus, modulation of $\mathrm{H}_{2} \mathrm{~S}$ may disrupt the cellular homeostasis of cancer as a whole, thereby leading to subsequent death. Perhaps due to this, $\mathrm{H}_{2} \mathrm{~S}$-based therapy has been demonstrated to be effective in multiple cancer types $(91,149,150)$.

Importantly, the distinct level of endogenous $\mathrm{H}_{2} \mathrm{~S}$ in cancerous and non-cancerous cells and some other reasons might afford them the different tolerances to $\mathrm{H}_{2} \mathrm{~S}$ supplementation or $\mathrm{H}_{2} \mathrm{~S}$ inhibition. This has been indicated by the demonstrated therapeutic window of the $\mathrm{H}_{2} \mathrm{~S}$-based approach for cancer therapy $(149,150)$. In addition, $\mathrm{H}_{2} \mathrm{~S}$ is a small lipophilic molecule that allows it to freely penetrate into the cell membrane of all types and become biologically active (37). This may at least have two implications: (i) $\mathrm{H}_{2} \mathrm{~S}$ may have a significant influence on the tumor microenvironment, which has shown to be important for tumor progression (283); (ii) it may be able to readily infiltrate into solid tumors. Compared with molecularly targeted therapy, $\mathrm{H}_{2} \mathrm{~S}$ is shown to affect multiple targets in cancer cells and as a result may overcome the limitations of molecular targeted drugs mentioned earlier. Therefore, although still in its infancy, $\mathrm{H}_{2} \mathrm{~S}$ based therapy may represent a novel and unique strategy for cancer treatment.

\section{B. The challenges of $\mathrm{H}_{2} \mathrm{~S}$-based cancer therapy}

Despite the earlier mentioned merits, successful translation of $\mathrm{H}_{2} \mathrm{~S}$ as a therapeutic agent still faces great challenges, 
particularly for cancer therapy. It is no doubt that $\mathrm{H}_{2} \mathrm{~S}$-related toxicity is always the first obstacle in the development of $\mathrm{H}_{2} \mathrm{~S}$-based drugs. Notably, promising progress has been made in the field as clearly seen from the successful transition of $\mathrm{H}_{2} \mathrm{~S}$ donors such as SG-1002 and ABT-346 from phase I into phase II clinical trials (292). However, to achieve the cancer killing effect, higher doses of $\mathrm{H}_{2} \mathrm{~S}$ donors are expected compared with those for other indications such as heart failure and inflammatory diseases. This may narrow the therapeutic window of these $\mathrm{H}_{2} \mathrm{~S}$ donors in the context of cancer therapy, which could be an impediment for their further development.

In addition, most studies, particularly those done with $\mathrm{H}_{2} \mathrm{~S}$ acute releaser $\mathrm{NaSH}$ or $\mathrm{Na}_{2} \mathrm{~S}$, seemed to neglect the toxic effect of these compounds themselves and failed to include normal cells to profile the therapeutic window of $\mathrm{H}_{2} \mathrm{~S}$ donors when studying their anti-cancer activities $(103,317,318$, $330,338)$. Therefore, the demonstration of whether and how $\mathrm{H}_{2} \mathrm{~S}$ discriminates cancer cells and normal cells will surely encourage the enthusiasm to develop $\mathrm{H}_{2} \mathrm{~S}$ donors for cancer therapy.

\section{Future Directions}

\section{A. Relationship between $\mathrm{H}_{2} \mathrm{~S}$ level and cancer progression}

Although evidence suggests the implication of $\mathrm{H}_{2} \mathrm{~S}$ in cancer development, a clear relationship between $\mathrm{H}_{2} \mathrm{~S}$ level and cancer progression remains lacking. For instance, no reports have shown the level of $\mathrm{H}_{2} \mathrm{~S}$ in the plasma or tumor microenvironment in cancer patients compared with normal subjects till now. Moreover, most studies have ignored the fact that modulation of $\mathrm{H}_{2} \mathrm{~S}$-producing enzymes can alter not only the level of $\mathrm{H}_{2} \mathrm{~S}$ but also other byproducts such as pyruvate, glutathione, and L-homocysteine (169). The possibility that the altered levels of these byproducts have influenced the cell viability of cancer cells has not been excluded in previous studies. In addition, the levels of $\mathrm{H}_{2} \mathrm{~S}$ have not been measured on modulation of $\mathrm{H}_{2} \mathrm{~S}$-producing enzymes as well as in most studies. Therefore, a clear relationship between $\mathrm{H}_{2} \mathrm{~S}$ level and cancer progression may be beneficial to decipher the role of $\mathrm{H}_{2} \mathrm{~S}$ in cancer development, thereby helping develop better $\mathrm{H}_{2} \mathrm{~S}$-based small molecules for cancer therapy.

\section{B. Test of drug-like $\mathrm{H}_{2} \mathrm{~S}$ donors in cancer}

$\mathrm{H}_{2} \mathrm{~S}$ donors such as GYY4137 and SPRC have shown promising anti-tumor effects. However, their marginal potency and as-yet-unknown human toxicity may hinder their use as anti-cancer agents in humans. Recently, a batch of drug-like $\mathrm{H}_{2} \mathrm{~S}$ donors have been developed and tested to be safe in clinical trials. Among them, an orally active $\mathrm{H}_{2} \mathrm{~S}$ donor SG-1002 is undergoing Phase II study for heart failure; ATB-346 is being tested for osteoarthritis; ATB-352 is under the investigation for acute pain; and ATB-350 is being evaluated for thrombosis (292). It is worth mentioning that SG-1002 has been demonstrated to be safe and produced a sustained increase in both plasma $\mathrm{H}_{2} \mathrm{~S}$ and plasma NO levels in humans (230). Interestingly, a promising outcome has been observed for some pediatric cancer patients as described in the patent (patent number: US8771755B2). The detailed information of such $\mathrm{H}_{2} \mathrm{~S}$ donors can be found in Wallace and Wang's recent review (292). Testing of these drug-like $\mathrm{H}_{2} \mathrm{~S}$ donors will not only consolidate the anti-cancer effect of $\mathrm{H}_{2} \mathrm{~S}$ donation but also shed light on the translation of $\mathrm{H}_{2} \mathrm{~S}$ as a therapeutic agent for human cancers.

\section{Understand the molecular mechanisms underlying $\mathrm{H}_{2} \mathrm{~S}$ effects}

$\mathrm{H}_{2} \mathrm{~S}$ elicits most of its biological effects by induction of protein persulfidation. Among these target proteins, NF- $\kappa \mathrm{B}$ and Keap1/Nrf2 are closely related to cancer progression. Interestingly, endogenous $\mathrm{H}_{2} \mathrm{~S}$ or $\mathrm{H}_{2} \mathrm{~S}$ at low levels has been found to stimulate the translocation of p65/p50 into the nucleus (245) whereas high levels of $\mathrm{H}_{2} \mathrm{~S}$ apparently inhibit the activity of $\mathrm{NF}-\kappa \mathrm{B}$, particularly at inflammatory conditions $(92,309)$. This may partially explain the dual role of $\mathrm{H}_{2} \mathrm{~S}$ in cancer development. The revelation and in-depth depiction about the interaction between $\mathrm{H}_{2} \mathrm{~S}$ and its target proteins will surely facilitate our understanding on the role of $\mathrm{H}_{2} \mathrm{~S}$ in cancer biology. On the other hand, protein cysteine persulfides may be generated by CSE in an $\mathrm{H}_{2} \mathrm{~S}$-independent manner (112), implying that CSE may modulate cancer cell survival even in the absence of changes of $\mathrm{H}_{2} \mathrm{~S}$ levels in cancer cells.

\section{Confirm $\mathrm{H}_{2} \mathrm{~S}$-linked persulfidation of target proteins}

As reviewed earlier, several target proteins have been identified to be persulfidated and, therefore, take part in cancer development. However, the reliability of the most commonly method for the identification, namely the biotin switch assay was recently questioned because it seems that the thiol-blocking reagent $S$-methyl methanethiosulfonate used in the method would not differentiate free thiols and persulfides (78). Therefore, further studies are warranted to confirm $\mathrm{H}_{2} \mathrm{~S}$-linked persulfidation of target proteins by employing a more reliable method. Recently, two other persulfide detection methods, namely tag switch assay and protein persulfide detection protocol (ProPerDP) were developed by Xian and collegues (337) and Nagy and colleagues (66), respectively. Significantly, the ProPerDP method is to date the only method alkylating sulfhydral group before cell lysis that potentially avoids artificial redox post-translational modifications, including persulfidation, during lysing cells (66), representing a huge merit of this method.

\section{E. Crosstalk of $\mathrm{H}_{2} \mathrm{~S}$ with $\mathrm{NO}$ in cancer}

For a long period, $\mathrm{H}_{2} \mathrm{~S}$ and $\mathrm{NO}$ signaling pathways have been observed to be intimately intertwined with mutual potentiation of responses, particularly in the cardiovascular system (198). However, the crosstalk between these two gaseous transmitters remains largely unexplored in the context of cancer biology. An article from Cortese-Krott et al. has recently identified the key bioactive reaction products of $\mathrm{NO} / \mathrm{H}_{2} \mathrm{~S}$ interaction to be $\mathrm{S} / \mathrm{N}$-hybrid species, inorganic polysulfides, and nitroxyl in physiological conditions (59). Intriguingly, all these species have been shown to possess anti-tumor effects by previous studies $(46,51,255 \mathrm{a})$, indicating the potential of the crosstalk between the two gaseous transmitters in cancer biology. However, the validation of such interaction is rarely studied in the field of cancer biology. It is expected that an indepth understanding of such interaction may not only facilitate our understanding on tumorigenesis but also lead to novel strategies for cancer treatment. 


\section{F. Inorganic polysulfide accounts for the anti-cancer effect of $\mathrm{H}_{2} \mathrm{~S}$ ?}

$\mathrm{H}_{2} \mathrm{~S}$ is a very short-lived molecule; however, numerous studies have shown the long-lasting biological effects of $\mathrm{H}_{2} \mathrm{~S}$ in mammalian systems. Therefore, it is reasonable to speculate whether the formation of certain more stable substance(s) accounts for $\mathrm{H}_{2} \mathrm{~S}$-derived effects. Kimura and colleagues have recently identified inorganic polysulfides in the solution of $\mathrm{NaSH}$ (114). Intriguingly, compared with $\mathrm{NaSH}$, the polysufides $\left(\mathrm{Na}_{2} \mathrm{~S}_{2}, \mathrm{Na}_{2} \mathrm{~S}_{3}\right.$, and $\left.\mathrm{Na}_{2} \mathrm{~S}_{4}\right)$ elicit much stronger effects on the activation of TRPA1 in rat astrocytes (214) and activation of Keap1/Nrf2 in neuronal cells (40, 214). The existence of endogenous inorganic polysulfides has also been demonstrated by the group (136). Moreover, garlic-derived polysufides have long been well known to possess anti-tumor effects (192). Therefore, it will be of great value to evaluate whether inorganic polysulfides are the active molecules derived from $\mathrm{H}_{2} \mathrm{~S}$ and display the antitumor effect.

\section{G. A new regulatory circuit of thioredoxin and $\mathrm{H}_{2} \mathrm{~S}$ by controlling persulfidation in cancer?}

Thioredoxin, a small redox-regulating protein, has been found to be highly expressed in multiple cancers and plays important roles in cancer cell survival (126). Notably, two separate studies recently showed that thioredoxin acts as depersulfidase and, therefore, may control $\mathrm{H}_{2} \mathrm{~S}$ signaling by reducing protein persulfidation and regenerating $\mathrm{H}_{2} \mathrm{~S}(66$, 302). Interestingly, $\mathrm{H}_{2} \mathrm{~S}$ was known to upregulate the expression of thioredoxin by activating the Keap 1-Nrf2 pathway (38). Moreover, the fourth interaction mediated by $\mathrm{H}_{2} \mathrm{~S}$ was shown to reduce the disulfide bonds of proteins (220, 289 ), coincidently, an event leading to thioredoxin activation (126), suggesting a possibility of direct interaction between $\mathrm{H}_{2} \mathrm{~S}$ and thioredoxin. Altogether, this evidence implies a likelihood that thioredoxin and $\mathrm{H}_{2} \mathrm{~S}$ may work coordinately to control persulfidation in cancer cells and therefore their survival and progression.

\section{H. $\mathrm{H}_{2} \mathrm{~S}$-mediated immune cell regulation in cancer progression and therapy}

The crosstalk between immune cells and cancer cells has gained great attention due to the impressive clinical benefits of restoration of tumor-suppressed immune function. Currently, it has been shown that $\mathrm{H}_{2} \mathrm{~S}$ can regulate the physiological function of immune cells. For example, Roberts and colleagues $(183,184)$ found that $\mathrm{H}_{2} \mathrm{~S}$ is an endogenous potentiator of $\mathrm{T}$ cell activation. Recently, Yang et al. (330) showed that $\mathrm{H}_{2} \mathrm{~S}$ deficiency by knocking out CBS led to systemic autoimmune disease due to regulatory $\mathrm{T}$ (Treg) cell deficiency, suggesting that $\mathrm{H}_{2} \mathrm{~S}$ takes part in the regulation of Treg-cell-associated immune homeostasis. Despite this, the studies of $\mathrm{H}_{2} \mathrm{~S}$-mediated immune cell regulation remain lacking in the context of cancer progression and therapy.

\section{Concluding Remarks}

On recognition to be the third gaseous transmitter, the image of $\mathrm{H}_{2} \mathrm{~S}$ is expanding in mammalian systems. In the past decade, numerous studies demonstrated complicated roles of $\mathrm{H}_{2} \mathrm{~S}$ in the context of cancer development. Based on the published evidence, bell-shaped models have been proposed to explain the role of $\mathrm{H}_{2} \mathrm{~S}$ in cancer development. Specifically, endogenous $\mathrm{H}_{2} \mathrm{~S}$ or a relatively low level of exogenous $\mathrm{H}_{2} \mathrm{~S}$ may exhibit pro-cancer effects, whereas exposure to $\mathrm{H}_{2} \mathrm{~S}$ for long period or a high amount may lead to cancer cell death. However, one should bear in mind that the consequence of CSE or 3MST inhibition in cancer cell is still largely unexplored, which needs to be examined in the future. Nevertheless, the models, indeed, have been favored by most studies in the field.

Remarkably, $\mathrm{H}_{2} \mathrm{~S}$ is not alone in the regulation of cancer biology, because it intertwines with the other two gasotransmitters such as NO and CO. Better portrayal of the crosstalk among these gaseous transmitters may not only lead to an in-depth understanding of cancer progression but also shed light on novel strategies for cancer therapy. Recently, the developments of CBS inhibitors and $\mathrm{H}_{2} \mathrm{~S}$ donors have gained enthusiasm because of their potential value as novel anti-cancer therapeutics. More selective CBS inhibitors compared with traditionally used AOAA are now available and some of them have shown anti-tumor activity. Moreover, $\mathrm{H}_{2}$ S-releasing hybrids, especially HS-NSAIDs and HSNO compounds, have shown very promising anti-tumor activity with marginal toxicity, indicating their value for cancer therapy. Nonetheless, the development and application of $\mathrm{H}_{2} \mathrm{~S}$-based therapy for cancer treatment is still in its infancy. In the future, more studies are still warranted to identify $\mathrm{H}_{2} \mathrm{~S}$ targeted signaling molecules and develop better compounds with higher selectivity and potency.

\section{Acknowledgments}

This work was supported by Ministry of Education of Singapore Tier 2 Research grant (MOE2017-T2-2-029), NMRC (CIRG/1363/2013 and CIRG1432/2015), and Medical Research Council UK (MR/M022706/1).

\section{References}

1. Abe $\mathrm{K}$ and Kimura $\mathrm{H}$. The possible role of hydrogen sulfide as an endogenous neuromodulator. J Neurosci 16: 1066-1071, 1996.

2. Agrawal $\mathrm{N}$ and Banerjee R. Human polycomb 2 protein is a SUMO E3 ligase and alleviates substrate-induced inhibition of cystathionine $\beta$-synthase sumoylation. PloS One 3: e4032, 2008.

3. Ahangarpour A, Fard AA, Gharibnaseri MK, Jalali T, and Rashidi I. Hydrogen sulfide ameliorates the kidney dysfunction and damage in cisplatin-induced nephrotoxicity in rat. Veterinary Research Forum: An International Quarterly Journal. Urmia, Iran: Faculty of Veterinary Medicine, Urmia University, 2014, p. 121.

4. Akagi R. Purification and characterization of cysteine aminotransferase from rat liver cytosol. Acta Med Okayama 36: 187-197, 1982.

5. Alexander BE, Coles SJ, Fox BC, Khan TF, Maliszewski J, Perry A, Pitak MB, Whiteman M, and Wood ME. Investigating the generation of hydrogen sulfide from the phosphonamidodithioate slow-release donor GYY4137. MedChemComm 6: 1649-1655, 2015.

6. Almy L. A method for the estimation of hydrogen sulfide in proteinaceous food products. J Am Chem Soc 47: 13811390, 1925. 
7. Altaany Z, Ju Y, Yang G, and Wang R. The coordination of S-sulfhydration, S-nitrosylation, and phosphorylation of endothelial nitric oxide synthase by hydrogen sulfide. Sci Signal 7: ra87, 2014.

8. Arany I and Safirstein RL. Cisplatin nephrotoxicity. Semin Nephrol 23: 460-464, 2003.

9. Asimakopoulou A, Panopoulos P, Chasapis CT, Coletta C, Zhou Z, Cirino G, Giannis A, Szabo C, Spyroulias GA, and Papapetropoulos A. Selectivity of commonly used pharmacological inhibitors for cystathionine $\beta$ synthase (CBS) and cystathionine $\gamma$ lyase (CSE). Br J Pharmacol 169: 922-932, 2013.

10. Attene-Ramos MS, Wagner ED, Gaskins HR, and Plewa MJ. Hydrogen sulfide induces direct radical-associated DNA damage. Mol Cancer Res 5: 455-459, 2007.

11. Bajorin DF, Bosl GJ, Alcock NW, Niedzwiecki D, Gallina E, and Shurgot B. Pharmacokinetics of cis-diamminedi chloroplatinum (II) after administration in hypertonic saline. Cancer Res 46: 5969-5972, 1986.

12. Barsegian A, Chattopadhyay M, Kodela R, Boring D, Crowell JA, and Kashfi K. Hydrogen sulfide-releasing aspirin suppresses $\mathrm{NF}-\kappa \mathrm{B}$ signaling in estrogen receptor negative breast cancer cells in vitro and in vivo. Cancer Res 71(8 Suppl):1349, 2011.

13. Bartholomew TC, Powell GM, Dodgson KS, and Curtis CG. Oxidation of sodium sulphide by rat liver, lungs and kidney. Biochem Pharmacol 29: 2431-2437, 1980.

14. Bartkova J, Horejsí Z, Koed K, and Dramer A. DNA damage response as a candidate anti-cancer barrier in early human tumorigenesis. Nature 434: 864, 2005.

15. Baskar R and Bian J. Hydrogen sulfide gas has cell growth regulatory role. Eur J Pharmacol 656: 5-9, 2011.

16. Bass SE, Sienkiewicz P, MacDonald CJ, Cheng RY, Sparatore A, Del Soldato P, Roberts DD, Moody TW, Wink DA, and Yeh GC. Novel dithiolethione-modified nonsteroidal anti-inflammatory drugs in human hepatoma HepG2 and colon LS180 cells. Clin Cancer Res 15: 1964 1972, 2009.

17. Bat-Chen W, Golan T, Peri I, Ludmer Z, and Schwartz B. Allicin purified from fresh garlic cloves induces apoptosis in colon cancer cells via Nrf2. Nutr Cancer 62: 947-957, 2010.

18. Beauchamp RO, Jr., Bus JS, Popp JA, Boreiko CJ, and Andjelkovich DA. A critical review of the literature on hydrogen sulfide toxicity. Crit Rev Toxicol 13: 25-97, 1984.

19. Beg AA and Baltimore D. An essential role for NF-kB in preventing TNF-a-induced cell death. Science 274: 782784, 1996.

20. Beg AA, William CS, Bronson RT, Ghosh S, and Baltimore D. Embryonic lethality and liver degeneration in mice lacking the ReIA component of NF-kappaB. Nature 376: 167, 1995.

21. Bełtowski J. Hypoxia in the renal medulla: implications for hydrogen sulfide signaling. J Pharmacol Exp Ther 334: 358-363, 2010.

22. Benavides GA, Squadrito GL, Mills RW, Patel HD, Isbell TS, Patel RP, Darley-Usmar VM, Doeller JE, and Kraus DW. Hydrogen sulfide mediates the vasoactivity of garlic. Proc Natl Acad Sci U S A 104: 17977-17982, 2007.

23. Bertout JA, Patel SA, and Simon MC. The impact of $\mathrm{O}_{2}$ availability on human cancer. Nat Rev Cancer 8: 967, 2008.

24. Bhattacharyya S, Saha S, Giri K, Lanza IR, Nair KS, Jennings NB, Rodriguez-Aguayo C, Lopez-Berestein G,
Basal E, and Weaver AL. Cystathionine beta-synthase (CBS) contributes to advanced ovarian cancer progression and drug resistance. PLoS One 8: e79167, 2013.

25. Bir SC, Kolluru GK, McCarthy P, Shen X, Pardue S, Pattillo CB, and Kevil CG. Hydrogen sulfide stimulates ischemic vascular remodeling through nitric oxide synthase and nitrite reduction activity regulating hypoxia-inducible factor- $1 \alpha$ and vascular endothelial growth factor-dependent angiogenesis. J Am Heart Assoc 1: e004093, 2012.

26. Bostelaar T, Vitvitsky V, Kumutima J, Lewis BE, Yadav PK, Brunold TC, Filipovic M, Lehnert N, Stemmler TL, and Banerjee R. Hydrogen sulfide oxidation by myoglobin. J Am Chem Soc 138: 8476-8488, 2016.

27. Boyd MR and Paull KD. Some practical considerations and applications of the National Cancer Institute in vitro anticancer drug discovery screen. Drug Dev Res 34: 91109, 1995.

28. Braunstein A, Goryachenkova E, and Lac ND. Reactions catalysed by serine sulfhydrase from chicken liver. Biochim Biophys Acta 171: 366-368, 1969.

29. Braunstein A, Goryachenkova E, Tolosa E, Willhardt I, and Yefremova L. Specificity and some other properties of liver serine sulphhydrase: evidence for its identity with cystathionine $\beta$-synthase. Biochim Biophys Acta 242: 247-260, 1971.

30. Bryant M, Campbell LL, Reddy C, and Crabill M. Growth of desulfovibrio in lactate or ethanol media low in sulfate in association with $\mathrm{H}_{2}$-utilizing methanogenic bacteria. Appl Environ Microbiol 33: 1162-1169, 1977.

31. Cai WJ, Wang MJ, Moore PK, Jin HM, Yao T, and Zhu YC. The novel proangiogenic effect of hydrogen sulfide is dependent on Akt phosphorylation. Cardiovasc Res 76: 29-40, 2007.

32. Cai WJ, Wang MJ, Ju LH, Wang C, and Zhu YC. Hydrogen sulfide induces human colon cancer cell proliferation: role of Akt, ERK and p21. Cell Biol Int 34: 565-572, 2010.

33. Calabrese EJ, Dhawan G, Kapoor R, Iavicoli I, and Calabrese V. HORMESIS: a fundamental concept with widespread biological and biomedical applications. Gerontology 62: 530-535, 2016.

34. Calabrese V, Cornelius C, Dinkova-Kostova AT, Calabrese EJ, and Mattson MP. Cellular stress responses, the hormesis paradigm, and vitagenes: novel targets for therapeutic intervention in neurodegenerative disorders. Antioxid Redox Signal 13: 1763-1811, 2010.

35. Calabrese V, Giordano J, Signorile A, Laura Ontario M, Castorina S, De Pasquale C, Eckert G, and Calabrese EJ. Major pathogenic mechanisms in vascular dementia: roles of cellular stress response and hormesis in neuroprotection. J Neurosci Res 94: 1588-1603, 2016.

36. Calvert JW, Coetzee WA, and Lefer DJ. Novel insights into hydrogen sulfide-mediated cytoprotection. Antioxid Redox Signal 12: 1203-1217, 2010.

37. Cao X and Bian JS. The role of hydrogen sulfide in renal system. Front Pharmacol 7: 385, 2016.

38. Cao X, Cao L, Ding L, and Bian JS. A new hope for a devastating disease: hydrogen sulfide in Parkinson's disease. Mol Neurobiol 55: 3789-3799, 2018.

39. Cao X, Kong CM, Mathi KM, Lim YP, Cacheux-Rataboul $\mathrm{V}$, and Wang $\mathrm{X}$. The use of transformed IMR90 cell model to identify the potential extra-telomeric effects of hTERT in cell migration and DNA damage response. BMC Biochem 15: 17, 2014. 
40. Cao X, Nie X, Xiong S, Cao L, Wu Z, Moore PK, and Bian JS. Renal protective effect of polysulfide in cisplatininduced nephrotoxicity. Redox Biol 15: 513-521, 2018.

41. Cao X, Wu Z, Xiong S, Cao L, Sethi G, and Bian JS. The role of hydrogen sulfide in cyclic nucleotide signaling. Biochem Pharmacol 149: 20-28, 2018.

42. Cao X, Xiong S, Zhou Y, Wu ZY, Ding 1, Zhu Y, Wood M, Whiteman M, Moore PK, and Bian JS. Renal protective effect of hydrogen sulfide in cisplatin-induced nephrotoxicity. Antioxid Redox Signal 29: 455-470, 2018.

43. Carballal S, Trujillo M, Cuevasanta E, Bartesaghi S, Moller MN, Folkes LK, Garcia-Bereguiain MA, Gutierrez-Merino C, Wardman P, Denicola A, Radi R, and Alvarez B. Reactivity of hydrogen sulfide with peroxynitrite and other oxidants of biological interest. Free Radic Biol Med 50: 196-205, 2011.

44. Carmeliet $\mathrm{P}$ and Jain RK. Molecular mechanisms and clinical applications of angiogenesis. Nature 473: 298, 2011.

45. Cerda-Colón JF, Silfa E, and López-Garriga J. Unusual rocking freedom of the heme in the hydrogen sulfidebinding hemoglobin from Lucina pectinata. J Am Chem Soc 120: 9312-9317, 1998.

46. Cerella C, Dicato M, Jacob C, and Diederich M. Chemical properties and mechanisms determining the anti-cancer action of garlic-derived organic sulfur compounds. AntiCancer Agents Med Chem 11, 267-271, 2011.

47. Chakraborty PK, Xiong X, Mustafi SB, Saha S, Dhanasekaran D, Mandal NA, McMeekin S, Bhattacharya R, and Mukherjee P. Role of cystathionine beta synthase in lipid metabolism in ovarian cancer. Oncotarget 6: 37367 , 2015.

48. Chao C, Zatarain JR, Ding Y, Coletta C, Mrazek AA, Druzhyna N, Johnson P, Chen H, Hellmich JL, Asimakopoulou A, Yanagi K, Olah G, Szoleczky P, Törö G, Bohanon FJ, Cheema M, Lewis R, Eckelbarger D, Ahmad A, Módis, K, Unterreiner A, Szczesny B, Papapetropoulos A, Zhou J, Hellmich MR, and Szabo C. Cystathionine- $\beta$-synthase inhibition for colon cancer: enhancement of the efficacy of aminooxyacetic acid via the prodrug approach. Mol Med 22: 361, 2016.

49. Chattopadhyay M, Kodela R, Nath N, Barsegian A, Boring $\mathrm{D}$, and Kashfi K. Hydrogen sulfide-releasing aspirin suppresses $\mathrm{NF}-\kappa \mathrm{B}$ signaling in estrogen receptor negative breast cancer cells in vitro and in vivo. Biochem Pharmacol 83: 723-732, 2012.

50. Chattopadhyay M, Kodela R, Nath N, Dastagirzada YM, Velázquez-Martínez CA, Boring D, and Kashfi K. Hydrogen sulfide-releasing NSAIDs inhibit the growth of human cancer cells: a general property and evidence of a tissue type-independent effect. Biochem Pharmacol 83: 715-722, 2012.

51. Chattopadhyay M, Kodela R, Olson KR, and Kashfi K. NOSH-aspirin (NBS-1120), a novel nitric oxide-and hydrogen sulfide-releasing hybrid is a potent inhibitor of colon cancer cell growth in vitro and in a xenograft mouse model. Biochem Biophys Res Commun 419: 523528, 2012.

52. Chattopadhyay M, Nath N, Kodela R, Sobocki T, Metkar S, Gan ZY, and Kashfi K. Hydrogen sulfide-releasing aspirin inhibits the growth of leukemic Jurkat cells and modulates $\beta$-catenin expression. Leuk Res 37: 1302-1308, 2013.
53. Chiku T, Padovani D, Zhu W, Singh S, Vitvitsky V, and Banerjee $\mathrm{R}_{2} \mathrm{H}_{2} \mathrm{~S}$ biogenesis by human cystathionine $\gamma$-lyase leads to the novel sulfur metabolites lanthionine and homolanthionine and is responsive to the grade of hyperhomocysteinemia. J Biol Chem 284: 11601-11612, 2009.

54. Circu ML and Aw TY. Reactive oxygen species, cellular redox systems, and apoptosis. Free Radic Biol Med 48: 749-762, 2010.

55. Coletta C, Papapetropoulos A, Erdelyi K, Olah G, Módis K, Panopoulos P, Asimakopoulou A, Gerö D, Sharina I, and Martin E. Hydrogen sulfide and nitric oxide are mutually dependent in the regulation of angiogenesis and endothelium-dependent vasorelaxation. Proc Natl Acad Sci U S A 109: 9161-9166, 2012.

56. Cooper CE and Brown GC. The inhibition of mitochondrial cytochrome oxidase by the gases carbon monoxide, nitric oxide, hydrogen cyanide and hydrogen sulfide: chemical mechanism and physiological significance. $J$ Bioenerg Biomembr 40: 533, 2008.

57. Cornelison TL and Reed E. Nephrotoxicity and hydration management for cisplatin, carboplatin, and ormaplatin. Gynecol Oncol 50: 147-158, 1993.

58. Cornell S. Differentiating among incretin therapies: a multiple-target approach to type 2 diabetes. J Clin Pharm Ther 37: 510-524, 2012.

59. Cortese-Krott MM, Kuhnle GG, Dyson A, Fernandez BO, Grman M, DuMond JF, Barrow MP, McLeod G, Nakagawa H, Ondrias K, Nagy P, King SB, Saavedra JE, Keefer LK, Singer M, Butler AR, and Feelisch M. Key bioactive reaction products of the $\mathrm{NO} / \mathrm{H}_{2} \mathrm{~S}$ interaction are S/N-hybrid species, polysulfides, and nitroxyl. Proc Natl Acad Sci U S A 112: E4651-E4660, 2015.

60. Cotter TG. Apoptosis and cancer: the genesis of a research field. Nat Rev Cancer 9: 501, 2009.

61. DeLeon ER, Gao Y, Huang E, and Olson KR. Garlic oil polysulfides $\mathrm{H}_{2} \mathrm{~S}$ - and $\mathrm{O}_{2}$-independent prooxidants in buffer and antioxidants in cells. Am J Physiol Regul Integr Comp Physiol 310: R1212-R1225, 2016.

62. DeLeon ER, Stoy GF, and Olson KR. Passive loss of hydrogen sulfide in biological experiments. Anal Biochem 421: 203-207, 2012.

63. Deplancke B and Gaskins HR. Hydrogen sulfide induces serum-independent cell cycle entry in nontransformed rat intestinal epithelial cells. FASEB J 17: 1310-1312, 2003.

64. Distrutti E, Sediari L, Mencarelli A, Renga B, Orlandi S, Antonelli E, Roviezzo F, Morelli A, Cirino G, Wallace JL, and Fiorucci S. Evidence that hydrogen sulfide exerts antinociceptive effects in the gastrointestinal tract by activating KATP channels. J Pharmacol Exp Ther 316: 325335, 2006.

65. Doeller JE, Isbell TS, Benavides G, Koenitzer J, Patel H, Patel RP, Lancaster JR, Darley-Usmar VM, and Kraus DW. Polarographic measurement of hydrogen sulfide production and consumption by mammalian tissues. Anal Biochem 341: 40-51, 2005.

66. Doka E, Pader I, Biro A, Johansson K, Cheng Q, Ballago K, Prigge JR, Pastor-Flores D, Dick TP, Schmidt EE, Arner ES, and Nagy P. A novel persulfide detection method reveals protein persulfide- and polysulfide-reducing functions of thioredoxin and glutathione systems. Sci Adv 2: e1500968, 2016.

67. Dugbartey GJ, Bouma HR, Lobb I, and Sener A. Hydrogen sulfide: a novel nephroprotectant against cisplatininduced renal toxicity. Nitric Oxide 57: 15-20, 2016. 
68. This reference has been deleted.

69. Eberhardt M, Dux M, Namer B, Miljkovic J, Cordasic N, Will C, Kichko TI, De La Roche J, Fischer M, and Suárez SA. $\mathrm{H}_{2} \mathrm{~S}$ and $\mathrm{NO}$ cooperatively regulate vascular tone by activating a neuroendocrine HNO-TRPA1-CGRP signalling pathway. Nat Commun 5: 4381, 2014.

70. Elsey DJ, Fowkes RC, and Baxter GF. Regulation of cardiovascular cell function by hydrogen sulfide $\mathrm{H}_{2} \mathrm{~S}$. Cell Biochem Funct 28: 95-106, 2010.

71. Erickson PF, Maxwell IH, Su LJ, Baumann M, and Glode LM. Sequence of cDNA for rat cystathionine gammalyase and comparison of deduced amino acid sequence with related Escherichia coli enzymes. Biochem J 269: 335-340, 1990.

72. Evan GI and Vousden KH. Proliferation, cell cycle and apoptosis in cancer. Nature 411: 342, 2001.

73. Faccenda A, Wang J, and Mutus B. Polydimethylsiloxane permeability-based method for the continuous and specific detection of hydrogen sulfide. Anal Chem 84: 52435249, 2012.

74. Fan K, Li N, Qi J, Yin P, Zhao C, Wang L, Li Z, and Zha $\mathrm{X}$. Wnt/ $\beta$-catenin signaling induces the transcription of cystathionine- $\gamma$-lyase, a stimulator of tumor in colon cancer. Cell Signal 26: 2801-2808, 2014.

75. Feng J, Weitner M, Shi W, Zhang S, Sullivan D, and Zhang Y. Identification of additional anti-persister activity against Borrelia burgdorferi from an FDA drug library. Antibiotics 4: 397-410, 2015.

76. Feng W, Teo XY, Novera W, Ramanujulu PM, Liang D, Huang D, Moore PK, Deng LW, and Dymock BW. Discovery of new $\mathrm{H}_{2} \mathrm{~S}$ releasing phosphordithioates and 2, 3dihydro-2-phenyl-2-sulfanylenebenzo [d][1, 3, 2] oxazaphospholes with improved antiproliferative activity. $J$ Med Chem 58: 6456-6480, 2015.

77. Feng X, Chen Y, Zhao J, Tang C, Jiang Z, and Geng B. Hydrogen sulfide from adipose tissue is a novel insulin resistance regulator. Biochem Biophys Res Commun 380: 153-159, 2009.

78. Filipovic MR. Persulfidation (S-sulfhydration) and $\mathrm{H}_{2} \mathrm{~S}$. In: Chemistry, Biochemistry and Pharmacology of Hydrogen Sulfide, edited by Moore PK, and Whiteman M. Berlin, Germany: Springer, 2015, pp. 29-59.

79. Filipovic MR, Zivanovic J, Alvarez B, and Banerjee R. Chemical biology of $\mathrm{H}_{2} \mathrm{~S}$ signaling through persulfidation. Chem Rev 118: 1253-1337, 2018.

80. Fischer E. Formation of methylene blue as a reaction of hydrogen sulfide [In German]. Eur J Inorg Chem 16: 2234-2236, 1883.

81. Florea AM and Büsselberg D. Cisplatin as an anti-tumor drug: cellular mechanisms of activity, drug resistance and induced side effects. Cancers (Basel) 3: 1351-1371, 2011.

82. Fu M, Zhang W, Wu L, Yang G, Li H, and Wang R. Hydrogen sulfide $\left(\mathrm{H}_{2} \mathrm{~S}\right)$ metabolism in mitochondria and its regulatory role in energy production. Proc Natl Acad Sci U S A 109: 2943-2948, 2012.

83. Fu Z, Liu X, Geng B, Fang L, and Tang C. Hydrogen sulfide protects rat lung from ischemia-reperfusion injury. Life Sci 82: 1196-1202, 2008.

84. Furne J, Saeed A, and Levitt MD. Whole tissue hydrogen sulfide concentrations are orders of magnitude lower than presently accepted values. Am J Physiol Regul Integr Comp Physiol 295: R1479-R1485, 2008.

85. Furne J, Springfield J, Koenig T, DeMaster E, and Levitt MD. Oxidation of hydrogen sulfide and methanethiol to thiosulfate by rat tissues: a specialized function of the colonic mucosa. Biochem Pharmacol 62: 255-259, 2001.

86. Gai JW, Qin W, Liu M, Wang HF, Zhang M, Li M, Zhou WH, Ma QT, Liu GM, and Song WH. Expression profile of hydrogen sulfide and its synthases correlates with tumor stage and grade in urothelial cell carcinoma of bladder. Urol Oncol 34: 166.e15-166.e20, 2016.

87. Gallegos-Arreola MP, Figuera-Villanueva LE, RamosSilva A, Salas-González E, Puebla-Pérez AM, PeraltaLeal V, García-Ortiz JE, Dávalos-Rodríguez IP, and Zúñiga-González GM. The association between the 844ins68 polymorphism in the CBS gene and breast cancer. Arch Med Sci 10: 1214, 2014.

88. Gan ZY, Chattopadhyay M, Kodela R, Boring D, Crowell JA, and Kashfi K. Hydrogen sulfide-releasing aspirin inhibits the growth of leukemic Jurkat cells and modulates $\beta$-catenin expression Cancer Res 71(8 Suppl): Abstract no. 4608, 2011.

89. Geng B, Yang J, Qi Y, Zhao J, Pang Y, Du J, and Tang C. $\mathrm{H}_{2} \mathrm{~S}$ generated by heart in rat and its effects on cardiac function. Biochem Biophys Res Commun 313: 362-368, 2004.

90. Gerweck LE and Seetharaman K. Cellular $\mathrm{pH}$ gradient in tumor versus normal tissue: potential exploitation for the treatment of cancer. Cancer Res 56: 1194-1198, 1996.

91. Giustarini D, Del Soldato P, Sparatore A, and Rossi R. Modulation of thiol homeostasis induced by $\mathrm{H}_{2} \mathrm{~S}$-releasing aspirin. Free Radic Biol Med 48: 1263-1272, 2010.

92. Gong QH, Wang Q, Pan LL, Liu XH, Xin H, and Zhu YZ. S-propargyl-cysteine, a novel hydrogen sulfide-modulated agent, attenuates lipopolysaccharide-induced spatial learning and memory impairment: involvement of TNF signaling and $\mathrm{NF}-\kappa \mathrm{B}$ pathway in rats. Brain Behav Immun 25: 110-119, 2011.

93. Goodwin LR, Francom D, Dieken FP, Taylor JD, Warenycia MW, Reiffenstein R, and Dowling G. Determination of sulfide in brain tissue by gas dialysis/ion chromatography: postmortem studies and two case reports. J Anal Toxicol 13: 105-109, 1989.

94. Goubern M, Andriamihaja M, Nübel T, Blachier F, and Bouillaud F. Sulfide, the first inorganic substrate for human cells. FASEB J 21: 1699-1706, 2007.

95. Guo H, Gai JW, Wang Y, Jin HF, Du JB, and Jin J. Characterization of hydrogen sulfide and its synthases, cystathionine $\beta$-synthase and cystathionine $\gamma$-lyase, in human prostatic tissue and cells. Urology 79: 483.e1-483.e5, 2012.

96. Guo Z, Chen G, Zeng G, Li Z, Chen A, Wang J, and Jiang L. Fluorescence chemosensors for hydrogen sulfide detection in biological systems. Analyst 140: 1772-1786, 2015.

97. Hanahan D and Weinberg RA. Hallmarks of cancer: the next generation. Cell 144: 646-674, 2011.

98. Hanif R, Pittas A, Feng Y, Koutsos MI, Qiao L, Staiano-Coico L, Shiff SI, and Rigas B. Effects of nonsteroidal antiinflammatory drugs on proliferation and on induction of apoptosis in colon cancer cells by a prostaglandin-independent pathway. Biochem Pharmacol 52: 237-245, 1996.

99. Hartle MD and Pluth MD. A practical guide to working with $\mathrm{H}_{2} \mathrm{~S}$ at the interface of chemistry and biology. Chem Soc Rev 45: 6108-6117, 2016.

100. Hartwell LH and Kastan MB. Cell cycle control and cancer. Science 266: 1821-1828, 1994.

101. He F, Cui X, and Ren J. A novel QCM-based biosensor for detection of microorganisms producing hydrogen sulfide. Anal Lett 41: 2697-2709, 2008. 
102. Hellmich MR, Coletta C, Chao C, and Szabo C. The therapeutic potential of cystathionine $\beta$-synthetase/hydrogen sulfide inhibition in cancer. Antioxid Redox Signal 22: 424448, 2015.

103. Hellmich MR and Szabo C. Hydrogen sulfide and cancer. Handb Exp Pharmacol 230: 233-241, 2015.

104. Höckel M, Schlenger K, Aral B, Mitze M, Schäffer U, and Vaupel P. Association between tumor hypoxia and malignant progression in advanced cancer of the uterine cervix. Cancer Res 56: 4509-4515, 1996.

105. Hockel M and Vaupel P. Tumor hypoxia: definitions and current clinical, biologic, and molecular aspects. J Natl Cancer Inst 93: 266-276, 2001.

106. Hoeijmakers JH. DNA damage, aging, and cancer. $N$ Engl J Med 361: 1475-1485, 2009.

107. Hosoki R, Matsuki N, and Kimura H. The possible role of hydrogen sulfide as an endogenous smooth muscle relaxant in synergy with nitric oxide. Biochem Biophys Res Commun 237: 527-531, 1997.

108. Howard EW, Ling MT, Chua CW, Cheung HW, Wang X, and Wong YC. Garlic-derived S-allylmercaptocysteine is a novel in vivo antimetastatic agent for androgenindependent prostate cancer. Clin Cancer Res 13: 18471856, 2007.

109. Hughes MN, Centelles MN, and Moore KP. Making and working with hydrogen sulfide: the chemistry and generation of hydrogen sulfide in vitro and its measurement in vivo: a review. Free Radic Biol Med 47: 13461353, 2009.

110. Hui Y, Du J, Tang C, Bin G, and Jiang H. Changes in arterial hydrogen sulfide (H $2 \mathrm{~S})$ content during septic shock and endotoxin shock in rats. $J$ Infect 47: 155-160, 2003.

111. Hulbert PB and Yakubu SI. Monobromobimane: a substrate for the fluorimetric assay of glutathione transferase. J Pharm Pharmacol 35: 384-386, 1983.

112. Ida T, Sawa T, Ihara H, Tsuchiya Y, Watanabe Y, Kumagai Y, Suematsu M, Motohashi H, Fujii S, and Matsunaga $\mathrm{T}$. Reactive cysteine persulfides and $\mathrm{S}$ polythiolation regulate oxidative stress and redox signaling. Proc Natl Acad Sci U S A 111: 7606-7611, 2014.

113. Insko MA, Deckwerth TL, Hill P, Toombs CF, and Szabo C. Detection of exhaled hydrogen sulphide gas in rats exposed to intravenous sodium sulphide. Br J Pharmacol 157: 944-951, 2009.

114. Ishigami M, Hiraki K, Umemura K, Ogasawara Y, Ishii $\mathrm{K}$, and Kimura $\mathrm{H}$. A source of hydrogen sulfide and a mechanism of its release in the brain. Antioxid Redox Signal 11: 205-214, 2009.

115. Jackson MR, Melideo SL, and Jorns MS. Human sulfide: quinone oxidoreductase catalyzes the first step in hydrogen sulfide metabolism and produces a sulfane sulfur metabolite. Biochemistry 51: 6804-6815, 2012.

116. Jackson MR, Melideo SL, and Jorns MS. Role of human sulfide: quinone oxidoreductase in $\mathrm{H}_{2} \mathrm{~S}$ metabolism. Methods Enzymol 554: 255-270, 2015.

117. Jacobs MB, Braverman $M$, and Hochheiser S. Ultramicrodetermination of sulfides in air. Anal Chem 29: 13491351, 1957.

118. Jhee KH and Kruger WD. The role of cystathionine $\beta$ synthase in homocysteine metabolism. Antioxid Redox Signal 7: 813-822, 2005.

119. Johansen D, Ytrehus K, and Baxter GF. Exogenous hydrogen sulfide $\left(\mathrm{H}_{2} \mathrm{~S}\right)$ protects against regional myocardial ischemia-reperfusion injury. Basic Res Cardiol 101: 5360, 2006.

120. Jurkowska H, Placha W, Nagahara N, and Wróbel M. The expression and activity of cystathionine- $\gamma$-lyase and 3mercaptopyruvate sulfurtransferase in human neoplastic cell lines. Amino Acids 41: 151-158, 2011.

121. Kabil $\mathrm{O}$ and Banerjee R. Redox biochemistry of hydrogen sulfide. J Biol Chem 285: 21903-21907, 2010.

122. Kabil O, Weeks CL, Carballal Sn, Gherasim C, Alvarez B, Spiro TG, and Banerjee R. Reversible heme-dependent regulation of human cystathionine $\beta$-synthase by a flavoprotein oxidoreductase. Biochemistry 50: 8261-8263, 2011.

123. Kaium M, Liu Y, Zhu Q, Liu Ch, Duan JL, Tan BK, and Zhu YZ. $\mathrm{H}_{2} \mathrm{~S}$ donor S-propargyl-cysteine, increases CSE in SGC-7901 and cancer-induced mice: evidence for a novel anti-cancer effect of endogenous $\mathrm{H}_{2} \mathrm{~S}$ ? PLoS One 6: e20525, 2011.

124. Kamoun P. Endogenous production of hydrogen sulfide in mammals. Amino Acids 26: 243-254, 2004.

125. Kaneko Y, Kimura Y, Kimura H, and Niki I. L-Cysteine inhibits insulin release from the pancreatic $\beta$-cell. Diabetes 55: 1391-1397, 2006.

126. Karlenius TC and Tonissen KF. Thioredoxin and cancer: a role for thioredoxin in all states of tumor oxygenation. Cancers (Basel) 2: 209-232, 2010.

127. Kashfi K. Anti-cancer activity of new designer hydrogen sulfide-donating hybrids. Antioxid Redox Signal 20: 831846, 2014.

128. Kashfi K and Olson KR. Biology and therapeutic potential of hydrogen sulfide and hydrogen sulfide-releasing chimeras. Biochem Pharmacol 85: 689-703, 2013.

129. Kayashima T, Mori M, Yoshida H, Mizushina Y, and Matsubara K. 1,4-Naphthoquinone is a potent inhibitor of human cancer cell growth and angiogenesis. Cancer Lett 278: 34-40, 2009.

130. Kensler TW and Wakabayashi N. Nrf2: friend or foe for chemoprevention? Carcinogenesis 31: 90-99, 2009.

131. Kida M, Sugiyama T, Yoshimoto T, and Ogawa Y. Hydrogen sulfide increases nitric oxide production with calcium-dependent activation of endothelial nitric oxide synthase in endothelial cells. Eur J Pharm Sci 48: 211215, 2013.

132. Kim J, Hong SJ, Park JH, Park SY, Kim SW, Cho EY, Do I-G, Joh J-W, and Kim DS. Expression of cystathionine $\beta$-synthase is downregulated in hepatocellular carcinoma and associated with poor prognosis. Oncol Rep 21: 1449-1454, 2009.

133. Kimura H. Hydrogen sulfide: from brain to gut. Antioxid Redox Signal 12: 1111-1123, 2010.

134. Kimura H. Hydrogen sulfide: its production, release and functions. Amino Acids 41: 113-121, 2011.

135. Kimura H, Shibuya N, and Kimura Y. Hydrogen sulfide is a signaling molecule and a cytoprotectant. Antioxid Redox Signal 17: 45-57, 2012.

136. Kimura Y, Mikami Y, Osumi K, Tsugane M, Oka J-I, and Kimura $\mathrm{H}$. Polysulfides are possible $\mathrm{H}_{2} \mathrm{~S}$-derived signaling molecules in rat brain. FASEB $J$ 27: 24512457, 2013.

137. King AL, Polhemus DJ, Bhushan S, Otsuka H, Kondo K, Nicholson CK, Bradley JM, Islam KN, Calvert JW, and Tao YX. Hydrogen sulfide cytoprotective signaling is endothelial nitric oxide synthase-nitric oxide dependent. Proc Natl Acad Sci U S A 111: 3182-3187, 2014.

138. Kodela R, Chattopadhyay M, and Kashfi K. NOSH-aspirin: a novel nitric oxide-hydrogen sulfide-releasing 
hybrid: a new class of anti-inflammatory pharmaceuticals. ACS Med Chem Lett 3: 257-262, 2012.

139. Koenitzer JR, Isbell TS, Patel HD, Benavides GA, Dickinson DA, Patel RP, Darley-Usmar VM, Lancaster JR, Doeller JE, and Kraus DW. Hydrogen sulfide mediates vasoactivity in an $\mathrm{O}_{2}$-dependent manner. Am J Physiol Heart Circ Physiol 292: H1953-H1960, 2007.

140. Kolluru GK, Shen X, Bir SC, and Kevil CG. Hydrogen sulfide chemical biology: pathophysiological roles and detection. Nitric Oxide 35: 5-20, 2013.

141. Koppenol WH and Bounds PL. Signaling by sulfurcontaining molecules. quantitative aspects. Arch Biochem Biophys 617: 3-8, 2017.

142. Kram L, Grambow E, Mueller-Graf F, Sorg H, and Vollmar B. The anti-thrombotic effect of hydrogen sulfide is partly mediated by an upregulation of nitric oxide synthases. Thromb Res 132: e112-e117, 2013.

143. Krijgsheld KR, Glazenburg EJ, Scholtens E, and Mulder GJ. The oxidation of L-and D-cysteine to inorganic sulfate and taurine in the rat. Biochim Biophys Acta 677: 7-12, 1981.

144. Kune GA, Kune S, and Watson LF. Colorectal cancer risk, chronic illnesses, operations, and medications: case control results from the Melbourne Colorectal Cancer Study. Cancer Res 48: 4399-4404, 1988.

145. Lagoutte E, Mimoun S, Andriamihaja M, Chaumontet C, Blachier F, and Bouillaud F. Oxidation of hydrogen sulfide remains a priority in mammalian cells and causes reverse electron transfer in colonocytes. Biochim Biophys Acta 1797: 1500-1511, 2010.

146. Lawrence MS, Stojanov P, Mermel CH, Garraway LA, Golub TR, Meyerson M, Gabriel SB, Lander ES, and Getz G. Discovery and saturation analysis of cancer genes across 21 tumor types. Nature 505: 495, 2014.

147. Lee M, McGeer E, Kodela R, Kashfi K, and McGeer PL. NOSH-aspirin (NBS-1120), a novel nitric oxide and hydrogen sulfide releasing hybrid, attenuates neuroinflammation induced by microglial and astrocytic activation: a new candidate for treatment of neurodegenerative disorders. Glia 61: 1724-1734, 2013.

148. Lee SW, Cheng Y, Moore PK, and Bian JS. Hydrogen sulphide regulates intracellular $\mathrm{pH}$ in vascular smooth muscle cells. Biochem Biophys Res Commun 358: 11421147, 2007.

149. Lee $\mathrm{ZW}$, Teo $\mathrm{XY}$, Tay EW, Tan $\mathrm{CH}$, Hagen $\mathrm{T}$, Moore P, and Deng LW. Utilizing hydrogen sulfide as a novel anti-cancer agent by targeting cancer glycolysis and pH imbalance. Br J Pharmacol 171: 4322 4336, 2014.

150. Lee ZW, Zhou J, Chen CS, Zhao Y, Tan CH, Li L, Moore PK, and Deng LW. The slow-releasing hydrogen sulfide donor, GYY4137, exhibits novel anti-cancer effects in vitro and in vivo. PLoS One 6: e21077, 2011.

151. Levitt MD, Abdel-Rehim MS, and Furne J. Free and acidlabile hydrogen sulfide concentrations in mouse tissues: anomalously high free hydrogen sulfide in aortic tissue. Antioxid Redox Signal 15: 373-378, 2011.

152. Levitt MD, Furne J, Springfield J, Suarez F, and DeMaster E. Detoxification of hydrogen sulfide and methanethiol in the cecal mucosa. J Clin Invest 104: 1107, 1999.

153. Li H, Marshall ZM, and Whorton AR. Stimulation of cystine uptake by nitric oxide: regulation of endothelial cell glutathione levels. Am J Physiol Cell Physiol 276: C803-C811, 1999.
154. Li L, Bhatia M, Zhu YZ, Zhu YC, Ramnath RD, Wang ZJ, Anuar FBM, Whiteman M, Salto-Tellez M, and Moore PK. Hydrogen sulfide is a novel mediator of lipopolysaccharideinduced inflammation in the mouse. FASEB $J$ 19: 11961198, 2005.

155. Li L, Fox B, Keeble J, Salto-Tellez M, Winyard PG, Wood ME, Moore PK, and Whiteman M. The complex effects of the slow-releasing hydrogen sulfide donor GYY4137 in a model of acute joint inflammation and in human cartilage cells. J Cell Mol Med 17: 365-376, 2013.

156. This reference has been deleted.

157. Li L, Hsu A, and Moore PK. Actions and interactions of nitric oxide, carbon monoxide and hydrogen sulphide in the cardiovascular system and in inflammation-a tale of three gases! Pharmacol Ther 123: 386-400, 2009.

158. Li L and Moore P. Putative biological roles of hydrogen sulfide in health and disease: a breath of not so fresh air? Trends Pharmacol Sci 29: 84-90, 2008.

159. Li L, Rose P, and Moore PK. Hydrogen sulfide and cell signaling. Апnu Rev Pharmacol Toxicol 51: 169-187, 2011.

160. Li L, Rossoni G, Sparatore A, Lee LC, Del Soldato P, and Moore PK. Anti-inflammatory and gastrointestinal effects of a novel diclofenac derivative. Free Radic Biol Med 42: 706-719, 2007.

161. Li L, Salto-Tellez M, Tan CH, Whiteman M, and Moore PK. GYY4137, a novel hydrogen sulfide-releasing molecule, protects against endotoxic shock in the rat. Free Radic Biol Med 47: 103-113, 2009.

162. Li L, Whiteman M, Guan YY, Neo KL, Cheng Y, Lee SW, Zhao Y, Baskar R, Tan C-H, and Moore PK. Characterization of a novel, water-soluble hydrogen sulfide-releasing molecule (GYY4137). Circulation 117: 2351-2360, 2008

163. Liang M, Jin S, Wu DD, Wang MJ, and Zhu YC. Hydrogen sulfide improves glucose metabolism and prevents hypertrophy in cardiomyocytes. Nitric Oxide 46: 114-122, 2015 .

164. Liao D and Johnson RS. Hypoxia: a key regulator of angiogenesis in cancer. Cancer Metastasis Rev 26: 281290, 2007.

165. Libiad M, Yadav PK, Vitvitsky V, Martinov M, and Banerjee R. Organization of the human mitochondrial hydrogen sulfide oxidation pathway. J Biol Chem 289: 30901-30910, 2014.

166. Lippert AR, New EJ, and Chang CJ. Reaction-based fluorescent probes for selective imaging of hydrogen sulfide in living cells. J Am Chem Soc 133: 1007810080, 2011.

167. Liu M, Jia Z, Sun Y, Zhang A, and Yang T. A $\mathrm{H}_{2} \mathrm{~S}$ donor GYY4137 exacerbates cisplatin-induced nephrotoxicity in mice. Mediators Inflamm 2016: 8145785, 2016.

168. Liu X, Pan L, Zhuo Y, Gong Q, Rose P, and Zhu Y. Hypoxia-inducible factor- $1 \alpha$ is involved in the proangiogenic effect of hydrogen sulfide under hypoxic stress. Biol Pharm Bull 33: 1550-1554, 2010.

169. Liu YH, Lu M, Hu LF, Wong PTH, Webb GD, and Bian JS. Hydrogen sulfide in the mammalian cardiovascular system. Antioxid Redox Signal 17: 141-185, 2012.

170. Lu M, Choo CH, Hu LF, Tan BH, Hu G, and Bian JS. Hydrogen sulfide regulates intracellular $\mathrm{pH}$ in rat primary cultured glia cells. Neurosci Res 66: 92-98, 2010.

171. Lu S, Gao Y, Huang X, and Wang X. GYY4137, a hydrogen sulfide $\left(\mathrm{H}_{2} \mathrm{~S}\right)$ donor, shows potent anti-hepatocellular 
carcinoma activity through blocking the STAT3 pathway. Int J Oncol 44: 1259-1267, 2014.

172. Ma Z, Bi Q, and Wang Y. Hydrogen sulfide accelerates cell cycle progression in oral squamous cell carcinoma cell lines. Oral Dis 21: 156-162, 2015.

173. Malumbres $M$ and Barbacid M. Cell cycle, CDKs and cancer: a changing paradigm. Nat Rev Cancer 9: 153, 2009.

174. Manna P and Jain SK. Hydrogen sulfide and L-cysteine increase phosphatidylinositol 3, 4, 5-trisphosphate (PIP3) and glucose utilization by inhibiting phosphatase and tensin homolog (PTEN) protein and activating phosphoinositide 3-kinase $(\mathrm{PI} 3 \mathrm{~K}) /$ serine/threonine protein kinase $(\mathrm{AKT}) /$ protein kinase $\mathrm{C} \zeta / \lambda(\mathrm{PKC} \zeta / \lambda)$ in 3T311 adipocytes. J Biol Chem 286: 39848-39859, 2011.

175. Masilamani V, Al-Zhrani K, Al-Salhi M, Al-Diab A, and Al-Ageily M. Cancer diagnosis by autofluorescence of blood components. J Lumin 109: 143-154, 2004.

176. Mathai JC, Missner A, Kügler P, Saparov SM, Zeidel ML, Lee JK, and Pohl P. No facilitator required for membrane transport of hydrogen sulfide. Proc Natl Acad Sci U S A 106: 16633-16638, 2009.

177. McCune CD, Chan SJ, Beio ML, Shen W, Chung WJ, Szczesniak LM, Chai C, Koh SQ, Wong PT-H, and Berkowitz DB. "Zipped Synthesis" by cross-metathesis provides a cystathionine $\beta$-synthase inhibitor that attenuates cellular $\mathrm{H}_{2} \mathrm{~S}$ levels and reduces neuronal infarction in a rat ischemic stroke model. ACS Central Sci 2: 242-252, 2016.

178. Meng G, Wang J, Xiao Y, Bai W, Xie L, Shan L, Moore PK, and Ji Y. GYY4137 protects against myocardial ischemia and reperfusion injury by attenuating oxidative stress and apoptosis in rats. J Biomed Res 29: 203, 2015.

179. Meng G, Zhu J, Xiao Y, Huang Z, Zhang Y, Tang X, Xie L, Chen Y, Shao Y, and Ferro A. Hydrogen sulfide donor GYY4137 protects against myocardial fibrosis. Oxid Med Cell Longev 2015: 6910170, 2015.

180. Meng J, Adaikan PG, and Srilatha B. Hydrogen sulfide promotes nitric oxide production in corpus cavernosum by enhancing expression of endothelial nitric oxide synthase. Int J Impot Res 25: 86, 2013.

181. Mikami Y, Shibuya N, Kimura Y, Nagahara N, Yamada $\mathrm{M}$, and Kimura H. Hydrogen sulfide protects the retina from light-induced degeneration by the modulation of Ca2+ influx. J Biol Chem 286: 39379-39386, 2011.

182. Mikami Y, Shibuya N, Ogasawara Y, and Kimura H. Hydrogen sulfide is produced by cystathionine $\gamma$-lyase at the steady-state low intracellular $\mathrm{Ca} 2+$ concentrations. Biochem Biophys Res Commun 431: 131-135, 2013.

183. Miller TW, Kaur S, Ivins-O'Keefe K, and Roberts DD. Thrombospondin-1 is a CD47-dependent endogenous inhibitor of hydrogen sulfide signaling in T cell activation. Matrix Biol 32: 316-324, 2013.

184. Miller TW, Wang EA, Gould S, Stein EV, Kaur S, Lim L, Amarnath S, Fowler DH, and Roberts DD. Hydrogen sulfide is an endogenous potentiator of T cell activation. $J$ Biol Chem 287: 4211-4221, 2012.

185. Módis K, Coletta C, Asimakopoulou A, Szczesny B, Chao C, Papapetropoulos A, Hellmich MR, and Szabo C. Effect of S-adenosyl-L-methionine (SAM), an allosteric activator of cystathionine- $\beta$-synthase (CBS) on colorectal cancer cell proliferation and bioenergetics in vitro. Nitric Oxide 41: 146-156, 2014.

186. Módis K, Coletta C, Erdélyi K, Papapetropoulos A, and Szabo C. Intramitochondrial hydrogen sulfide production by 3-mercaptopyruvate sulfurtransferase maintains mitochondrial electron flow and supports cellular bioenergetics. FASEB J 27: 601-611, 2013.

187. Módis K, Ju Y, Ahmad A, Untereiner AA, Altaany Z, Wu L, Szabo C, and Wang R. S-Sulfhydration of ATP synthase by hydrogen sulfide stimulates mitochondrial bioenergetics. Pharmacol Res 113: 116-124, 2016.

188. Módis K, Panopoulos P, Coletta C, Papapetropoulos A, and Szabo C. Hydrogen sulfide-mediated stimulation of mitochondrial electron transport involves inhibition of the mitochondrial phosphodiesterase $2 \mathrm{~A}$, elevation of cAMP and activation of protein kinase A. Biochem Pharmacol 86: 1311-1319, 2013.

189. Mok YYP, Atan M, Bin MS, Ping CY, Jing WZ, Bhatia M, Moochhala S, and Moore PK. Role of hydrogen sulphide in haemorrhagic shock in the rat: protective effect of inhibitors of hydrogen sulphide biosynthesis. Br J Pharmacol 143: 881-889, 2004.

190. Morikawa T, Kajimura M, Nakamura T, Hishiki T, Nakanishi T, Yukutake Y, Nagahata Y, Ishikawa M, Hattori $\mathrm{K}$, and Takenouchi T. Hypoxic regulation of the cerebral microcirculation is mediated by a carbon monoxidesensitive hydrogen sulfide pathway. Proc Natl Acad Sci U S A 109: 1293-1298, 2012.

191. Morley KL, Ferguson PJ, and Koropatnick J. Tangeretin and nobiletin induce G1 cell cycle arrest but not apoptosis in human breast and colon cancer cells. Cancer Lett 251: 168-178, 2007.

192. Munday R, Munday JS, and Munday CM. Comparative effects of mono-, di-, tri-, and tetrasulfides derived from plants of the Allium family: redox cycling in vitro and hemolytic activity and Phase 2 enzyme induction in vivo. Free Radic Biol Med 34: 1200-1211, 2003.

193. Murata T, Sato T, Kamoda T, Moriyama H, Kumazawa Y, and Hanada N. Differential susceptibility to hydrogen sulfide-induced apoptosis between PHLDA1-overexpressing oral cancer cell lines and oral keratinocytes: role of PHLDA1 as an apoptosis suppressor. Exp Cell Res 320: 247-257, 2014.

194. Mustafa AK, Gadalla MM, Sen N, Kim S, Mu W, Gazi SK, Barrow RK, Yang G, Wang R, and Snyder SH. $\mathrm{H}_{2} \mathrm{~S}$ signals through protein S-sulfhydration. Sci Signal 2: ra72, 2009.

195. Mustafa AK, Sikka G, Gazi SK, Steppan J, Jung SM, Bhunia AK, Barodka VM, Gazi FK, Barrow RK, Wang R, Amzel LM, Berkowitz DE, and Snyder SH. Hydrogen sulfide as endothelium-derived hyperpolarizing factor sulfhydrates potassium channels. Circ Res 111: 240242, 2011.

196. Nagahara N. Regulation of mercaptopyruvate sulfurtransferase activity via intrasubunit and intersubunit redox-sensing switches. Antioxid Redox Signal 19: 1792$1802,2013$.

197. Nagahara N, Ito T, Kitamura H, and Nishino T. Tissue and subcellular distribution of mercaptopyruvate sulfurtransferase in the rat: confocal laser fluorescence and immunoelectron microscopic studies combined with biochemical analysis. Histochem Cell Biol 110: 243250, 1998.

198. Nagpure B and Bian JS. Interaction of hydrogen sulfide with nitric oxide in the cardiovascular system. Oxid Med Cell Longev 2016: 6904327, 2016.

199. Nagy P. Mechanistic chemical perspective of hydrogen sulfide signaling. Methods Enzymol 554: 3-29, 2015. 
200. Nagy P, Palinkas Z, Nagy A, Budai B, Toth I, and Vasas A. Chemical aspects of hydrogen sulfide measurements in physiological samples. Biochim Biophys Acta 1840: 876891, 2014.

201. Nagy P and Winterbourn CC. Rapid reaction of hydrogen sulfide with the neutrophil oxidant hypochlorous acid to generate polysulfides. Chem Res Toxicol 23: 1541-1543, 2010.

202. Nava M, Martin-Drumel MA, Lopez CA, Crabtree KN, Womack CC, Nguyen TL, Thorwirth S, Cummins CC, Stanton JF, and McCarthy MC. Spontaneous and selective formation of HSNO, a crucial intermediate linking $\mathrm{H}_{2} \mathrm{~S}$ and nitroso chemistries. J Am Chem Soc 138: 1144111444, 2016.

203. Nemeth Z, Li M, Csizmadia E, Döme B, Johansson M, Persson JL, Seth P, Otterbein L, and Wegiel B. Heme oxygenase-1 in macrophages controls prostate cancer progression. Oncotarget 6: 33675, 2015.

204. Nian H, Delage B, Ho E, and Dashwood RH. Modulation of histone deacetylase activity by dietary isothiocyanates and allyl sulfides: studies with sulforaphane and garlic organosulfur compounds. Environ Mol Mutagen 50: 213 221, 2009.

205. Nicholson RA, Roth SH, Zhang A, Zheng J, Brookes J, Skrajny B, and Bennington R. Inhibition of respiratory and bioenergetic mechanisms by hydrogen sulfide in mammalian brain. J Toxicol Environ Health A 54: 491507, 1998.

206. Niu WN, Yadav PK, Adamec J, and Banerjee R. Sglutathionylation enhances human cystathionine $\beta$-synthase activity under oxidative stress conditions. Antioxid Redox Signal 22: 350-361, 2015.

207. O'Neill LA and Kaltschmidt C. NF-kB: a crucial transcription factor for glial and neuronal cell function. Trends Neurosci 20: 252-258, 1997.

208. Oh GS, Pae HO, Lee BS, Kim BN, Kim JM, Kim HR, Jeon SB, Jeon WK, Chae HJ, and Chung HT. Hydrogen sulfide inhibits nitric oxide production and nuclear factor- $\kappa \mathrm{B}$ via heme oxygenase- 1 expression in RAW264. 7 macrophages stimulated with lipopolysaccharide. Free Radic Biol Med 41: 106-119, 2006.

209. Olson KR. Is hydrogen sulfide a circulating "gasotransmitter" in vertebrate blood? Biochim Biophys Acta 1787: 856-863, 2009.

210. Olson KR, DeLeon ER, Gao Y, Hurley K, Sadauskas V, Batz C, and Stoy GF. Thiosulfate: a readily accessible source of hydrogen sulfide in oxygen sensing. Am $J$ Physiol Regul Integr Comp Physiol 305: R592-R603, 2013.

211. Olson KR, DeLeon ER, and Liu F. Controversies and conundrums in hydrogen sulfide biology. Nitric Oxide 41: $11-26,2014$.

212. Olson KR, Gao Y, DeLeon ER, Arif M, Arif F, Arora N, and Straub KD. Catalase as a sulfide-sulfur oxido-reductase: an ancient (and modern?) regulator of reactive sulfur species (RSS). Redox Biol 12: 325-339, 2017.

213. Olson KR, Whitfield NL, Bearden SE, Leger JS, Nilson E, Gao Y, and Madden JA. Hypoxic pulmonary vasodilation: a paradigm shift with a hydrogen sulfide mechanism. Am J Physiol Regul Integr Comp Physiol 298: R51-R60, 2010.

214. Oosumi K, Tsugane M, Ishigami M, Nagai Y, Iwai T, Oka J, and Kimura H. Polysulfide activates TRP channels and increases intracellular $\mathrm{Ca} 2+$ in astrocytes. Neurosci Res 68: e109, 2010
215. Orlowski A. Hydrogen sulfur as a product of certain bacteria [In French]. J Med Milit Russe 11: 1895, 1985.

216. Osaki M, Oshimura M, and ItoH. PI3K-Akt pathway: its functions and alterations in human cancer. Apoptosis 9: 667-676, 2004.

217. Pabla N and Dong Z. Cisplatin nephrotoxicity: mechanisms and renoprotective strategies. Kidney Int 73: 994 1007, 2008.

218. Padilla-Camberos E, Zaitseva G, Padilla C, and Puebla AM. Antitumoral activity of allicin in murine lymphoma L5178Y. Asian Pac J Cancer Prev 11: 1241-1244, 2010.

219. Pagliara V, Saide A, Mitidieri E, di Villa BRdE, Sorrentino R, Russo G, and Russo A. 5-FU targets rpL3 to induce mitochondrial apoptosis via cystathionine- $\beta$-synthase in colon cancer cells lacking p53. Oncotarget 7: 50333, 2016.

220. Pálinkás Z, Furtmüller PG, Nagy A, Jakopitsch C, Pirker $\mathrm{KF}$, Magierowski M, Jasnos K, Wallace JL, Obinger C, and Nagy P. Interactions of hydrogen sulfide with myeloperoxidase. Br J Pharmacol 172: 1516-1532, 2015.

221. Pan Y, Ye S, Yuan D, Zhang J, Bai Y, and Shao C. Hydrogen sulfide $\left(\mathrm{H}_{2} \mathrm{~S}\right)$ /cystathionine $\gamma$-lyase (CSE) pathway contributes to the proliferation of hepatoma cells. Mutat Res 763: 10-18, 2014.

222. Panza E, De Cicco P, Armogida C, Scognamiglio G, Gigantino V, Botti G, Germano D, Napolitano M, Papapetropoulos A, and Bucci M. Role of the cystathionine $\gamma$ lyase/hydrogen sulfide pathway in human melanoma progression. Pigment Cell Melanoma Res 28: 61-72, 2015.

223. Papapetropoulos A, Pyriochou A, Altaany Z, Yang G, Marazioti A, Zhou Z, Jeschke MG, Branski LK, Herndon $\mathrm{DN}$, and Wang R. Hydrogen sulfide is an endogenous stimulator of angiogenesis. Proc Natl Acad Sci U S A 106: 21972-21977, 2009.

224. Patel P, Vatish M, Heptinstall J, Wang R, and Carson RJ. The endogenous production of hydrogen sulphide in intrauterine tissues. Reprod Biol Endocrinol 7: 10, 2009.

225. Paul BD and Snyder SH. $\mathrm{H}_{2} \mathrm{~S}$ signalling through protein sulfhydration and beyond. Nat Rev Mol Cell Biol 13: 499, 2012.

226. Pei Y, Wu B, Cao Q, Wu L, and Yang G. Hydrogen sulfide mediates the anti-survival effect of sulforaphane on human prostate cancer cells. Toxicol Appl Pharmacol 257: 420-428, 2011.

227. Peng H, Cheng Y, Dai C, King AL, Predmore BL, Lefer DJ, and Wang B. A fluorescent probe for fast and quantitative detection of hydrogen sulfide in blood. Angew Chem Int Ed 50: 9672-9675, 2011.

228. Picton R, Eggo M, Merrill G, Langman M, and Singh S. Mucosal protection against sulphide: importance of the enzyme rhodanese. Gut 50: 201-205, 2002.

229. Polhemus DJ and Lefer DJ. Emergence of hydrogen sulfide as an endogenous gaseous signaling molecule in cardiovascular disease. Circ Res 114: 730-737, 2014.

230. Polhemus DJ, Li Z, Pattillo CB, Gojon G, Sr., Gojon G, Jr., Giordano T, and Krum H. A novel hydrogen sulfide prodrug, SG1002, promotes hydrogen sulfide and nitric oxide bioavailability in heart failure patients. Cardiovasc Ther 33: 216-226, 2015.

231. Pomeroy R. The determination of sulphides in sewage. Sewage Wks J 8: 572-591, 1936.

232. Predmore BL, Lefer DJ, and Gojon G. Hydrogen sulfide in biochemistry and medicine. Antioxid Redox Signal 17: 119-140, 2012. 
233. Pupo E, Pla AF, Avanzato D, Moccia F, Cruz J-EA, Tanzi F, Merlino A, Mancardi D, and Munaron L. Hydrogen sulfide promotes calcium signals and migration in tumorderived endothelial cells. Free Radic Biol Med 51: 17651773, 2011.

234. Puranik M, Weeks CL, Lahaye D, Kabil Ö, Taoka S, Nielsen SB, Groves JT, Banerjee R, and Spiro TG. Dynamics of carbon monoxide binding to cystathionine $\beta$ synthase. J Biol Chem 281: 13433-13438, 2006.

235. Qandil AM. Prodrugs of nonsteroidal anti-inflammatory drugs (NSAIDs), more than meets the eye: a critical review. Int J Mol Sci 13: 17244-17274, 2012.

236. Qian Y, Karpus J, Kabil O, Zhang SY, Zhu HL, Banerjee $\mathrm{R}$, Zhao J, and He C. Selective fluorescent probes for live-cell monitoring of sulphide. Nat Commun 2: 495, 2011.

237. Rayet B and Gelinas C. Aberrant rel/nfkb genes and activity in human cancer. Oncogene 18: 6938-6947, 1999.

238. Reiffenstein RJ, Hulbert WC, and Roth SH. Toxicology of hydrogen sulfide. Annu Rev Pharmacol Toxicol 32: 109134, 1992.

239. Ries F and Klastersky J. Nephrotoxicity induced by cancer chemotherapy with special emphasis on cisplatin toxicity. Am J Kidney Dis 8: 368-379, 1986.

240. Roper MD and Kraus JP. Rat cystathionine beta-synthase: expression of four alternatively spliced isoforms in transfected cultured cells. Arch Biochem Biophys 298: 514-521, 1992.

241. Rose P, Moore PK, Ming SH, Nam OC, Armstrong JS, and Whiteman M. Hydrogen sulfide protects colon cancer cells from chemopreventative agent $\beta$-phenylethyl isothiocyanate induced apoptosis. World J Gastroenterol 11: 3990, 2005.

242. Savage $\mathbf{J}$ and Gould D. Determination of sulfide in brain tissue and rumen fluid by ion-interaction reversed-phase high-performance liquid chromatography. J Chromatogr 526: 540-545, 1990.

243. Schulze A and Harris AL. How cancer metabolism is tuned for proliferation and vulnerable to disruption. Nature 491: 364, 2012.

244. Searcy DG and Lee SH. Sulfur reduction by human erythrocytes. J Exp Zool 282: 310-322, 1998.

245. Sen N, Paul BD, Gadalla MM, Mustafa AK, Sen T, Xu R, Kim S, and Snyder SH. Hydrogen sulfide-linked sulfhydration of NF- $\kappa \mathrm{B}$ mediates its antiapoptotic actions. $\mathrm{Mol}$ Cell 45: 13-24, 2012.

246. Sen S, Kawahara B, Gupta D, Tsai R, Khachatryan M, Roy-Chowdhuri S, Bose S, Yoon A, Faull K, and FariasEisner R. Role of cystathionine $\beta$-synthase in human breast cancer. Free Radic Biol Med 86: 228-238, 2015.

247. Shan X, Dunbrack Jr RL, Christopher SA, and Kruger WD. Mutations in the regulatory domain of cystathionine $\beta$-synthase can functionally suppress patient-derived mutations in cis. Hum Mol Genet 10: 635-643, 2001.

248. Shatalin K, Shatalina E, Mironov A, and Nudler E. $\mathrm{H}_{2} \mathrm{~S}$ : a universal defense against antibiotics in bacteria. Science 334: 986-990, 2011.

249. Shen X, Pattillo CB, Pardue S, Bir SC, Wang R, and Kevil CG. Measurement of plasma hydrogen sulfide in vivo and in vitro. Free Radic Biol Med 50: 1021-1031, 2011.

250. Shi S, Li QS, Li H, Zhang L, Xu M, Cheng JL, Peng CH, $\mathrm{Xu} C Q$, and Tian Y. Anti-apoptotic action of hydrogen sulfide is associated with early JNK inhibition. Cell Biol Int 33: 1095-1101, 2009.
251. Shibuya N, Koike S, Tanaka M, Ishigami-Yuasa M, Kimura Y, Ogasawara Y, Fukui K, Nagahara N, and Kimura H. A novel pathway for the production of hydrogen sulfide from D-cysteine in mammalian cells. Nat Commun 4, 1366, 2013.

252. Shibuya N, Mikami Y, Kimura Y, Nagahara N, and Kimura H. Vascular endothelium expresses 3-mercaptopyruvate sulfurtransferase and produces hydrogen sulfide. $J$ Biochem 146: 623-626, 2009.

253. Shibuya N, Tanaka M, Yoshida M, Ogasawara Y, Togawa T, Ishii K, and Kimura H. 3-Mercaptopyruvate sulfurtransferase produces hydrogen sulfide and bound sulfane sulfur in the brain. Antioxid Redox Signal 11: 703-714, 2009.

254. Shigetoshi K, Nagata T, Kimura K, and Kudo K. Extractive alkylation and gas chromatographic analysis of sulfide. J Forensic Sci 33: 217-222, 1988.

255. Shintani T, Iwabuchi T, Soga T, Kato Y, Yamamoto T, Takano N, Hishiki T, Ueno Y, Ikeda S, and Sakuragawa T. Cystathionine $\beta$-synthase as a carbon monoxide-sensitive regulator of bile excretion. Hepatology 49: 141-150, 2009.

255a. Shoman E and Aly M. Nitroxyl (HNO): a possible strategy for fighting cancer. Curr Top Med Chem 16: 2464-2470, 2016.

256. Singh S, Madzelan P, Stasser J, Weeks CL, Becker D, Spiro TG, Penner-Hahn J, and Banerjee R. Modulation of the heme electronic structure and cystathionine $\beta$-synthase activity by second coordination sphere ligands: the role of heme ligand switching in redox regulation. J Inorg Biochem 103: 689-697, 2009.

257. Singh S, Padovani D, Leslie RA, Chiku T, and Banerjee $\mathrm{R}$. Relative contributions of cystathionine $\beta$-synthase and $\gamma$-cystathionase to $\mathrm{H}_{2} \mathrm{~S}$ biogenesis via alternative transsulfuration reactions. J Biol Chem 284: 22457-22466, 2009.

258. Skrzypek K, Tertil M, Golda S, Ciesla M, Weglarczyk K, Collet G, Guichard A, Kozakowska M, Boczkowski J, and Was $\mathrm{H}$. Interplay between heme oxygenase- 1 and miR-378 affects non-small cell lung carcinoma growth, vascularization, and metastasis. Antioxid Redox Signal 19: 644-660, 2013.

259. Son J, Lyssiotis CA, Ying H, Wang X, Hua S, Ligorio M, Perera RM, Ferrone CR, Mullarky E, and Shyh-Chang N. Glutamine supports pancreatic cancer growth through a KRAS-regulated metabolic pathway. Nature 496: 101, 2013.

260. Stipanuk MH. Sulfur amino acid metabolism: pathways for production and removal of homocysteine and cysteine. Anпи Rev Nutr 24: 539-577, 2004.

261. Suematsu M, Nakamura T, Tokumoto Y, Yamamoto T, Kajimura M, and Kabe Y. CO-CBS- $\mathrm{H}_{2} \mathrm{~S}$ axis: from vascular mediator to cancer regulator. Microcirculation 23: 183-190, 2016.

262. Sulpizio M, Falone S, Amicarelli F, Marchisio M, Di Giuseppe F, Eleuterio E, Di Ilio C, and Angelucci S. Molecular basis underlying the biological effects elicited by extremely low-frequency magnetic field (ELF-MF) on neuroblastoma cells. J Cell Biochem 112: 3797-3806, 2011.

263. Sun Y, Wang XM, Chen YH, Zhu RX, and Liao CC. Exhaled hydrogen sulfide in patients with chronic obstructive pulmonary disease and its correlation with exhaled nitric oxide. Chin Med J (Engl) 126: 3240-3244, 2013. 
264. Swaroop M, Bradley K, Ohura T, Tahara T, Roper MD, Rosenberg LE, and Kraus JP. Rat cystathionine betasynthase. Gene organization and alternative splicing. $J$ Biol Chem 267: 11455-11461, 1992.

265. Szabo C. Gasotransmitters in cancer: from pathophysiology to experimental therapy. Nat Rev Drug Discov 15: 185, 2016.

266. Szabo C, Coletta C, Chao C, Módis K, Szczesny B, Papapetropoulos A, and Hellmich MR. Tumor-derived hydrogen sulfide, produced by cystathionine- $\beta$-synthase, stimulates bioenergetics, cell proliferation, and angiogenesis in colon cancer. Proc Natl Acad Sci U S A 110: 12474-12479, 2013.

267. Szabo C and Hellmich MR. Endogenously produced hydrogen sulfide supports tumor cell growth and proliferation. Cell Cycle 12: 2915-2916, 2013.

268. Szabó $C$ and Papapetropoulos A. Hydrogen sulphide and angiogenesis: mechanisms and applications. $\mathrm{Br} J$ Pharmacol 164: 853-865, 2011.

269. Szabo C, Ransy C, Módis K, Andriamihaja M, Murghes B, Coletta C, Olah G, Yanagi K, and Bouillaud F. Regulation of mitochondrial bioenergetic function by hydrogen sulfide. Part I. Biochemical and physiological mechanisms. $\mathrm{Br} \mathrm{J}$ Pharmacol 171: 2099-2122, 2014.

270. Takano N, Sarfraz Y, Gilkes DM, Chaturvedi P, Xiang L, Suematsu M, Zagzag D, and Semenza GL. Decreased expression of cystathionine $\beta$-synthase promotes glioma tumorigenesis. Mol Cancer Res 12: 1398-1406, 2014.

271. Tang C, Li X, and Du J. Hydrogen sulfide as a new endogenous gaseous transmitter in the cardiovascular system. Curr Vasc Pharmacol 4: 17-22, 2006.

272. Tang G, Wu L, Liang W, and Wang R. Direct stimulation of KATP channels by exogenous and endogenous hydrogen sulfide in vascular smooth muscle cells. Mol Pharmacol 68: 1757-1764, 2005.

273. Tao M, Gao L, Pan J, and Wang X. Study on the inhibitory effect of allicin on human gastric cancer cell line SGC-7901 and its mechanism. Afr J Trad Complement Altern Med 11: 176-179, 2014.

274. Taoka S and Banerjee R. Characterization of NO binding to human cystathionine $\beta$-synthase: possible implications of the effects of $\mathrm{CO}$ and NO binding to the human enzyme. J Inorg Biochem 87: 245-251, 2001.

275. Tay A, Hu L, Lu M, Wong P, and Bian J. Hydrogen sulfide protects neurons against hypoxic injury via stimulation of ATP-sensitive potassium channel/protein kinase C/extracellular signal-regulated kinase/heat shock protein90 pathway. Neuroscience 167: 277-286, 2010.

276. Teng H, Wu B, Zhao K, Yang G, Wu L, and Wang R. Oxygen-sensitive mitochondrial accumulation of cystathionine $\beta$-synthase mediated by Lon protease. Proc Natl Acad Sci U S A 110: 12679-12684, 2013.

277. Tertil M, Golda S, Skrzypek K, Florczyk U, Weglarczyk K, Kotlinowski J, Maleszewska M, Czauderna S, Pichon $\mathrm{C}$, and Kieda C. Nrf2-heme oxygenase-1 axis in mucoepidermoid carcinoma of the lung: antitumoral effects associated with down-regulation of matrix metalloproteinases. Free Radic Biol Med 89: 147-157, 2015.

278. Thornburg JM, Nelson KK, Clem BF, Lane AN, Arumugam S, Simmons A, Eaton JW, Telang S, and Chesney J. Targeting aspartate aminotransferase in breast cancer. Breast Cancer Res 10: R84, 2008.

279. Thorson MK, Majtan T, Kraus JP, and Barrios AM. Identification of cystathionine $\beta$-synthase inhibitors using a hydrogen sulfide selective probe. Angew Chem Int Ed 52: 4641-4644, 2013.

280. Thorson MK, Van Wagoner RM, Harper MK, Ireland CM, Majtan T, Kraus JP, and Barrios AM. Marine natural products as inhibitors of cystathionine beta-synthase activity. Bioorg Med Chem Lett 25: 1064-1066, 2015.

281. Tiong CX, Lu M, and Bian JS. Protective effect of hydrogen sulphide against 6-OHDA-induced cell injury in SH-SY5Y cells involves PKC/PI3K/Akt pathway. $\mathrm{Br} J$ Pharmacol 161: 467-480, 2010.

282. Togawa T, Ogawa M, Nawata M, Ogasawara Y, Kawanabe $\mathrm{K}$, and Tanabe S. High performance liquid chromatographic determination of bound sulfide and sulfite and thiosulfate at their low levels in human serum by pre-column fluorescence derivatization with monobromobimane. Chem Pharm Bull 40: 3000-3004, 1992.

283. Trédan O, Galmarini CM, Patel K, and Tannock IF. Drug resistance and the solid tumor microenvironment. $J$ Natl Cancer Inst 99: 1441-1454, 2007.

284. Tripatara P, Patel NS, Collino M, Gallicchio M, Kieswich J, Castiglia S, Benetti E, Stewart KN, Brown PA, Yaqoob MM, Fantozzi R, and Thiemermann C. Generation of endogenous hydrogen sulfide by cystathionine gammalyase limits renal ischemia/reperfusion injury and dysfunction. Lab Invest 88: 1038-1048, 2008.

285. Tu X, Huang S, Li W, and Song J. Correlation of methylation of $\mathrm{CpG}$ island in cystathionine beta synthase promoter and clinicopathological features in colorectal cancer [In Chinese]. Zhonghua Zhong Liu Zhi 35: 351355, 2013.

286. Untereiner AA, Oláh G, Módis K, Hellmich MR, and Szabo C. $\mathrm{H}_{2} \mathrm{~S}$-induced $\mathrm{S}$-sulfhydration of lactate dehydrogenase a (LDHA) stimulates cellular bioenergetics in HCT116 colon cancer cells. Biochem Pharmacol 136: 86-98, 2017.

287. Vander Heiden MG, Cantley LC, and Thompson CB. Understanding the Warburg effect: the metabolic requirements of cell proliferation. Science 324: 10291033, 2009.

288. Vanneman M and Dranoff G. Combining immunotherapy and targeted therapies in cancer treatment. Nat Rev Cancer 12: 237-251, 2012.

289. Vasas A, Dóka É, Fábián I, and Nagy P. Kinetic and thermodynamic studies on the disulfide-bond reducing potential of hydrogen sulfide. Nitric Oxide 46: 93-101, 2015.

290. Wagner F, Asfar P, Calzia E, Radermacher P, and Szabó C. Bench-to-bedside review: hydrogen sulfide - the third gaseous transmitter: applications for critical care. Crit Care 13: 213, 2009.

291. Wallace JL, Dicay M, McKnight W, and Martin GR. Hydrogen sulfide enhances ulcer healing in rats. FASEB $J$ 21: 4070-4076, 2007.

292. Wallace JL and Wang R. Hydrogen sulfide-based therapeutics: exploiting a unique but ubiquitous gasotransmitter. Nat Rev Drug Discov 14: 329, 2015.

293. Wang K, Ahmad S, Cai M, Rennie J, Fujisawa T, Crispi F, Baily J, Miller MR, Cudmore M, Hadoke PW, Wang R, Gratacos E, Buhimschi IA, Buhimschi CS, and Ahmed A. Dysregulation of hydrogen sulfide producing enzyme cystathionine gamma-lyase contributes to maternal hypertension and placental abnormalities in preeclampsia. Circulation 127: 2514-2522, 2013.

294. Wang M, Guo Z, and Wang S. Regulation of cystathionine $\gamma$-lyase in mammalian cells by hypoxia. Biochem Genet 52: 29-37, 2014. 
295. Wang Q, Liu H-R, Mu Q, Rose P, and Zhu YZ. Spropargyl-cysteine protects both adult rat hearts and neonatal cardiomyocytes from ischemia/hypoxia injury: the contribution of the hydrogen sulfide-mediated pathway. J Cardiovasc Pharmacol 54: 139-146, 2009.

296. Wang R. Two's company, three'sa crowd: can $\mathrm{H}_{2} \mathrm{~S}$ be the third endogenous gaseous transmitter? FASEB J 16: 1792 1798, 2002.

297. Wang R. Physiological implications of hydrogen sulfide: a whiff exploration that blossomed. Physiol Rev 92: 791896, 2012.

298. Wang R. Shared signaling pathways among gasotransmitters. Proc Natl Acad Sci U S A 109: 8801-8802, 2012.

299. Warenycia MW, Smith KA, Blashko CS, Kombian SB, and Reiffenstein RJ. Monoamine oxidase inhibition as a sequel of hydrogen sulfide intoxication: increases in brain catecholamine and 5-hydroxytryptamine levels. Arch Toxicol 63: 131-136, 1989.

300. Weaver AN and Yang ES. Beyond DNA repair: additional functions of PARP-1 in cancer. Front Oncol 3: 290, 2013.

301. Webb BA, Chimenti M, Jacobson MP, and Barber DL. Dysregulated $\mathrm{pH}$ : a perfect storm for cancer progression. Nat Rev Cancer 11: 671, 2011.

302. Wedmann R, Onderka C, Wei S, Szijártó IA, Miljkovic JL, Mitrovic A, Lange M, Savitsky S, Yadav PK, and Torregrossa R. Improved tag-switch method reveals that thioredoxin acts as depersulfidase and controls the intracellular levels of protein persulfidation. Chem Sci 7: 3414-3426, 2016.

303. Wegiel B, Gallo D, Csizmadia E, Harris C, Belcher J, Vercellotti GM, Penacho N, Seth P, Sukhatme V, and Ahmed A. Carbon monoxide expedites metabolic exhaustion to inhibit tumor growth. Cancer Res 73: 70097021, 2013.

304. Wei WB, Hu X, Zhuang XD, Liao LZ, and Li WD. GYY4137, a novel hydrogen sulfide-releasing molecule, likely protects against high glucose-induced cytotoxicity by activation of the AMPK/mTOR signal pathway in H9c2 cells. Mol Cell Biochem 389: 249-256, 2014.

305. Weiseger R, Pinkus L, and Jakoby W. Thiol-S-methyltransferase: suggested role in detoxification of intestinal hydrogen sulphide. Biochem Pharmacol 29: 2885-2887, 1980.

306. Whiteman M, Armstrong JS, Chu SH, Jia-Ling S, Wong BS, Cheung NS, Halliwell B, and Moore PK. The novel neuromodulator hydrogen sulfide: an endogenous peroxynitrite 'scavenger'? J Neurochem 90: 765-768, 2004.

307. Whiteman M, Cheung NS, Zhu YZ, Chu SH, Siau JL, Wong BS, Armstrong JS, and Moore PK. Hydrogen sulphide: a novel inhibitor of hypochlorous acid-mediated oxidative damage in the brain? Biochem Biophys Res Commun 326: 794-798, 2005.

308. Whiteman M, Li L, Kostetski I, Chu SH, Siau JL, Bhatia M, and Moore PK. Evidence for the formation of a novel nitrosothiol from the gaseous mediators nitric oxide and hydrogen sulphide. Biochem Biophys Res Commun 343: 303-310, 2006.

309. Whiteman M, Li L, Rose P, Tan C-H, Parkinson DB, and Moore PK. The effect of hydrogen sulfide donors on lipopolysaccharide-induced formation of inflammatory mediators in macrophages. Antioxid Redox Signal 12: 1147-1154, 2010.

310. Whiteman M and Winyard PG. Hydrogen sulfide and inflammation: the good, the bad, the ugly and the promising. Expert Rev Clin Pharmacol 4: 13-32, 2011.
311. Whitfield NL, Kreimier EL, Verdial FC, Skovgaard N, and Olson KR. Reappraisal of $\mathrm{H}_{2} \mathrm{~S} /$ sulfide concentration in vertebrate blood and its potential significance in ischemic preconditioning and vascular signaling. Am J Physiol Regul Integr Comp Physiol 294: R1930-R1937, 2008.

312. Wiliński B, Wiliński J, Somogyi E, Piotrowska J, and Góralska M. Atorvastatin affects the tissue concentration of hydrogen sulfide inmouse kidneys and other organs. Pharmacol Rep 63: 184-188, 2011.

313. Wilkinson WJ and Kemp PJ. Carbon monoxide: an emerging regulator of ion channels. J Physiol 589: 30553062, 2011.

314. Wink DA, Vodovotz Y, Laval J, Laval F, Dewhirst MW, and Mitchell JB. The multifaceted roles of nitric oxide in cancer. Carcinogenesis 19: 711-721, 1998.

315. Wintner EA, Deckwerth TL, Langston W, Bengtsson A, Leviten D, Hill P, Insko MA, Dumpit R, VandenEkart E, and Toombs CF. A monobromobimane-based assay to measure the pharmacokinetic profile of reactive sulphide species in blood. Br J Pharmacol 160: 941-957, 2010.

316. Wróbel M, Czubak J, Bronowicka-Adamska P, Jurkowska H, Adamek D, and Papla B. Is development of high-grade gliomas sulfur-dependent? Molecules 19: 21350-21362, 2014.

317. Wu D, Li M, Tian W, Wang S, Cui L, Li H, Wang H, Ji A, and Li Y. Hydrogen sulfide acts as a double-edged sword in human hepatocellular carcinoma cells through EGFR/ ERK/MMP-2 and PTEN/AKT signaling pathways. Sci Rep 7: 5134, 2017.

318. Wu D, Si W, Wang M, Lv S, Ji A, and Li Y. Hydrogen sulfide in cancer: friend or foe? Nitric Oxide 50: 38-45, 2015.

319. Wu L and Wang R. Carbon monoxide: endogenous production, physiological functions, and pharmacological applications. Pharmacol Rev 57: 585-630, 2005.

320. Wu YM, Zhang KJ, Yue XT, Wang YQ, Yang Y, Li GC, Li N, and Wang YG. Enhancement of tumor cell death by combining cisplatin with an oncolytic adenovirus carrying MDA-7/IL-24. Acta Pharmacol Sin 30: 467, 2009.

321. Wu YC, Wang XJ, Yu L, Chan FK, Cheng AS, Yu J, Sung JJ, Wu WK, and Cho CH. Hydrogen sulfide lowers proliferation and induces protective autophagy in colon epithelial cells. PLoS One 7: e37572, 2012.

322. Xie ZZ, Liu Y, and Bian JS. Hydrogen sulfide and cellular redox homeostasis. Oxid Med Cell Longev 2016: 6043038, 2016.

323. Yadav PK, Yamada K, Chiku T, Koutmos M, and Banerjee R. Structure and kinetic analysis of $\mathrm{H}_{2} \mathrm{~S}$ production by human mercaptopyruvate sulfurtransferase. $\mathrm{J}$ Biol Chem 288: 20002-20013, 2013.

324. Yagdi E, Cerella C, Dicato M, and Diederich M. Garlicderived natural polysulfanes as hydrogen sulfide donors: Friend or foe? Food Chem Toxicol 95: 219-233, 2016.

325. Yamamoto T, Takano N, Ishiwata K, and Suematsu M. Carbon monoxide stimulates global protein methylation via its inhibitory action on cystathionine $\beta$-synthase. $J$ Clin Biochem Nutr 48: 96-100, 2010.

326. Yang G, Cao K, Wu L, and Wang R. Cystathionine $\gamma$ lyase overexpression inhibits cell proliferation via a $\mathrm{H}_{2} \mathrm{~S}$ dependent modulation of ERK1/2 phosphorylation and p21Cip/WAK-1. J Biol Chem 279: 49199-49205, 2004.

327. Yang G, Sun X, and Wang R. Hydrogen sulfide-induced apoptosis of human aorta smooth muscle cells via the 
activation of mitogen-activated protein kinases and caspase-3. FASEB J 18: 1782-1784, 2004.

328. Yang G, Wu L, Jiang B, Yang W, Qi J, Cao K, Meng Q, Mustafa $\mathrm{AK}, \mathrm{Mu} \mathrm{W}$, and Zhang $\mathrm{S} . \mathrm{H}_{2} \mathrm{~S}$ as a physiologic vasorelaxant: hypertension in mice with deletion of cystathionine $\gamma$-lyase. Science 322: 587-590, 2008.

329. Yang G, Zhao K, Ju Y, Mani S, Cao Q, Puukila S, Khaper $\mathrm{N}$, Wu L, and Wang R. Hydrogen sulfide protects against cellular senescence via S-sulfhydration of Keap1 and activation of Nrf2. Antioxid Redox Signal 18: 1906-1919, 2013.

330. Yang R, Qu C, Zhou Y, Konkel JE, Shi S, Liu Y, Chen C, Liu S, Liu D, and Chen Y. Hydrogen sulfide promotes Tet1-and Tet2-mediated Foxp3 demethylation to drive regulatory $\mathrm{T}$ cell differentiation and maintain immune homeostasis. Immunity 43: 251-263, 2015.

331. Yin J, Tu C, Zhao J, Ou D, Chen G, Liu Y, and Xiao X. Exogenous hydrogen sulfide protects against global cerebral ischemia/reperfusion injury via its anti-oxidative, anti-inflammatory and anti-apoptotic effects in rats. Brain Res 1491: 188-196, 2013.

332. Yin P, Zhao C, Li Z, Mei C, Yao W, Liu Y, Li N, Qi J, Wang L, Shi Y, Qiu S, Fan J, and Zha X. Sp1 is involved in regulation of cystathionine $\gamma$-lyase gene expression and biological function by PI3K/Akt pathway in human hepatocellular carcinoma cell lines. Cell Signal 24: 12291240, 2012.

333. Yong QC, Hu LF, Wang S, Huang D, and Bian JS. Hydrogen sulfide interacts with nitric oxide in the heart: possible involvement of nitroxyl. Cardiovasc Res 88: 482-491, 2010.

334. Yusuf M, Huat BTK, Hsu A, Whiteman M, Bhatia M, and Moore PK. Streptozotocin-induced diabetes in the rat is associated with enhanced tissue hydrogen sulfide biosynthesis. Biochem Biophys Res Commun 333: 1146$1152,2005$.

335. Zamble DB and Lippard SJ. Cisplatin and DNA repair in cancer chemotherapy. Trends Biochem Sci 20: 435-439, 1995.

336. Zanardo RC, Brancaleone V, Distrutti E, Fiorucci S, Cirino G, and Wallace JL. Hydrogen sulfide is an endogenous modulator of leukocyte-mediated inflammation. FASEB J 20: 2118-2120, 2006.

337. Zhang D, Macinkovic I, Devarie-Baez NO, Pan J, Park CM, Carroll KS, Filipovic MR, and Xian M. Detection of protein S-sulfhydration by a tag-switch technique. Angew Chem Int Ed 53: 575-581, 2014.

338. Zhang L, Qi Q, Yang J, Sun D, Li C, Xue Y, Jiang Q, Tian $\mathrm{Y}, \mathrm{Xu} \mathrm{C}$, and Wang R. An anticancer role of hydrogen sulfide in human gastric cancer cells. Oxid Med Cell Longev 2015: 636410, 2015.

339. Zhang LM, Jiang CX, and Liu DW. Hydrogen sulfide attenuates neuronal injury induced by vascular dementia via inhibiting apoptosis in rats. Neurochem Res 34: 19841992, 2009.

340. Zhang Z, Huang H, Liu P, Tang C, and Wang J. Hydrogen sulfide contributes to cardioprotection during ischemiareperfusion injury by opening KATP channels. Can $J$ Physiol Pharmacol 85: 1248-1253, 2007.

341. Zhao K, Ju Y, Li S, Altaany Z, Wang R, and Yang G. Ssulfhydration of MEK1 leads to PARP-1 activation and DNA damage repair. EMBO Rep 15: 792-800, 2014.

342. Zhao K, Li S, Wu L, Lai C, and Yang G. Hydrogen sulfide represses androgen receptor transactivation by targeting at the second zinc finger module. J Biol Chem 289: 2082420835, 2014.

343. Zhao W, Ndisang JF, and Wang R. Modulation of endogenous production of $\mathrm{H}_{2} \mathrm{~S}$ in rat tissues. Can J Physiol Pharmacol 81: 848-853, 2003.

344. Zhao W, Zhang J, Lu Y, and Wang R. The vasorelaxant effect of $\mathrm{H}_{2} \mathrm{~S}$ as a novel endogenous gaseous $\mathrm{K}$ ATP channel opener. EMBO J 20: 6008-6016, 2001.

345. Zhen Y, Pan W, Hu F, Wu H, Feng J, Zhang Y, and Chen J. Exogenous hydrogen sulfide exerts proliferation/antiapoptosis/angiogenesis/migration effects via amplifying the activation of NF- $\kappa \mathrm{B}$ pathway in PLC/PRF/5 hepatoma cells. Int J Oncol 46: 2194-2204, 2015.

346. Zhou H, Ding L, Wu Z, Cao X, Zhang Q, Lin L, and Bian JS. Hydrogen sulfide reduces RAGE toxicity through inhibition of its dimer formation. Free Radic Biol Med 104: 262-271, 2017.

347. Zhou Y, Wu Z, Cao X, Ding L, Wen Z, and Bian J-S. HNO suppresses LPS-induced inflammation in BV-2 microglial cells via inhibition of NF- $\kappa \mathrm{B}$ and p38 MAPK pathways. Pharmacol Res 111: 885-895, 2016.

348. Zhou Y, Yu J, Lei X, Wu J, Niu Q, Zhang Y, Liu H, Christen $\mathrm{P}$, Gehring $\mathrm{H}$, and $\mathrm{Wu} \mathrm{F}$. High-throughput tandem-microwell assay identifies inhibitors of the hydrogen sulfide signaling pathway. Chem Commun 49: 11782-11784, 2013.

349. Zhu YZ, Wang ZJ, Ho P, Loke YY, Zhu YC, Huang SH, Tan CS, Whiteman M, Lu J, and Moore PK. Hydrogen sulfide and its possible roles in myocardial ischemia in experimental rats. J Appl Physiol 102: 261-268, 2007.

Address correspondence to: Dr. Jin-Song Bian

Department of Pharmacology Yong Loo Lin School of Medicine National University of Singapore Singapore 117600 Singapore

E-mail: phcbjs@nus.edu.sg

Date of first submission to ARS Central, March 9, 2017; date of final revised submission, May 14, 2018; date of acceptance, May 22, 2018.

\begin{tabular}{|c|}
\hline $\begin{aligned} \text { Abbreviations Used } \\
3 \mathrm{MP}=3 \text {-mercaptopyruvate } \\
3 \mathrm{MST}=3 \text {-mercaptopyruvate sulfurtransferase } \\
\text { ADT-OH }=\text { 5-(4-hydroxyphenyl)-3H-1 } \\
\text { 2-dithiole- } 3 \text {-thione } \\
\mathrm{AE}=\text { anion exchanger } \\
\mathrm{AKT}=\text { protein kinase } \mathrm{B} \\
\mathrm{AOAA}=\text { aminooxyacetic acid } \\
\mathrm{ATP}=\text { adenosine triphosphate } \\
\mathrm{B}-\mathrm{TECs}=\text { endothelial cells obtained from breast } \\
\quad \text { carcinomas } \\
\mathrm{CAT}=\text { cysteine aminotransferase } \\
\mathrm{CBS}=\text { cystathionine } \beta \text {-synthase } \\
\mathrm{CO}=\text { carbon monoxide } \\
\mathrm{CSE}=\text { cystathionine } \gamma \text {-lyase } \\
\mathrm{DAO}=\text { D-amino acid oxidase }\end{aligned}$ \\
\hline
\end{tabular}




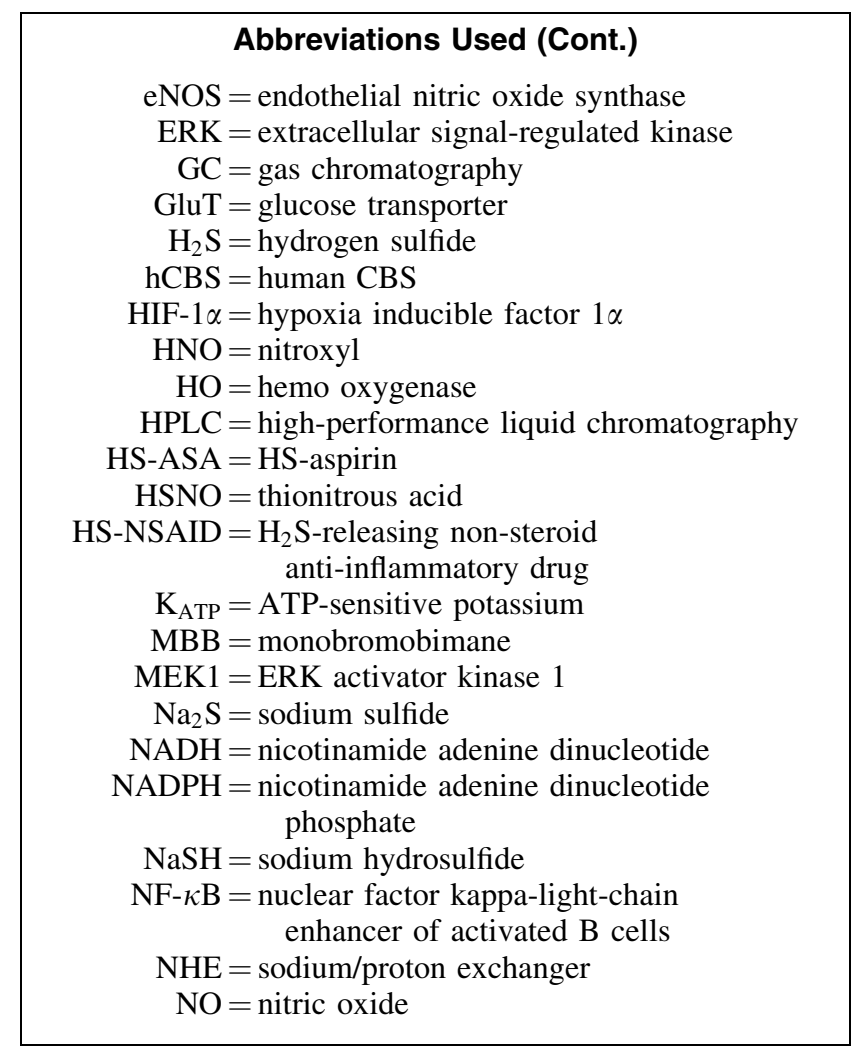

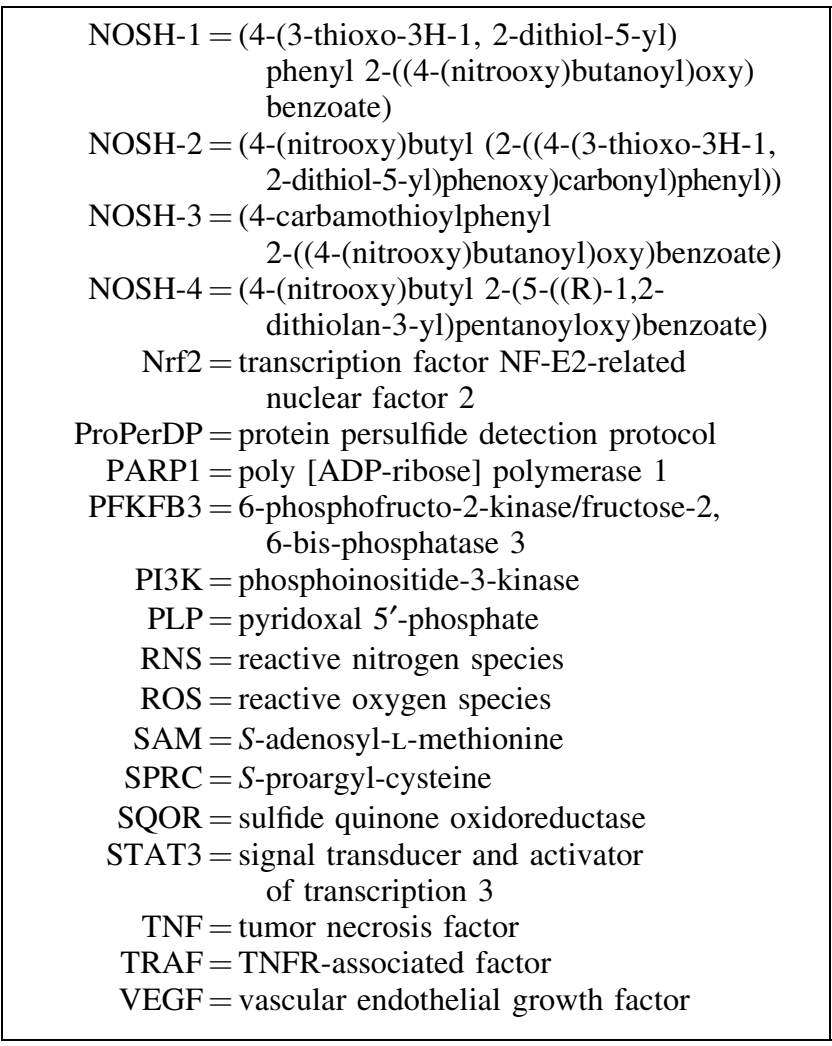

